US Army Corps

of Engineers ${ }_{\circledast}$

Engineer Research and

Development Center

Wetland Regulatory Assistance Program (WRAP)

\title{
Technical Guide for the Development, Evaluation, and Modification of Stream Assessment Methods for the Corps Regulatory Program
}

Gabrielle C. L. David, D. Eric Somerville, Julia M. McCarthy,

September 2021

Spencer D. MacNeil, Faith Fitzpatrick, Ryan Evans,

and David Wilson
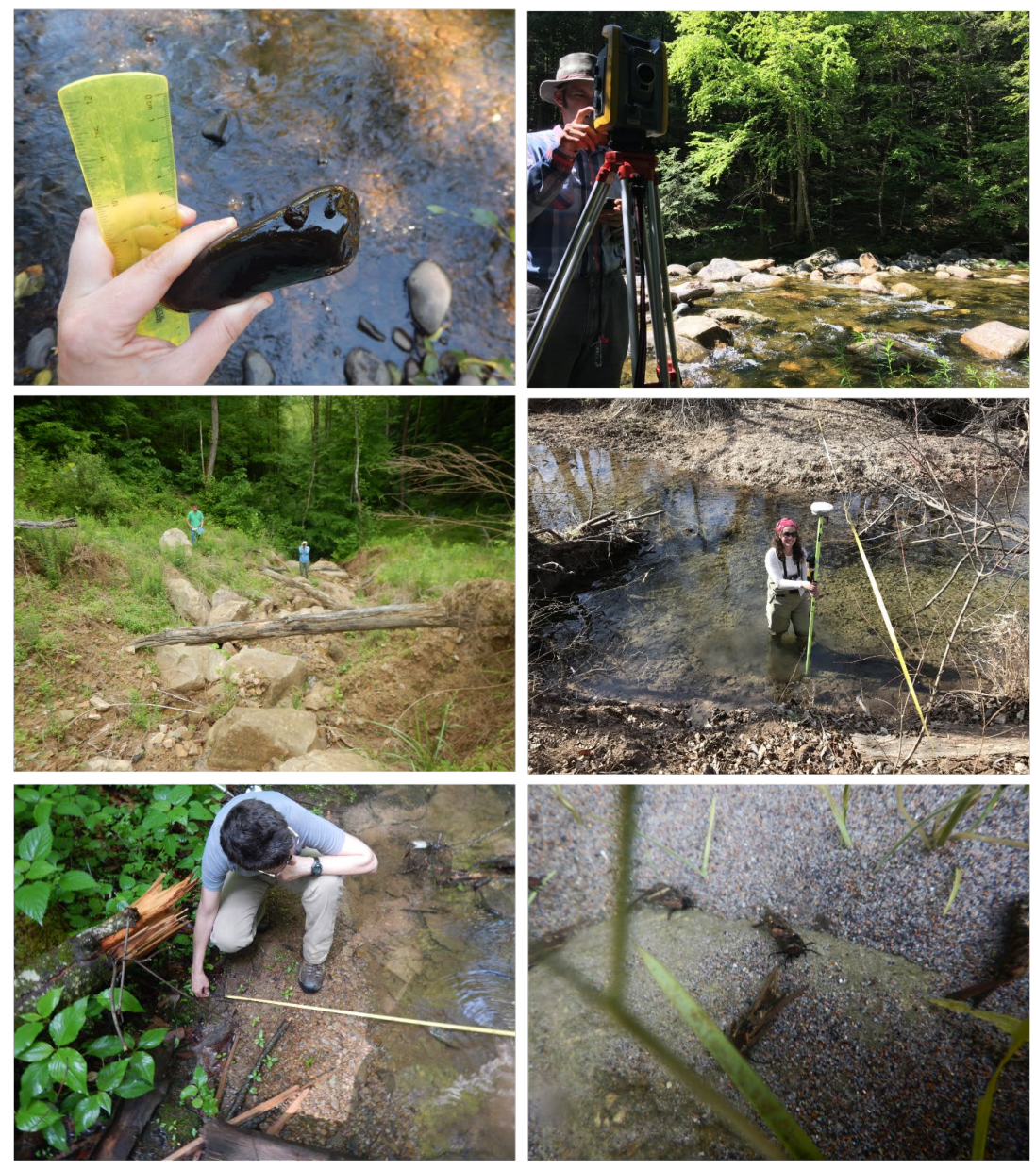

Approved for public release; distribution is unlimited. 
The U.S. Army Engineer Research and Development Center (ERDC) solves the nation's toughest engineering and environmental challenges. ERDC develops innovative solutions in civil and military engineering, geospatial sciences, water resources, and environmental sciences for the Army, the Department of Defense, civilian agencies, and our nation's public good. Find out more at www.erdc.usace.army.mil.

To search for other technical reports published by ERDC, visit the ERDC online library at https://erdclibrary.on.worldcat.org/discovery. 


\section{Technical Guide for the Development, Evaluation, and Modification of Stream Assessment Methods for the Corps Regulatory Program}

Gabrielle C. L. David

U.S. Army Engineer Research and Development Center Cold Regions Research and Engineering Laboratory 72 Lyme Road

Hanover, NH 03755

D. Eric Somerville

U.S. Environmental Protection Agency

Region 4, Water Division

980 College Station Road

Athens, GA 30605-2720

Julia M. McCarthy

U.S. Environmental Protection Agency

Region 8, Water Division

1595 Wynkoop Street

Denver, CO 80202

Faith Fitzpatrick

U.S. Geological Survey

Upper Midwest Water Science Center

8505 Research Way

Middleton, WI 53562
Spencer D. MacNeil

U.S. Army Corps of Engineers

Los Angeles District

60 S. California Street, Suite 201

Ventura, CA 93001

Ryan Evans

U.S. Army Corps of Engineers

Nashville District

3701 Bell Road

Nashville, TN 37214

David Wilson

U.S. Army Corps of Engineers

Charleston District

69-A Hagood Avenue

Charleston, SC 29403-5104

Final Report

Approved for public release; distribution is unlimited.

Prepared for Headquarters, U.S. Army Corps of Engineers

Washington, DC 20314-1000

Under Wetlands Regulatory Assistance Program (WRAP), AMSCO 088893, funding account U4371457, project 2017-ERD-0500-0002, “Developing National Stream Assessment, Performance, and Mitigation Monitoring Standards, Methods, and Technical Guidance" 


\section{Abstract}

The U.S. Army Corps Regulatory Program considers the loss (impacts) and gain (compensatory mitigation) of aquatic resource functions as part of Clean Water Act Section 404 permitting and compensatory mitigation decisions. To better inform this regulatory decision-making, the Regulatory Program needs transparent and objective approaches to assess the function and condition of aquatic resources, including streams.

Therefore, the Regulatory Program needs function-based stream assessments (1) to characterize a stream's condition or function, (2) to improve understanding of the impact of a proposed action on an aquatic resource, and/or (3) to inform the development of stream compensatory mitigation tools rooted in stream condition and/or function. A function-based stream assessment can provide regulatory decision makers with the resources to objectively consider alternatives, minimize impacts, assess unavoidable impacts, determine mitigation requirements, and monitor the success of mitigation projects.

A multiagency National Committee on Stream Assessment (NCSA) convened to create these guidelines to inform the development of new methods and evaluation of both national-level and regional methods currently in use. The resulting guidelines present nine phases, including rationale and recommendations to facilitate work efforts. The NCSA hopes that this technical guide promotes transparency, technical defensibility, and consistent application of stream assessments in the Regulatory Program.

DISCLAIMER: The contents of this report are not to be used for advertising, publication, or promotional purposes. Citation of trade names does not constitute an official endorsement or approval of the use of such commercial products. All product names and trademarks cited are the property of their respective owners. The findings of this report are not to be construed as an official Department of the Army position unless so designated by other authorized documents.

DESTROY THIS REPORT WHEN NO LONGER NEEDED. DO NOT RETURN IT TO THE ORIGINATOR. 


\section{Contents}

Figstract f...

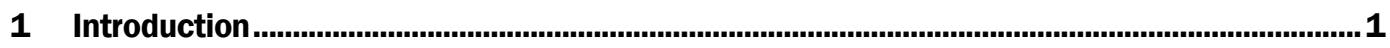

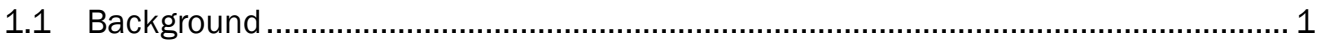

1.2 Relationship of stream assessments to other regulatory tools ............................... 4

1.3 Existing stream assessment methods................................................................ 6

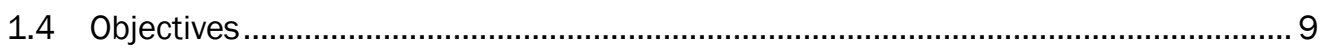

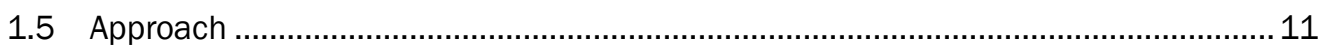

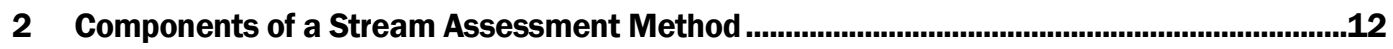

2.1 Phase 1: Develop a scope of work .............................................................. 13

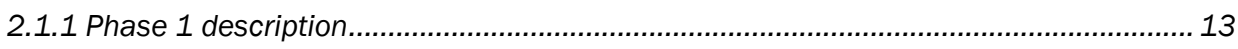

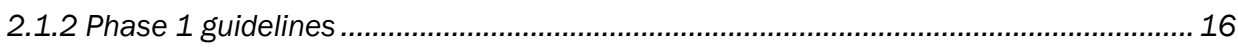

2.2 Phase 2: Gather a multidisciplinary project team............................................ 17

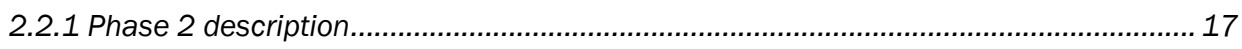

2.2.2 Phase 2 guidelines .................................................................................................... 18

2.3 Phase 3: Determine the types of streams, associated stream functions, and necessary stratification for streams in the region .............................................. 18

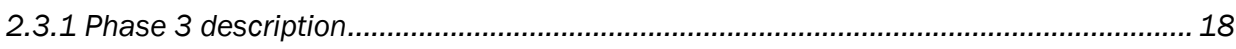

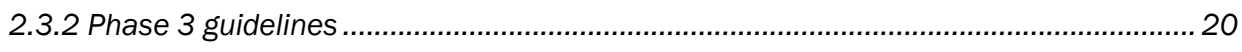

2.4 Phase 4: Select regionally relevant metrics .......................................................... 29

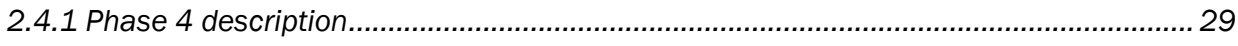

2.4.2 Phase 4 guidelines ..................................................................................................... 30

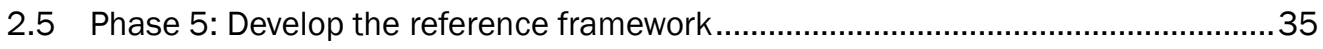

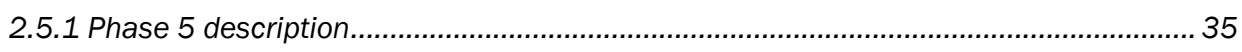

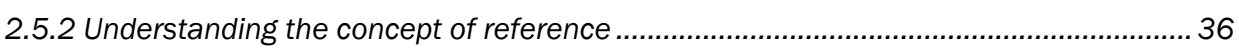

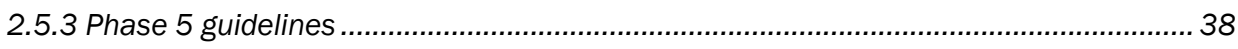

2.6 Phase 6: Build assessment models and develop scoring procedures .....................43

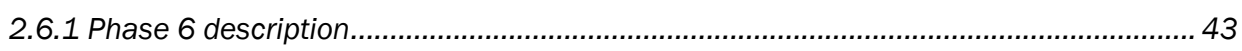

2.6.2 Phase 6 guidelines ....................................................................................................... 43

2.7 Phase 7: Develop assessment method protocols, validation, and

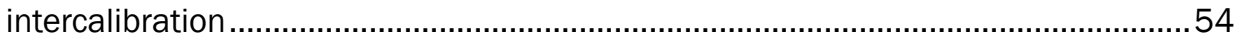

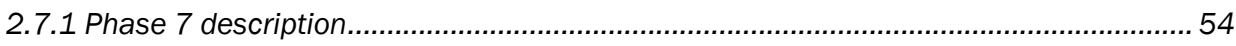

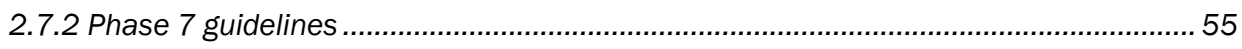

2.8 Phase 8: Carry out peer review, public comment, and beta-testing .........................58

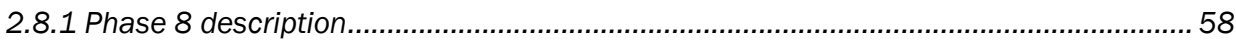

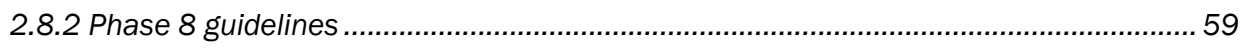




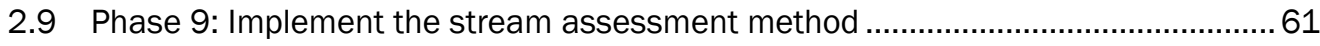

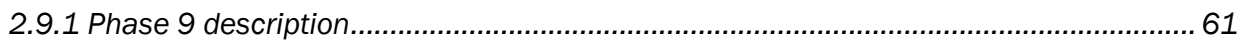

2.9.2 Phase 9 guidelines ............................................................................................. 61

3 Summary

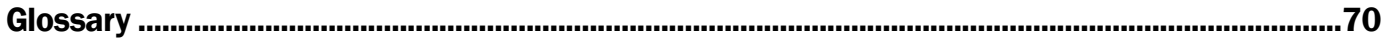

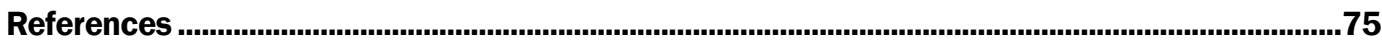

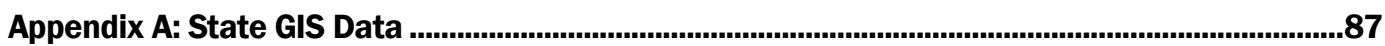

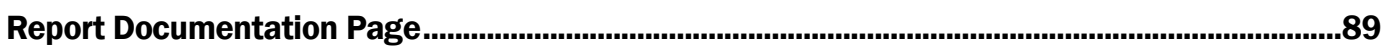




\section{Figures and Tables}

\section{Figures}

1 Comparison of stream functions described by Fischenich (2006) and organization of the stream functions pyramid described by Harman et al. (2012).

2 Phases to guide development of a stream assessment methodology for use in a specific state or USACE district

3 Scientific, regulatory, and management expertise to consider for the multidisciplinary assessment team.

$4 \quad$ Metric selection depends on understanding landscape connections. Watershed characteristics control channel and floodplain characteristics, which determine stream condition and function

5 Example of spatial scales to consider when identifying stream functions and corresponding indicator metrics for those functions. Stream functions and categories from Fischenich (2006). (Map data @ 2020 Google)

6 Metrics describing stream morphology, which is measured at different scales (cross section, longitudinal profile, and planform).

$7 \quad$ Flow chart illustrating the iterative process of metric selection and evaluation (adapted from Mckay et al. 2010)

8 Example of various concepts of biological reference conditions (adapted from Stoddard et al. 2006). The dashed red line represents the differing levels of human disturbance on the landscape, whereas the solid black line is the natural range of variability. The range of conditions that currently exists can be evaluated based on different methods of grouping (i.e., stratifying) streams. Stream groups may be defined based on ecoregion, drainage area, or channel type. However, "minimally disturbed" reference streams may not exist among some groups (B and $C$ ) due to the degree of landscape disturbance.

9 Example of how to identify discriminatory assessment metrics: (a) A scatter plot of an indicator metric (function-based metric) versus an independent variable across the range of conditions in the region. (b) A box plot illustrating the discriminatory power of the metric $(y)$ relative to stream condition classes.

10 Examples illustrating standardized function-based metrics converted to index values (top) for development of a reference curves (bottom).

11 Example from Nadeau et al. (2018) of how to convert indicator metric data into index values. (Image reproduced from Nadeau et al. 2018.

Public domain.)

12 Example of a sensitivity analysis adapted from Smith et al. (2013). The different color lines indicate that a variable is being held constant at 0 , $0.1,0.5$, and 1.0. On the left, flood frequency is changing on the $x$-axis while holding constant for leaf litter and coarse woody debris. On the right ,leaf litter (or coarse woody debris) is being changed on the $x$-axis while holding constant for flood frequency. Leaf litter and coarse woody debris produced the same results; therefore, the same plot is shown. Flood frequency is found to be more influential on Functional Capacity Index (FCl) scores in this example. 


\section{Tables}

1 Examples of stream assessment methods and stream mitigation guidance currently in use by USACE Regulatory Districts and the output scoring of the methods. The stream methodologies used to arrive at these final scores vary widely between districts from rapid visual assessments to time-intensive quantitative measurements. Follow the URLs, or go to the district websites, to find what methods are used and how the scores are then input into credit and debit tools

2 Descriptions of classification frameworks developed for a variety of purposes and applications, such as to describe flow regime, drainage networks, channel morphology, and floodplain morphology ...

3 Examples of regional and national stream and riparian datasets..

4 Summary of the phases and the factors to consider in each phase of developing stream assessment approaches (adapted from Dorney and Adamus 2018)

A-1 Source of GIS data for U.S. states. This is list is not exhaustive but is meant to provide users with primary locations for GIS data for U.S. states 


\section{Preface}

This study was conducted for the U.S. Army Corps of Engineers (USACE) Headquarters through the Wetlands Regulatory Assistance Program (WRAP) under AMSCO 088893, funding account U4371457, project 2017ERD-0500-000, "Developing National Stream Assessment, Performance, and Mitigation Monitoring Standards, Methods, and Technical Guidance." The technical monitor was Mr. Kyle Gordon, WRAP Program Manager.

The work was performed by the Lidar and Wetlands Group of the Remote Sensing and Geographic Information Systems Center of Expertise, U.S. Army Engineer Research and Development Center (ERDC), Cold Regions Research and Engineering Laboratory (CRREL). At the time of publication, Dr. Elias Deeb was Group Lead; and Mr. David Finnegan was Center Director. The Deputy Director of ERDC-CRREL was Mr. David B. Ringelberg, and the Director was Dr. Joseph L. Corriveau.

Portions of this report's text have been modified and reprinted from R. D. Smith, C. V. Noble, and J. F. Berkowitz, Hydrogeomorphic (HGM) Approach to Assessing Wetland Functions: Guidelines for Developing Guidebooks (Version 2), ERDC/EL TR-13-11 (Vicksburg, MS: U.S. Army Engineer Research and Development Center, 2013), https://hdl.handle.net/11681/6955.

COL Teresa A. Schlosser was Commander of ERDC, and Dr. David W. Pittman was the Director. 


\section{Acronyms and Abbreviations}

CEM

CRREL

CSQT

CWA

DA

ELI

EPA

ERDC

FCI

GIS

HGM

IDRAIM

NAWQA

NCSAM

NCSA

PACFISH/INFISH

QAPP

QA/QC

RBP

REFORM

RHA

RIBITS
Channel Evolution Models

Cold Regions Research and Engineering Laboratory

Colorado Stream Quantification Tool

Clean Water Act

Department of the Army

Environmental Law Institute

U.S. Environmental Protection Agency

U.S. Army Engineer Research and Development Center

Functional Capacity Index

Geographic Information System

Hydrogeomorphic

Sistema di valutazione idromorfologica, analisi emonitoraggio dei corsi d'acqua

National Water Quality Assessment

North Carolina Stream Assessment Method

National Committee on Stream Assessment

Pacific Anadromous Fish / Inland Fish

Quality Assurance Project Plan

Quality Assurance/Quality Control

Rapid Bioassessment Protocols

Restoring Rivers for Effective Catchment Management

Rivers and Harbors Appropriation Act

Regulatory In-Lieu Fee and Bank Information Tracking System 


$\begin{array}{ll}\text { RMN } & \text { Regional Environmental Monitoring Networks } \\ \text { SEM } & \text { Stream Evolution Model } \\ \text { SFAM } & \text { Stream Functional Assessment Method } \\ \text { SVAP2 } & \text { Stream Quantification Tool } \\ \text { SWVM } & \text { Stream Visual Assessment Protocol } \\ \text { TXRAM } & \text { Stream and Wetland Valuation Metric } \\ \text { USACE } & \text { Texas Rapid Assessment Method } \\ \text { USFS } & \text { U.S. Army Corps of Engineers } \\ \text { USGS } & \text { U.S. Forest Service } \\ \text { USM } & \text { U.S. Geological Survey } \\ \text { WOTUS } & \text { Unified Stream Methodology } \\ \text { WRAP } & \text { Waters of the United States } \\ & \text { Wetlands Regulatory Assistance Program }\end{array}$




\section{Acknowledgements}

In addition to the authors listed for this technical guide, the following additional members of the National Committee on Stream Assessment provided critical input, technical review, and collaboration:

\author{
Patti Grace-Jarrett \\ U.S. Army Corps of Engineers \\ Louisville District \\ PO Box 59 \\ Louisville, KY 40202 \\ Michelle Mattson \\ U.S. Army Corps of Engineers \\ Institute of Water Resources \\ 7701 Telegraph Road \\ Alexandria, VA 22315 \\ Daniel Cenderelli \\ U.S. Forest Service \\ National Stream and Aquatic Ecology Center \\ Fort Collins, CO 80525
}

\author{
Tim Beechie \\ National Oceanic and \\ Atmospheric Administration \\ Northwest Fisheries Science Center \\ 2725 Montlake Boulevard East \\ Seattle, WA 98112 \\ Joe Wheaton \\ Utah State University \\ Department of Watershed Sciences \\ Logan, UT 84322-5210
}

Thanks to the following for their critical input and technical review:

\author{
Justin Elkins \\ U.S. Army Corps of Engineers \\ 441 G Street, NW \\ Washington, D.C. 20314-1000 \\ Tracie-Lynn Nadeau \\ U.S. Environmental Protection Agency \\ Region 10, Oregon Operations Office \\ 805 SW Broadway, Suite 500 \\ Portland, OR 97205 \\ Eric Stein \\ Southern California Coastal Water \\ Research Project \\ 3535 Harbor Blvd. \\ Costa Mesa, CA 92626-1437
}

\author{
Brian Topping \\ U.S. Environmental Protection Agency \\ Office of Wetlands, Oceans \& Watersheds \\ 1200 Pennsylvania Ave NW (4504T) \\ Washington, D.C. 20460 \\ Andrea Wagner \\ U.S. Army Corps of Engineers \\ Portland District, Regulatory Branch \\ Eugene Field Office \\ 211 E. 7th Ave., Suite 105 \\ Eugene, OR 97401-2763
}




\section{Introduction}

\subsection{Background}

Stream assessments are a critical part of the U.S. Army Corps of Engineers (USACE) Regulatory Program, the mission of which is to protect aquatic resources and navigation (capacity and condition) while allowing for reasonable development through fair and balanced permit decisions, pursuant to Section 404 of the Clean Water Act (CWA Section 404); ${ }^{*}$ Section 10 of the Rivers and Harbors Appropriation Act of 1899 (RHA); ${ }^{\dagger}$ and Section 103 of the Marine Protection, Research, and Sanctuaries Act. ${ }^{*}$

CWA Section 404 requires that no discharge of dredged or fill material be permitted into Waters of the United States (WOTUS) if it causes or contributes to significant degradation of WOTUS. During the regulatory review process, permit applicants must first demonstrate efforts "to avoid and minimize impacts to [WOTUS] to the maximum extent practicable." § Compensatory mitigation for unavoidable impacts may then be required as a condition of a Department of the Army (DA) permit.

"The fundamental objective of compensatory mitigation is to offset environmental losses resulting from unavoidable impacts to WOTUS authorized by DA permits." ** "Compensatory mitigation requirements must be commensurate with the amount and type of impact authorized by a DA permit" and be "based on what is practicable and capable of compensating for the aquatic resource functions that will be lost as a result of the permitted activity." ${ }^{\dagger+}$ This focus on aquatic resource functions is repeated throughout the 2008 Federal regulations governing compensatory mitigation, ${ }^{\ddagger \neq}$ hereinafter referred to as the 2008 Mitigation Rule.

\footnotetext{
* 33 U.S.C. § 1344 et seq. (2011).

† Rivers and Harbors Appropriation Act of 1899, 33 U.S.C. $\S 403$ et seq. (2019).

‡ Marine Protection, Research, and Sanctuaries Act of 1972, 33 U.S.C. § 1401 (2010).

$\S$ Compensatory Mitigation for Losses of Aquatic Resources, 73 Fed. Reg. 70 (10 Apr. 2008), 19,59419705.

** Compensatory Mitigation for Losses of Aquatic Resources, 33 C.F.R. § 332.3(a) (2011).

†† 33 C.F.R. § 332.3(a).

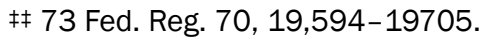


Ecosystem functions are defined in the 2008 Mitigation Rule as the "physical, chemical, and biological processes that occur in ecosystems,"* and functional capacity is the "degree to which an area of aquatic resources performs a specific function." The area of aquatic resource in the context of this technical guide may be a stream reach or a compilation of stream reaches making up a project area (e.g., a proposed impact requiring CWA Section 404 authorization or a proposed compensatory mitigation project to offset impacts). The term functional capacity may also be used to refer to the overall degree of function performed by an aquatic resource, as opposed to only the degree of function for a single specific function. In cases where appropriate functional or condition assessment methods are available, federal regulations state that such "methods should be used where practicable to determine how much compensatory mitigation is required.” $¥$

Stream assessment for the Regulatory Program must balance the need for objective decision-making with the concurrent need to make those regulatory decisions in a timely manner. It is consequently often necessary to assess stream condition as a proxy for stream function by evaluating a suite of indicators that represent structural and compositional attributes of the stream ecosystem. Stream condition is the relative ability of a riverine ecosystem to support and maintain a community of organisms, which has species composition, diversity, and functional organization comparable to high-quality reference aquatic resources in the region (Davies 2000). Stream condition is, therefore, the state of the stream at the time of the assessment-a snapshot (Nadeau et al. 2018)-as opposed to a function, which is a process occurring over time. Like stream function, stream condition can vary through both space and time throughout the assessed stream reach or watershed (Scarsbrook and Townsend 1993; Hatch et al. 2010; Grabowski et al. 2014; Nadeau et al. 2018).

In 2006, an international committee of scientists, engineers, and practitioners defined 15 key stream and riparian zone functions that they aggregated into 5 categories: system dynamics, hydrology, geomorphology, biology, and physiochemical (Figure 1; Fischenich 2006). Drawing on the efforts of Fischenich (2006) to characterize stream functions, the stream functions pyramid developed by Harman et al. (2012) proposed a hierarchical framework that connects stream functions with various function-

* 33 C.F.R. § 332.2.

† 33 C.F.R. $\S 332.2$.

‡33 C.F.R. § 332.3(f). 
based parameters, which then relate to a scoring system for evaluating the condition of streams (Figure 1). The purpose behind the development of the stream functions pyramid was to provide an approach for assessing stream restoration or mitigation design. The stream functions pyramid is essentially a five-level hierarchical framework, with hydrology at the base of the pyramid and successive categories of hydraulics, geomorphology, physicochemical, and then biology (aquatic life) at the top of the pyramid.

Figure 1. Comparison of stream functions described by Fischenich (2006) and organization of the stream functions pyramid described by Harman et al. (2012).

\begin{tabular}{|lll|}
\hline Stream functions described by Fischenich (2006) & \\
& & \\
System Dynamics & Geomorphology & Biology \\
Maintain stream evolution processes & Sediment continuity & Support biological communites and processes \\
Energy management processes & Maintain substrates and structural processes & Provide necessary aquatic and riparian habitats \\
Provide for riparian succession & Quality and quantity of sediments & Maintain trophic structure and processes
\end{tabular}

Hydrology

Surface water storage processes

Maintain surface/subsurface connections and processes

General hydrodynamic balance

\section{Physiochemical}

Maintain water and soil quality

Maintain chemical processes and nutrient cycles

Maintain landscape pathways

\section{Stream functions pyramid from Harman et al. (2012)}

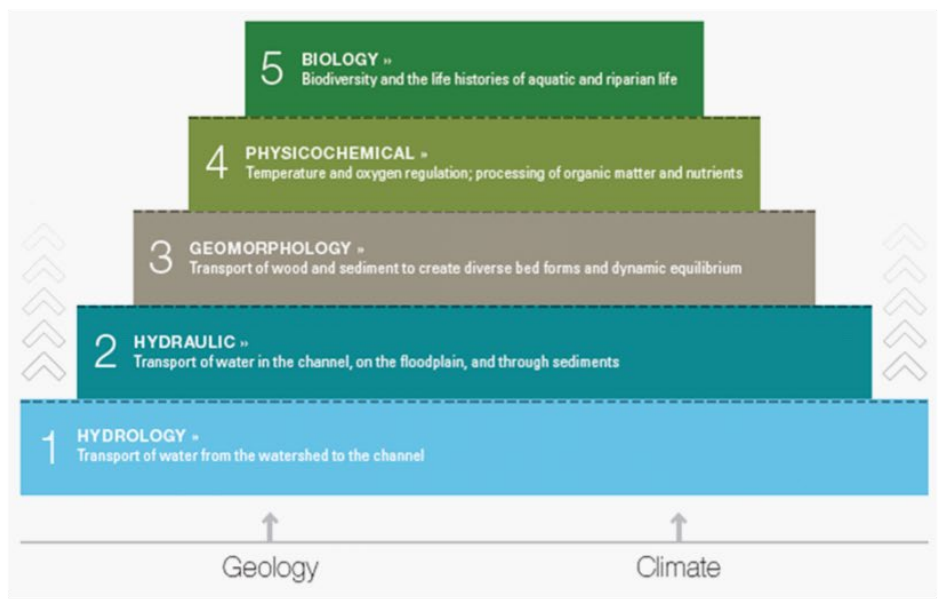

The stream functions pyramid emphasizes the need to address the foundation of the pyramid, in terms of hydrologic and physical processes, to support higher-level functional categories, like biologic processes. Although the 
pyramid provides a framework for identifying and organizing stream functions, it does not intrinsically illustrate the interrelationships of functions in various levels of the pyramid hierarchy nor does it address the change in hierarchy that may occur. For example, it may be that biology increases in significance seasonally, with vegetation dominating stream function and influencing the way all other functions respond to the system. Underlying the foundation of the pyramid, as well as Fischenich's (2006) functions, are geology and climate, which influence all other parts of the pyramid.

\subsection{Relationship of stream assessments to other regulatory tools}

An effective stream assessment method underlies development of other function-based regulatory tools that allow regulators and their partners to (1) develop mitigation crediting and debiting protocols, (2) determine mitigation project performance, (3) compare streams to a target condition, and (4) determine the current status of a stream and in what direction the stream is trending. The development of stream assessment methods in the Regulatory Program has often comingled with the development of these tools for other regulatory purposes. This can possibly lead to some difficulty differentiating the results of the assessment relative to the output of the other tools. The National Committee on Stream Assessment (NCSA) contends that objective assessment of stream condition at proposed impact and mitigation sites is necessary to inform development of these other function-based tools.

Crediting and debiting protocols are used in the Regulatory Program to assign "units of measure (e.g., linear feet, area, etc.) representing the accrual or attainment of aquatic [resource] functions" at a mitigation site or the "loss of aquatic [resource] functions at an impact site," respectively. ${ }^{*}$ Harman et al. (2021) discusses in detail identifying and applying units of measure in crediting and debiting protocols. These protocols are not necessarily stream assessment methods themselves, though they should be predicated on an objective assessment of stream conditions, both at proposed mitigation sites (credits) and proposed impact sites (debits).

The 2008 Mitigation Rule requires that compensatory mitigation projects be evaluated using ecological performance standards based on attributes that are objective, verifiable, and based on the "best available science that

* 33 C.F.R. § 332.2. 
can be measured or assessed in a practicable manner." Performance standards should "relate to the [specific] objectives of the compensatory mitigation project" and provide sufficient information to allow regulatory decision makers to determine whether it is developing into the desired resource type and providing the expected functions. ${ }^{*}$ Objective stream assessment methods can therefore inform the identification of appropriate ecological performance standards for the Regulatory Program.

To compare an aquatic resource to a target condition, or otherwise characterize its functional capacity, a stream needs to be put into context with other streams in a given geographic area (e.g., state, ecoregion, physiographic province, etc.). The 2008 Mitigation Rule defines reference aquatic resources as "a set of aquatic resources that represent the full range of variability exhibited by a regional class of aquatic resources as a result of natural processes and anthropogenic disturbances." ${ }^{\dagger}$ Reference conditions, as used in this technical guide, may therefore be defined as the full range of variability exhibited by a regional class of aquatic resources as a result of natural processes and anthropogenic disturbances. A stream assessment method based on or related to regional reference conditions can provide this context.

Assessing the current status of a stream's condition is important not only for evaluating the likely impacts of a proposed project on stream condition and/or function but also to assess baseline (i.e., preproject) conditions at proposed mitigation projects. The former is an important consideration to inform regulatory decisions on the number of debits required to compensate for unavoidable authorized impacts, and the latter is necessary for assigning mitigation credits by representing the "floor" for evaluation of functional improvement or functional lift following mitigation activities. Each of these uses for stream assessments also requires that the output of the assessment provides a regional context for similar aquatic resources.

Assessment of stream conditions conducted over a recurring time interval, such as postmitigation monitoring or postproject impact monitoring, can illustrate a trend of either improving or degrading conditions if the component indicators used by the stream assessment method and the output of the assessment itself are sensitive to the changes occurring in the stream ecosystem over time. Evidence of such a trend may inform management

* 33 C.F.R. $\S 332.5$.

† 33 C.F.R. $\S 332.2$. 
actions to hasten, reverse, or halt the trend, depending on project objectives and the direction in which stream conditions are trending.

\subsection{Existing stream assessment methods}

Stream assessment methods are developed for many different purposes, including both regulatory purposes (e.g., Section 404 CWA and/or State or local regulations) and nonregulatory purposes, such as resource management inventories or other targeted resource surveys. The USACE Regulatory Districts currently use a variety of methods to conduct stream assessments as part of the CWA Section 404 Regulatory Program, some of which are inextricable components of broader guidance (Table 1 ).

Even stream assessment methods developed for application outside of the USACE Regulatory Program may be appropriate to apply in the regulatory context. However, it is important to evaluate whether such methods would be able to effectively and efficiently meet the needs of the Regulatory Program. It is consequently important to specify not only what the programmatic goals of the assessment method are but also how to evaluate whether those goals will be met.

Bain et al. (1999) compiled and reviewed methods for aquatic habitat assessment used by North American fishery agencies, and Somerville and Pruitt (2004) evaluated regulatory and nonregulatory physical stream assessment methods used in the United States. Bain et al. (1999) found that methods more often focused on general aquatic environmental quality with less focus on assessing habitat in relation to fisheries. They emphasized the need for adequate sampling design when evaluating habitat resources. Somerville and Pruitt (2004) in particular recommended that stream assessment methods for the CWA Section 404 Regulatory Program should include a classification system to reduce variability, be objective and quantitative, have a fluvial geomorphic emphasis, and include a plan for data management.

There have been significant changes to the CWA Section 404 Regulatory Program in the two decades since the above referenced reviews were conducted, not the least of which was adoption of the 2008 Mitigation Rule. There have also been significant advances in stream assessment on both a regional and national scale (e.g., Wadeable Stream Assessment [EPA 2006]; National River and Streams Assessment 2008-2009 and 2013- 
2014 [EPA 2016, 2020]). Objective stream assessments with a firm platform for data management are still critical for any programmatic use of stream assessment information. Similarly, stratifying streams based on factors that affect stream function or indicator metrics of those functions remains important, regardless of whether a formal stream classification protocol is utilized. However, numerous critical evaluations of stream restoration activities have also been published in the last twenty years, many of which have reported mixed results on the biological efficacy of common stream restoration practices (Roni et al. 2008; Miller et al. 2010; Palmer, Hondula, et al. 2014). To address this deficiency, biological functions and indicators should receive the same degree of attention in stream assessment and stream restoration efforts for the Regulatory Program. While fluvial geomorphology is still important, it should perhaps no longer hold the same degree of critical prominence recommended by Somerville and Pruitt (2004) nearly two decades ago.

Table 1. Examples of stream assessment methods and stream mitigation guidance currently in use by USACE Regulatory Districts and the output scoring of the methods. The stream methodologies used to arrive at these final scores vary widely between districts from rapid visual assessments to time-intensive quantitative measurements. Follow the URLs, or go to the district websites, to find what methods are used and how the scores are then input into credit and debit tools.

\begin{tabular}{|c|c|c|c|c|}
\hline $\begin{array}{l}\text { Stream } \\
\text { Methodology }\end{array}$ & $\begin{array}{l}\text { USACE } \\
\text { District }\end{array}$ & URL & $\begin{array}{l}\text { Output of } \\
\text { Assessment } \\
\text { Method }^{*}\end{array}$ & Reference \\
\hline $\begin{array}{l}\text { Charleston } \\
\text { District Mitigation } \\
\text { Guidelines }\end{array}$ & $\begin{array}{l}\text { Charleston } \\
\text { District }\end{array}$ & $\begin{array}{l}\text { https://www.mvk.usace.army.mil/Portals/58 } \\
\text { /docs/regulatory/Charleston\%20 } \\
\text { Method\%202010\%20Guidelines.pdf }\end{array}$ & Index score & USACE (2011a) \\
\hline $\begin{array}{l}\text { Colorado Stream } \\
\text { Quantification } \\
\text { Tool (CSQT) v1.0 }\end{array}$ & $\begin{array}{l}\text { Omaha } \\
\text { District }\end{array}$ & $\begin{array}{l}\text { https://www.nwo.usace.army.mil/Missions/R } \\
\text { egulatory-Program/Colorado } \\
\text { /Mitigation/ }\end{array}$ & Index score & $\begin{array}{l}\text { CSQT Steering } \\
\text { Committee } \\
(2019 a, 2019 b)\end{array}$ \\
\hline $\begin{array}{l}\text { Galveston District } \\
\text { Level I Stream } \\
\text { Assessment } \\
\text { Method }\end{array}$ & $\begin{array}{l}\text { Galveston } \\
\text { District }\end{array}$ & $\begin{array}{l}\text { https://www.swg.usace.army.mil/Business- } \\
\text { With-Us/Regulatory/Streams/ }\end{array}$ & $\begin{array}{l}\text { Categorical } \\
\text { rating }\end{array}$ & USACE (2013) \\
\hline $\begin{array}{l}\text { Galveston District } \\
\text { Level II Stream } \\
\text { Assessment } \\
\text { Method }\end{array}$ & $\begin{array}{l}\text { Galveston } \\
\text { District }\end{array}$ & $\begin{array}{l}\text { https://www.swg.usace.army.mil/Business- } \\
\text { With-Us/Regulatory/Streams/ }\end{array}$ & Index score & USACE (2013) \\
\hline Georgia SQT & $\begin{array}{l}\text { Savannah } \\
\text { District }\end{array}$ & $\begin{array}{l}\text { https://www.sas.usace.army.mil/Portals/61/ } \\
\text { docs/Regulatory/Mitigation\%20Documents } \\
\text { /SOP.pdf?ver=2018-07-03-144058-600 }\end{array}$ & Index score & USACE (2018a) \\
\hline
\end{tabular}

* Categorical rating = score results from an assigned rating evaluation of categorical groups (i.e., Poor, Good, Excellent, Low, High). Index score are final scores in assessment methods that can be calculated from qualitative and/or quantitative assessments. Index scores = scores derived from an index (multicategory rating system, such as the Environmental Protection Agency [EPA] Rapid Bioassessment Protocol [RBP] habitat evaluation) and adding up the subcategories to produce a final score. Stream functional capacity score $=$ a rating system that includes a combination of both categorical ratings and numerical values, which are combined to determine the overall stream function. 
Table 1 (cont.). Examples of stream assessment methods and stream mitigation guidance currently in use by USACE Regulatory Districts and the output scoring of the methods. The stream methodologies used to arrive at these final scores vary widely between districts from rapid visual assessments to time-intensive quantitative measurements. Follow the URLs, or go to the district websites, to find what methods are used and how the scores are then input into credit and debit tools.

\begin{tabular}{|c|c|c|c|c|}
\hline $\begin{array}{l}\text { Stream } \\
\text { Methodology }\end{array}$ & $\begin{array}{l}\text { USACE } \\
\text { District }\end{array}$ & URL & $\begin{array}{l}\text { Output of } \\
\text { Assessment } \\
\text { Method* }^{*}\end{array}$ & Reference \\
\hline $\begin{array}{l}\text { Georgia Stream } \\
\text { Qualitative } \\
\text { Assessment }\end{array}$ & $\begin{array}{l}\text { Savannah } \\
\text { District }\end{array}$ & $\begin{array}{l}\frac{\text { https://www.sas.usace.army.mil/Portals/61/ }}{\text { docs/Regulatory/Mitigation\%20Documents }} \\
\text { LSOP.pdf?ver=2018-07-03-144058-600 }\end{array}$ & $\begin{array}{l}\text { Stream } \\
\text { functional } \\
\text { capacity score } \\
\text { (qualitative) }\end{array}$ & USACE (2018b) \\
\hline $\begin{array}{l}\text { Hydrogeomorphic } \\
\text { (HGM) Approach }\end{array}$ & $\begin{array}{l}\text { Huntington } \\
\text { District }\end{array}$ & $\begin{array}{l}\text { https://wetlands.el.erdc.dren.mil/pdfs } \\
\text { /trel17-1.pdf }\end{array}$ & $\begin{array}{l}\text { Index score } \\
\text { (functional } \\
\text { capacity index) }\end{array}$ & $\begin{array}{l}\text { Summers et al. } \\
(2017)\end{array}$ \\
\hline $\begin{array}{l}\text { North Carolina } \\
\text { Stream } \\
\text { Assessment } \\
\text { Method (NCSAM) }\end{array}$ & $\begin{array}{l}\text { Wilmington } \\
\text { District }\end{array}$ & $\begin{array}{l}\text { https://ribits.usace.army.mil/ribits_apex/f?p } \\
=107: 150: 10661163635161:: \text { N0::P150_DOC } \\
\text { UMENT_ID:36298 }\end{array}$ & $\begin{array}{l}\text { Stream } \\
\text { functional } \\
\text { capacity score } \\
\text { (stream function } \\
\text { rating) }\end{array}$ & $\begin{array}{l}\text { North Carolina } \\
\text { Stream Functional } \\
\text { Assessment Team } \\
(2015)\end{array}$ \\
\hline $\begin{array}{l}\text { Oregon Stream } \\
\text { Function } \\
\text { Assessment } \\
\text { Method (SFAM) } \\
\text { for Oregon (v1.0) }\end{array}$ & $\begin{array}{l}\text { Portland } \\
\text { District }\end{array}$ & $\begin{array}{l}\text { https://www.oregon.gov/dsl/WW/Pages } \\
\text { LSFAM.aspx }\end{array}$ & $\begin{array}{l}\text { Stream } \\
\text { functional } \\
\text { capacity score; } \\
\text { landscape } \\
\text { context score }\end{array}$ & $\begin{array}{l}\text { Nadeau, Hicks, } \\
\text { et al. (2020) }\end{array}$ \\
\hline $\begin{array}{l}\text { Stream Visual } \\
\text { Assessment } \\
\text { Protocol (SVAP2) }\end{array}$ & $\begin{array}{l}\text { New } \\
\text { England } \\
\text { District }\end{array}$ & $\begin{array}{l}\text { https://www.nrcs.usda.gov/Internet/FSE_DO } \\
\text { CUMENTS/nrcs144p2_042678.pdf }\end{array}$ & $\begin{array}{l}\text { Index score } \\
\text { (qualitative) }\end{array}$ & $\begin{array}{l}\text { Natural Resources } \\
\text { Conservation } \\
\text { Service (2009) }\end{array}$ \\
\hline $\begin{array}{l}\text { Tennessee } \\
\text { Stream Mitigation } \\
\text { Guidelines }\end{array}$ & $\begin{array}{l}\text { Nashville } \\
\text { and } \\
\text { Memphis } \\
\text { Districts }\end{array}$ & $\begin{array}{l}\text { https://www.tn.gov/environment/permit- } \\
\text { permits/water-permits1/aquatic-resource- } \\
\text { alteration-permit--arap-/permit-water-arap- } \\
\text { compensatory-mitigation.html }\end{array}$ & Index score & $\begin{array}{l}\text { Tennessee } \\
\text { Department of } \\
\text { Environment and } \\
\text { Conservation } \\
(2019)\end{array}$ \\
\hline $\begin{array}{l}\text { Texas Rapid } \\
\text { Assessment } \\
\text { Method (TXRAM) } \\
\text { Stream Module }\end{array}$ & $\begin{array}{l}\text { Fort Worth } \\
\text { District }\end{array}$ & $\begin{array}{l}\text { https://www.swf.usace.army.mil/Portals/47/ } \\
\text { docs/regulatory/Permitting/Submittal\%20 } \\
\text { Forms/TXRAM_Wetlands_and_Streams_Mod } \\
\text { ules_Version_2.0_Final.pdf }\end{array}$ & Index score & USACE (2015) \\
\hline $\begin{array}{l}\text { Virginia Unified } \\
\text { Stream } \\
\text { Methodology } \\
\text { (USM) }\end{array}$ & $\begin{array}{l}\text { Norfolk } \\
\text { District }\end{array}$ & $\begin{array}{l}\text { https://www.nao.usace.army.mil/Portals/31 } \\
\text { /docs/regulatory/commonreq/USM } \\
\text { Final_Draft.pdf }\end{array}$ & $\begin{array}{l}\text { Index score } \\
\text { (reach condition } \\
\text { index) }\end{array}$ & $\begin{array}{l}\text { USACE and Virginia } \\
\text { Department of } \\
\text { Environmental } \\
\text { Quality (2007) }\end{array}$ \\
\hline $\begin{array}{l}\text { West Virginia } \\
\text { Stream and } \\
\text { Wetland Valuation } \\
\text { Metric (SWVM) }\end{array}$ & $\begin{array}{l}\text { Huntington } \\
\text { District }\end{array}$ & $\begin{array}{l}\text { https://www.Irh.usace.army.mil/Portals/38/ } \\
\frac{\text { docs/regulatory/WV\%20Stream\%20and\%20 }}{\text { Wetland\%20Valuration\%20Metric.pdf }}\end{array}$ & Index score & USACE (2011b) \\
\hline Wyoming SQT & $\begin{array}{l}\text { Omaha } \\
\text { District }\end{array}$ & $\begin{array}{l}\text { https://www.nwo.usace.army.mil/Missions/R } \\
\text { egulatory-Program/Wyoming/Mitigation// }\end{array}$ & Index score & USACE (2018c) \\
\hline
\end{tabular}

* Categorical rating = score results from an assigned rating evaluation of categorical groups (i.e., Poor, Good, Excellent, Low, High). Index score are final scores in assessment methods that can be calculated from qualitative and/or quantitative assessments. Index scores $=$ scores derived from an index (multicategory rating system, such as the Environmental Protection Agency [EPA] Rapid Bioassessment Protocol [RBP] habitat evaluation) and adding up the subcategories to produce a final score. Stream functional capacity score $=$ a rating system that includes a combination of both categorical ratings and numerical values, which are combined to determine the overall stream function. 


\subsection{Objectives}

In making CWA Section 404 permitting and compensatory mitigation decisions, the USACE Regulatory Program, along with its federal, state, and local partners, considers the loss (impacts) and attainment or accrual of aquatic resource functions (compensatory mitigation). Monitoring plans, crediting and debiting protocols, and ecological performance standards for mitigation are most robust and transparent when they rely on objective assessment methods. To better inform regulatory decision-making, the USACE Regulatory Program needs transparent and objective stream assessment approaches. There are currently no consistent guidelines for USACE Regulatory Districts to develop or modify stream assessment methods. Regional assessment methods are important, as they are better able to capture the variation among stream ecosystems within each region than nationally applied methods.

The objective of this Technical Guide for the Development, Evaluation, and Modification of Stream Assessment Methods for the Corps Regulatory Program is to provide the USACE Regulatory Program, along with national, state, tribal, and local partners, a framework to guide either the development of new stream assessment methods or the evaluation; comparison; and if necessary, regionalization of existing stream assessment methods for use in the Regulatory Program (Figure 2). A multiagency national committee, the NCSA, was convened to inform this framework. This resulting process framework from the NCSA is intended to promote transparency, technical defensibility, and consistency in the development of stream assessments across the Regulatory Program. 
Figure 2. Phases to guide development of a stream assessment methodology for use in a specific state or USACE district.

Phase 1

Phase 2

Phase 3

Phase 4

Phase 5

Phase 6

Phase 7

Phase 8

Phase 9

\section{Develop a scope of work}

Develop scope of work to determine specific tasks, identification of project leads and contributors, project development timeframes and milestones, and budget.

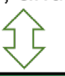

\section{Gather a multidisciplinary project team}

A multidisciplinary team of experts should be gathered to develop, implement, and review the stream assessment protocol.

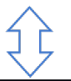

$$
\text { Determine stream types, stream functions and necessary stratification }
$$

Determine the range (heterogeneity) of stream types in the region and if there is a need to stratify as part of the stream assessment. Examine available classification systems and determine if they inform stratification and how they relate to stream function and condition.

\section{Select regionally relevant metrics}

Regional context highlights which stream functions are of most interest and ultimately what metrics best represent those functions in the stream and surrounding area.

\section{Develop the reference framework}

Understand and define the concept of reference. Outline how reference information will be collected and set standards for data documentation, quality, and use. Define the range of reference aquatic resources and compile reference data available to characterize each proposed indicator metric.

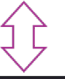

\section{Build assessment models and develop scoring procedure}

Determine the type of assessment outputs (e.g. scoring procedure) that best support intended programmatic uses of the stream assessment method. Build appropriate models for each metric and determine protocols for combining metrics and/or functions.

\section{Assessment method protocols, validation and intercalibration}

Test method for accuracy (validation) and repeatability (intercalibration). Construct field forms for standardaized data collection, documentation, and storage. Apply new method to new sites to determine validity or compare to long-term measurements of condition and functions from available datasets.

\section{Peer review, public comment and beta-testing}

Have the stream assessment method reviewed by those who were not involved in its development. Goals of peer review include determining the usability, applicability, credibility, and relevance of measures. Iterate with previous phases and revise assessment method, documentation, and training methods based on user feedback.

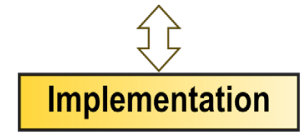

Finalize end products and distribute to end users, stakeholders, and the public. Develop a plan for reviewing and updating assessment method and data management approaches. Develop a training plan and provide continued support, training, and technical assistance. 


\subsection{Approach}

A multiagency National Committee on Stream Assessment assembled to create this guide. Members came from federal agencies involved in stream management, including stream assessment, mitigation, monitoring, and restoration. The committee worked together to construct the framework (Figure 2) for developing stream assessment methods with the intent of promoting consistency, technical defensibility, peer review, and application. The framework will guide both development of new stream assessment methodologies and modifications to those currently in use.

This technical guide describes each phase of the framework. Each subsection provides guidelines, resources, and questions to consider when developing or modifying a method. Before developing a method, first read through this technical guide carefully and consider the approach under each phase. Some phases may occur sequentially, but some may be iterative, so it is useful to understand the entire scope of this document before beginning Phase 1 (development of a scope of work). The questions and ideas presented in each phase will guide formation and execution of a plan. The final chapter summarizes all the questions and phases, and the glossary provides the current code of federal regulation definitions for common terms used throughout this manual. Overall, this technical guide provides an outline for approaching development and modification of an assessment method (Figure 2) and includes the references and a summary of resources needed when working through each phase of the process. 


\section{Components of a Stream Assessment Method}

To minimize subjectivity and variability among regulators and practitioners, stream assessment methods for the CWA Section 404 Regulatory Program need to be objective, measurable, and repeatable. In the process of developing an assessment method, it may be useful to consider a method that is scalable from a rapid assessment to more intensive approaches. For example, the same level of rigor required to verify that a stream mitigation project is meeting its ecological performance standards may not be necessary to evaluate the impact of a proposed small project for which a CWA Section 404 permit application has been submitted. Stream assessments for the Regulatory Program should include indicators to characterize chemical, physical, and biological functions. These field indicators should be responsive to regionally relevant projects authorized under CWA Section 404 (e.g., changes to flow regime, water quality, geomorphology, and secondary or cumulative effects) and be responsive within the timescales associated with typical postconstruction mitigation monitoring (e.g., 515 years), responsive meaning that a change can be detected across the time and spatial scales over which the assessment method is being applied.

Furthermore, a regionally relevant stream assessment method should be able to appropriately assess the condition and/or function of the range of stream resources located in the region. Different stream resources may have the same or very similar functions, but they can differ in condition and in the indicators that represent those conditions and/or functions. Stratification of regional stream types may therefore be a critical precursor for effective development of stream assessment methods for use in the Regulatory Program (Somerville and Pruitt 2010; Fritz et al. 2020). Stratification is a method of sorting the stream resources into distinct groups or layers. For example, stream resources may include stream wetland complexes, beaver-dominated systems, headwaters, tidal, or multithread (e.g., braided or anastomosing) systems. Once stream resources are stratified within a region, it may become apparent that different assessment methods are needed for the different resources.

The NCSA recommends a phased approach to guide development of new stream assessment methods for the Regulatory Program. The same phased approach should also inform the evaluation and, if necessary, modification 
of existing methods (Figure 2). Subsequent sections of this technical guide describe each phase in detail. These guidelines are not meant to be prescriptive. They should instead guide the process of developing or evaluating stream assessment methods. If an existing method is already in use in another region or for a nonregulatory purpose in the same region and needs to be modified, the considerations and resources referenced in each phase of this guide may help identify what might be missing from the assessment method. Additionally, if a method is being modified, each phase can assist with what needs to be updated or improved to best satisfy the programmatic needs of the Regulatory Program. Although laid out sequentially, the actions and efforts in each phase of this guide will often occur concurrently or iteratively with other phases. It is important to periodically reconfirm decisions made in previous phases as new information is generated from work taking place in subsequent phases.

\subsection{Phase 1: Develop a scope of work}

\subsubsection{Phase 1 description}

The process of developing or modifying a stream assessment method for programmatic regulatory purposes can be multifaceted and may require input from many different parties. A project scope of work is useful for outlining the specific tasks to accomplish, the interrelationships of those tasks, and timeframes within which to complete each task. The scope of work should identify all desired work products from each task and each phase of the development process and also the resources necessary to complete each of those elements (e.g., human resources, budget, expertise, etc.). In this way, the scope of work is a road map that guides the project and serves as a resource to consult periodically to ensure that no critical elements are overlooked. The development of the scope of work may begin before any other phase is initiated but will likely be augmented or revised based on input from the project's multidisciplinary partners convened in Phase 2.

2.1.1.1 Goals for the scope of work: updating an existing stream assessment method or developing a new method

While there are many reasons why stream assessment methods are developed, the Regulatory Program specifically needs function-based stream assessments (1) to characterize a stream's condition or function, (2) to im- 
prove understanding of the impact of a proposed action on an aquatic resource, or (3) to inform the development of stream compensatory mitigation tools rooted in stream condition and/or function.

Before developing a new stream assessment method, it is important to first consider methods currently in use in adjacent states or regions (e.g., Table 1) or those used for nonregulatory purposes within the region. Developing a new method may require considerably more time and funding than adapting an existing method. Consultations with peers, colleagues, and stakeholders may provide feedback and insight about assessment methods currently being used in other states or USACE districts. Other state and federal agencies may also be sources of information regarding existing stream assessment methods. The following considerations may help focus evaluations of existing stream assessment methods:

1. Is there concern with limitations of an existing method? For example, does the method assess all stream conditions and/or functions properly? How does the method stratify stream types, and is the method capable of appropriately measuring or differentiating conditions of stream resources found in the target region?

2. Is there any redundancy in the metrics and data collection? Can the method be streamlined?

3. Do some metrics need to be updated or regionalized with local data to better address stream resources found in the target region?

4. Does the assessment method have flexibility between rapid and intensive approaches for different assessment needs?

5. Is the method sensitive to the changes in function and condition associated with the types of activities authorized under CWA Section 404 and within the timescales of typical postproject monitoring (e.g., $5^{-15}$ years)?

6. To what degree do the results reflect stream function and/or condition? That is, what is the accuracy of assessment results; and is additional field testing or long-term data collection needed to further verify and validate the method?

\subsubsection{Flexibility in method}

The USACE Regulatory Program reviews projects that have a range of impacts on streams in terms of both magnitude and spatial area. Direct impacts may range from minor impacts affecting very short stream reaches to impacts affecting thousands of linear feet of stream. Secondary impacts may similarly affect short stream reaches or entire watersheds. Therefore, 
it is useful for stream assessment methods to have flexibility, allowing for both rapid and intensive assessments depending on the type of information needed to support decision-making and the geographic or time scale over which the project will be conducted.

The time it takes to complete any stream assessment in the field is affected by the expertise and experience of practitioners (i.e., training), availability of necessary information and equipment, and size of the project area (Roper et al. 2002; Belletti et al. 2017). The higher the resolution of data needed or desired, the more time it takes to collect and process the data. A rapid approach can be useful for small projects with limited impacts or as an initial screening of multiple potential project sites. Rapid approaches can include collection of both qualitative and quantitative data. However, most rapid approaches are limited in terms of resolution and quantitative data, and they often lack the ability to capture all stream and riparian variables that are relevant for more-substantial projects (Somerville and Pruitt 2004).

Quantitative data are important for retaining the resolution of data necessary to support impact assessment of major projects, to design mitigation projects, to develop mitigation performance standards, and to guide effectiveness monitoring. For example, detailed site-specific analysis should precede mitigation project design, and postmitigation monitoring should also be subject to more rigorous analysis to evaluate whether mitigation project goals are met and ecological performance standards satisfied. Major projects with significant potential for secondary impacts may also require robust postconstruction monitoring as a condition of regulatory authorization.

Note that for small-scale projects that can use a rapid approach, the general conclusions based on either rapid or intensive methods should be similar. For example, a rapid, categorical assessment of stream condition based on subjective estimates of indicator metrics (e.g., good, fair, or poor) should reach similar conclusions about condition as more intensive objective measurement of targeted stream attributes.

\subsubsection{Data management plan for development of the stream assessment method}

A comprehensive data management plan outlined in the scope of work can assist in developing the overall plan, timeline, and budget for the project. 
The project can be either development of a new method or refinement of a method currently in use. The following questions may be useful to consider when developing a data management plan (EPA 2002; ELI [Environmental Law Institute] 2020):

1. What type of data will be collected to develop the stream assessment method? What data format and templates will be used?

2. What metadata will be collected and stored with the data? Metadata documentation is essential for keeping track of the type, quality, and ownership of any data that is gathered.

3. How will data quality be assessed?

4. What type of database will be maintained? How will data be entered into the database, and who is responsible for doing so?

5. What is the plan for data processing and management? How will the data be stored? Who will manage the data?

6. Who will have access to the data, and how will it be accessed? Will open data platforms be used? What is the long-term data access plan?

Another important consideration in data management is whether there will be accommodation or development of tools to report, analyze, display, and share data (ELI 2020). If so, the data management plan should address how the database will be queried, the types of data analysis that will be accommodated, and how it will be displayed, including whether and how the data will be made available and accessible to the public.

\subsubsection{Phase 1 guidelines}

The NCSA recommends that development of a scope of work includes the following five steps:

1. Explicitly define the overall programmatic goals and objectives for developing, or adapting, a stream assessment method. Soliciting the input of stakeholders during development of these goals may foster cooperation of all relevant parties and help to ensure broad endorsement of the final products. The development team should plan to regularly engage with stakeholders throughout the development process.

2. Identify and describe each proposed task to develop a new stream assessment method or to review and revise an existing method. Specifically, outline the plan for each phase listed in this framework and include both a timeline and the outcomes or products expected from each task and each phase. Recognize that these specific details may change. However, 
recording them early in the development process will help keep the project focused.

3. Identify the project leaders, contributors, and potential special-use teams (e.g., technical teams from which to solicit specific input or expertise). Identify pertinent stakeholder groups (if not already identified) and forums to solicit their input.

4. Construct a detailed budget and identify potential funding sources. Note, however, that specific budget expenditures may change as subsequent phases identify data needs. Identifying adequate funding resources is critical for stakeholder engagement, production of figures, and production of the documents that encompass the method (e.g., user manual, workbook/calculator, scientific support document).

5. Conceptualize the data management plan and identify parties capable of developing that plan in detail. Also identify parties capable of hosting the data repository.

\subsection{Phase 2: Gather a multidisciplinary project team}

\subsubsection{Phase 2 description}

The development team will benefit by including members with expertise in all relevant physical, chemical, and biological processes that occur in streams, as well as those familiar with policy implications and applied permitting and restoration experience (Smith et al. 2013; Nadeau et al. 2018; Fritz et al. 2020) (Figure 3). Many factors may affect the size and scope of the team, including the expertise of core team members, the level of effort needed to devise or adapt the stream assessment method, and the variety of unique stream resources within the region where the assessment will be applied.

Figure 3. Scientific, regulatory, and management expertise to consider for the multidisciplinary assessment team.

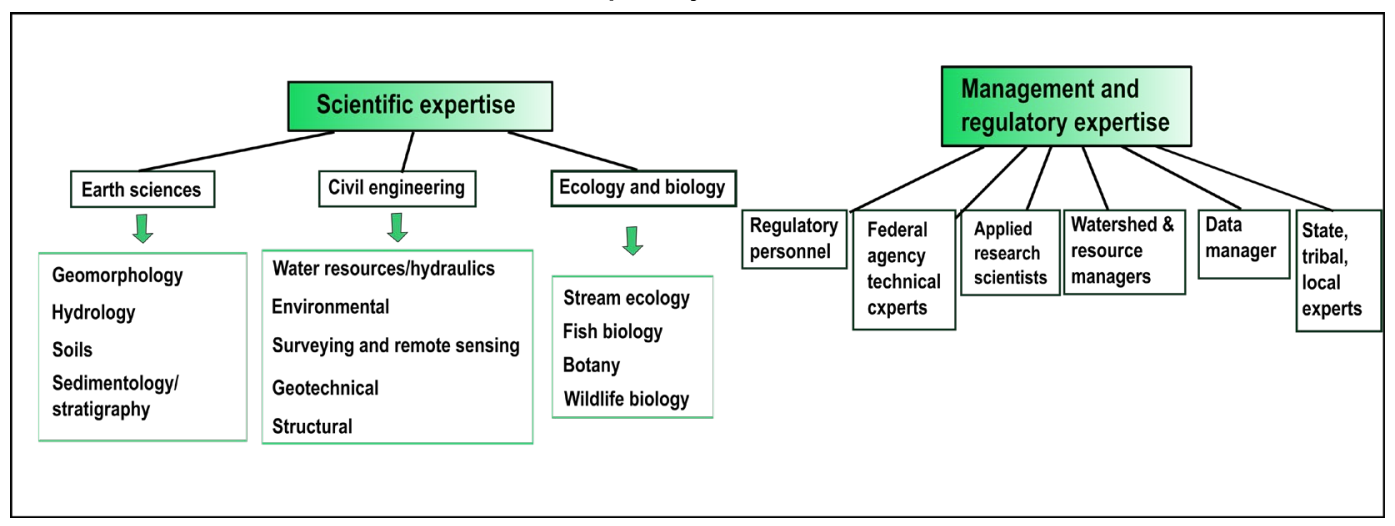




\subsubsection{Phase 2 guidelines}

The NCSA recommends that compilation of a multidisciplinary team to support development of a stream assessment method for the Regulatory Program includes the following steps:

1. Identify skills and expertise needed on the assessment team, including subregional representation if the target region is large and inclusive of diverse stream resources.

2. Contact local, state, federal, tribal, and academic experts to join the assessment team.

3. Once the multidisciplinary assessment team is assembled, clearly outline the goals, timelines, and expectations for engagement of the team and review and refine the project scope of work developed in Phase 1, if applicable.

\subsection{Phase 3: Determine the types of streams, associated stream functions, and necessary stratification for streams in the region}

\subsubsection{Phase 3 description}

A watershed is the area of land "that drains to a common waterway, such as a stream, lake, estuary, wetland, or ultimately the ocean." "* The condition of the watershed thereby directly and indirectly affects the condition of the streams within that watershed. Thus, the watershed is the area within which physical, chemical, and biological processes determine the condition, function, and services of streams (Thorne et al. 1997; Alexander et al. 2007; Wipfli et al. 2007; Roni and Beechie 2013; ELI and The Nature Conservancy 2014; Wohl 2018). The functions that occur in streams, supported by their watershed, can change over time and space (Nadeau et al. 2018).

Streams adjust their planform, longitudinal profile, and cross section based on the amount of water and sediment that moves through the channel over time. The diversity of climates and landscapes results in a variety of stream types that interact in complex ways with the land. These interactions result in a range of habitats for aquatic and riparian organisms based on differences in the cycling of water, sediment, and nutrients through the system. Within any region, there can be significant heterogeneity in stream condition and function. Efforts to first recognize this heterogeneity 
and then stratify, or classify, streams to reduce natural, expected variability among streams will facilitate the identification of relevant functions. Metrics that are capable of representing the functional capacity of streams can then also be identified.

The purpose of classifying streams is to organize otherwise complex natural systems into groups having similar characteristics. This allows the results of stream assessments to be compared with other members of the same group (e.g., at both reference and impact sites). Further, similarities and differences can be more easily communicated among practitioners, regulators, and other stakeholders (Tadaki et al. 2014; Rinaldi et al. 2016). For example, classification of streams based on channel form is an attempt to link streams shaped by similar geomorphic processes. Similarly, organizing streams based on ecoregion or water temperature can aid identification of patterns in aquatic biological communities. Stratifying or classifying streams as part of a stream assessment method helps to reduce variability and improves signal-to-noise power of the assessment method. This phase in developing or adapting a stream assessment method for the Regulatory Program focuses on characterizing streams in a particular region, identifying the functions performed by those streams, and stratifying or classifying streams by intrinsic channel, valley, and/or watershed characteristics that affect those functions and the expression of indicators of those functions in the field.

Stratification of stream types may be relevant for identifying indicator metrics (Phase 4) and relevant sources of reference data (Phase 5). It is also possible that stratification of streams conceptualized in this phase may change during subsequent phases of method development. Do not classify simply for the sake of classifying. Instead, stratify or classify stream types only to the degree necessary to minimize natural variation and identify indicator metrics of stream function that are effective at discriminating streams among differing levels of functional capacity. Any stratification or classification should relate to the main programmatic goals for the stream assessment method and the metrics selected to indicate the degree to which a stream is functioning. It is also important to carefully consider and reevaluate this phase as reference data is collected. If, for example, there is no differentiation of metric data among stream classes, there may be no cause for classifying streams for that metric, or a different approach to stratification may be applicable. 


\subsubsection{Phase 3 guidelines}

\subsubsection{Consider the range of stream resources within the region}

Development of a stream assessment method should be preceded by broader efforts to first identify and understand the range of natural variability among streams throughout the region. Variability may be the result of differing locations along the hydrographic continuum (e.g., headwater streams vs. large rivers), differing geologic or ecological settings, differing thermal regimes, variations in natural land cover (e.g., grasslands vs. forests), etc. (Figure 4). The development team should consider the many factors that introduce heterogeneity into regional streams, and attempt to organize this information using conceptual models and/or classification frameworks. This will help identify factors that exert the most influence on stream functions performed or capable of being performed by each stream type in the region and will also aid in identifying the most applicable metrics indicative of each function.

Conceptual models are often used to provide simplified versions of reality to help understand the complex structures and interlinked processes affecting stream systems. Development of a simplified regional conceptual model can assist in understanding expected changes in stream functions (i.e., processes) across stream types or in response to stressors. Ultimately, changes in these stream processes result in different metrics being of interest in different locations of the channel network or across differing ecological or geologic settings (Fischenich 2006; Fritz et al. 2006; McKay et al. 2010; Somerville 2010; Nadeau et al. 2018). 
Figure 4. Metric selection depends on understanding landscape connections. Watershed characteristics control channel and floodplain characteristics, which determine stream condition and function.

\section{Landscape \\ Characteristics}<smiles>C1CC2CC1C2</smiles>

\section{Watershed}

Characteristics

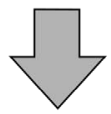

\section{Stream Sediment}

\& Flow Regimes

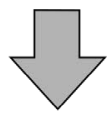

\section{Stream Form}

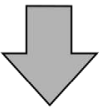

\section{Surface-Groundwater Interactions}

(Hyporheic Zone)

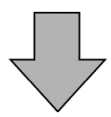

\section{Channel and Floodplain Habitat

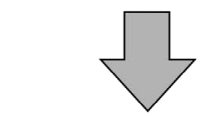

\section{Expected Stream Condition and Function}

Climate

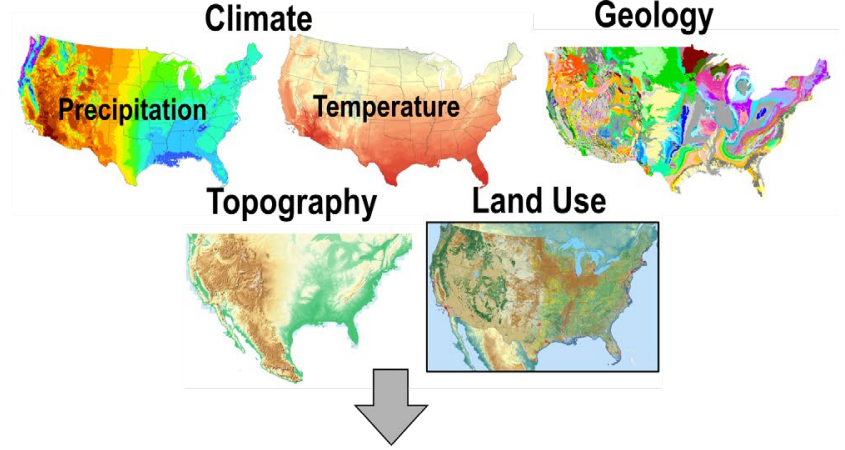

Soils and Vegetation

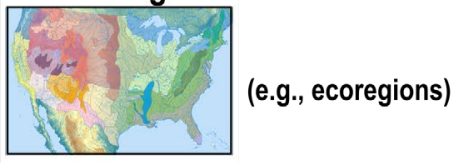

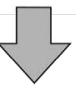

Watersheds

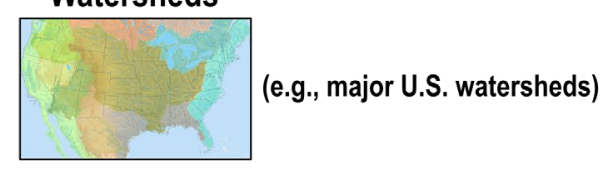

Ex. 1: Sediment transport zone; aquatic insects are mainly collector/shredders,

and fish are juvenile trout

Ex. 2: Sediment deposition zone; aquatic insects are mainly collector/grazers; spawning habitat for coho and chinook salmon

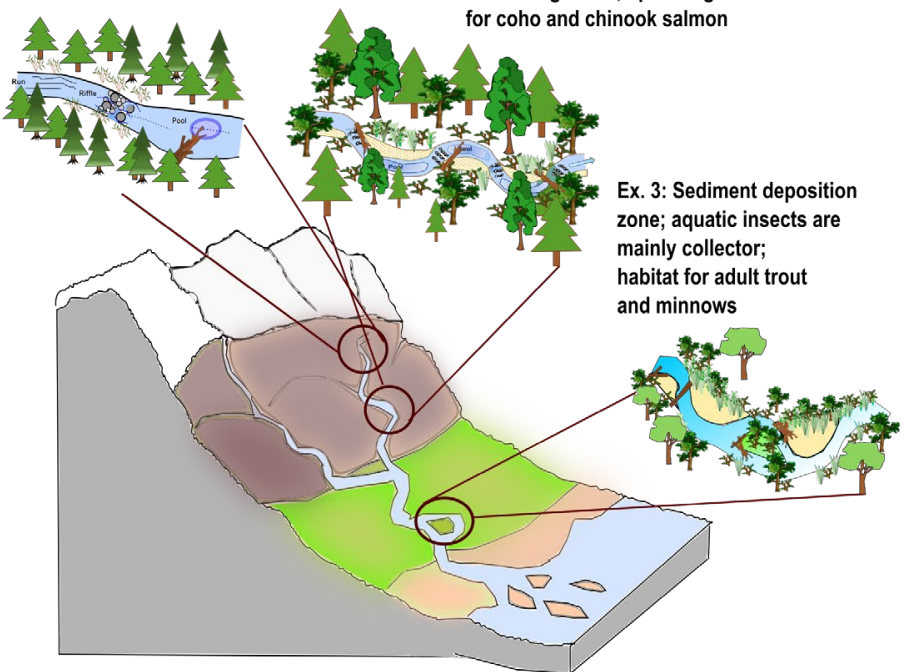

2.3.2.2 Identify the functions of streams in the region and how they may differ among stream types or landscape settings

As noted in Fischenich (2006), the character of stream systems is the result of dynamic and interrelated processes. High quality streams support 
and maintain a critical suite of functions. Fischenich (2006) presented 15 critical stream and riparian corridor functions organized into 5 categories: system dynamics, hydrologic balance, sediment processes and character, biological support, and chemical processes and landscape (Figure 1). The development team should consider how to organize or frame stream functions in the assessment method to best meet the regulatory programmatic goals of the region. Some assessment approaches consider functions and indicator metrics for a wide variety of specific functions (e.g., from hydrology to biology) while other assessment approaches focus on a smaller subset of functions, such as only hydrologic or geomorphic functions, or aggregate specific functions into broader categorical groups (see Somerville and Pruitt 2004; Somerville 2010).

Stratification of stream resources in the region may be necessary to determine which stream functions and/or indicator metrics for those functions are most applicable for different resource types in the region. Although presented discretely in this technical guide, identification of functions, stratification of regional stream resources, identification of metrics, and development of conceptual models should be considered iteratively because each of these tasks affects the others. For example, surface water storage, as indicated by floodplain connectivity, may be important to assess in alluvial and unconfined valley settings but less so in colluvial reaches or confined valley settings. Similarly, when considering geomorphic functions, the role of large wood may not be relevant in grassland stream systems that have minimal natural sources of wood recruitment but is important in higher-order, broad floodplain systems (Collins et al. 2012; U.S. Bureau of Reclamation and U.S. Army Engineer Research and Development Center 2016; Wohl et al. 2019).

\subsubsection{Stratification of streams in the region}

There are several factors to consider when determining how to stratify streams in the region or whether to either develop a classification system or use an existing one. Consider the geographic scale over which stream characteristics will be identified or have been identified, how the classification will be used in the assessment method, and how classification will affect metric development.

Table 2 summarizes a variety of stream classification systems that have been developed based on various factors, including flow regime, drainage network, channel morphology, and floodplain morphology. Many of the 
examples in Table 2 focus on geomorphic and hydrologic classification schemes, but development of a stream assessment method should consider ecological ones also. For instance, ecoregions are broad ecological classifications commonly underlying development of assessment methods (Omernik and Griffith 2014). Some classification systems integrate multiple factors into a single scheme, such as the Northeast Aquatic Habitat Classification System developed for conservation planning in New England (Olivero and Anderson 2008), which incorporates stream size, gradient, geologic buffering capacity, and temperature into a single classification framework. Several review articles compare different stream classification frameworks (see Goodwin 1999, Kasprak et al. 2016, Melles et al 2014, and Tadaki et al. 2014).

Ultimately, classification systems emphasize different physical stream and riparian characteristics, which can lead to differences in their output (Kasprak et al. 2016). Many classification systems will consider only one factor for classification and will not necessarily integrate river and floodplain morphology and hydrology (Rinaldi et al. 2016; Wohl 2016; Pasternack 2018a, 2018b). Therefore, when applying a stream classification framework for resource management or regulatory purposes, it is important to consider whether the framework may already predetermine the importance of particular stream characteristics (Tadaki et al. 2014).

Most stream classification frameworks are hierarchical in nature, which means they have a graded organizational structure (Dollar et al. 2007). The hierarchy helps to partition stream systems into discrete levels, with upper levels usually exerting some constraint on what is likely at lower levels. Unfortunately, the scales of the hierarchical levels used to define a stream based on geomorphology may not match the scale for a hydrological or ecological organization (Montgomery and MacDonald 2002; Thoms and Parsons 2002). Figure 5 provides examples of classification schemes applied at different landscape scales. There needs to be careful consideration of how to interlink scale-dependent frameworks, as a site may have multiple classifications that apply depending on the function or metric evaluated. Biological communities may or may not be correlated with geomorphic stream type, especially if streams of significantly different sizes or positions in the river network are classified as the same stream type. Thus, different classifications may be applicable when considering different stream functions. 
Table 2. Descriptions of classification frameworks developed for a variety of purposes and applications, such as to describe flow regime, drainage networks, channel morphology, and floodplain morphology.

\begin{tabular}{|c|c|c|c|c|}
\hline Name & Reference & Purpose & Benefits & Limitations \\
\hline \multicolumn{5}{|c|}{ Classification by Flow Regime } \\
\hline Natural flow regime & $\begin{array}{l}\text { Poff et al. } \\
(1997)\end{array}$ & $\begin{array}{l}\text { Connects ecology } \\
\text { and form to range } \\
\text { of flows, not just a } \\
\text { single flow }\end{array}$ & $\begin{array}{l}\text { Recognizes ecologic } \\
\text { importance of flow } \\
\text { variability }\end{array}$ & $\begin{array}{l}\text { Needs gage data to } \\
\text { identify flow regimes }\end{array}$ \\
\hline $\begin{array}{l}\text { REFORM (Restoring } \\
\text { Rivers for Effective } \\
\text { Catchment Management) } \\
\text { and IDRAIM (sistema di } \\
\text { valutazione } \\
\text { idromorfologica, analisi e } \\
\text { monitoraggio dei corsi } \\
\text { d'acqua [Multiscale } \\
\text { hierarchical framework]) }\end{array}$ & $\begin{array}{l}\text { Rinaldi et al. } \\
(2015,2016)\end{array}$ & $\begin{array}{l}\text { Classifies rivers } \\
\text { based on channel } \\
\text { morphology, } \\
\text { floodplain } \\
\text { morphology, flow } \\
\text { regime, and } \\
\text { groundwater- } \\
\text { surface water } \\
\text { interactions }\end{array}$ & $\begin{array}{l}\text { Developed specifically } \\
\text { for river managers in } \\
\text { European Union for } \\
\text { flood management } \\
\text { and stream mitigation } \\
\text { work }\end{array}$ & $\begin{array}{l}\text { Need gage data (at } \\
\text { least } 20 \text { years of data) }\end{array}$ \\
\hline \multicolumn{5}{|c|}{ Classification by Drainage network } \\
\hline $\begin{array}{l}\text { Erosion, transport, and } \\
\text { deposition zones }\end{array}$ & $\begin{array}{l}\text { Schumm } \\
(1977)\end{array}$ & $\begin{array}{l}\text { Encompasses } \\
\text { process-based view } \\
\text { of river network }\end{array}$ & $\begin{array}{l}\text { Gives overall } \\
\text { understanding of } \\
\text { erosional and } \\
\text { depositional zones } \\
\text { within a watershed }\end{array}$ & $\begin{array}{l}\text { Watershed-scale } \\
\text { analysis; lumps many } \\
\text { channel types together }\end{array}$ \\
\hline Stream order & $\begin{array}{l}\text { Horton } \\
(1945) \\
\text { Strahler } \\
(1952)\end{array}$ & $\begin{array}{l}\text { Provides } \\
\text { descriptive } \\
\text { classification of } \\
\text { river network }\end{array}$ & $\begin{array}{l}\text { Organizational } \\
\text { scheme that helps } \\
\text { with communicating } \\
\text { relative stream size } \\
\text { and location within a } \\
\text { basin }\end{array}$ & $\begin{array}{l}\text { Depends on resolution } \\
\text { of the map used to } \\
\text { identify the drainage } \\
\text { network; provides little } \\
\text { information about } \\
\text { stream shape and } \\
\text { processes }\end{array}$ \\
\hline River continuum & $\begin{array}{l}\text { Vannote et } \\
\text { al. (1980) }\end{array}$ & $\begin{array}{l}\text { Identifies expected } \\
\text { gradient of } \\
\text { hydroecologic } \\
\text { changes in } \\
\text { longitudinal } \\
\text { direction }\end{array}$ & $\begin{array}{l}\text { Identifies expected } \\
\text { macroinvertebrate } \\
\text { functional groups for } \\
\text { each portion of the } \\
\text { channel network } \\
\text { based on energy } \\
\text { inputs and outputs }\end{array}$ & $\begin{array}{l}\text { Assumes gradual } \\
\text { change, ignores } \\
\text { discontinuities created } \\
\text { by tributaries, dams, } \\
\text { and road-stream } \\
\text { crossings }\end{array}$ \\
\hline Process domains & $\begin{array}{l}\text { Montgomery } \\
(1999)\end{array}$ & $\begin{array}{l}\text { Describes division } \\
\text { of river network } \\
\text { based on } \\
\text { disturbance } \\
\text { processes, channel } \\
\text { morphologies, and } \\
\text { aquatic habitats }\end{array}$ & $\begin{array}{l}\text { Identifies geomorphic } \\
\text { units within the } \\
\text { landscape that help } \\
\text { understand river } \\
\text { behavior; useful as a } \\
\text { land management } \\
\text { tool }\end{array}$ & $\begin{array}{l}\text { Need knowledge of } \\
\text { disturbance processes; } \\
\text { lumps channel types } \\
\text { together }\end{array}$ \\
\hline River styles framework & $\begin{array}{l}\text { Brierley and } \\
\text { Fryirs (2005) }\end{array}$ & $\begin{array}{l}\text { Supplies basin-wide } \\
\text { template for river } \\
\text { management }\end{array}$ & $\begin{array}{l}\text { Includes process- } \\
\text { based watershed- } \\
\text { scale classification } \\
\text { system }\end{array}$ & $\begin{array}{l}\text { Classification based on } \\
\text { the order variables } \\
\text { appear in framework (a } \\
\text { priori determinations of } \\
\text { importance) }\end{array}$ \\
\hline
\end{tabular}


Table 2 (cont.). Descriptions of classification frameworks developed for a variety of purposes and applications, such as to describe flow regime, drainage networks, channel morphology, and floodplain morphology.

\begin{tabular}{|c|c|c|c|c|}
\hline Name & Reference & Purpose & Benefits & Limitations \\
\hline \multicolumn{5}{|c|}{ Classification by Geomorphology } \\
\hline $\begin{array}{l}\text { Planform pattern } \\
\text { (straight, } \\
\text { meandering, and } \\
\text { braided) }\end{array}$ & $\begin{array}{l}\text { Leopold and } \\
\text { Wolman } \\
(1957)\end{array}$ & $\begin{array}{l}\text { Identifies channel form } \\
\text { and connects to } \\
\text { landscape processes }\end{array}$ & $\begin{array}{l}\text { Contains quantitative } \\
\text { method of } \\
\text { determining channel } \\
\text { patterns }\end{array}$ & $\begin{array}{l}\text { Empirical and } \\
\text { descriptive }\end{array}$ \\
\hline Mountain streams & $\begin{array}{l}\text { Montgomery } \\
\text { and } \\
\text { Buffington } \\
(1997)\end{array}$ & $\begin{array}{l}\text { Describes } \\
\text { geomorphological } \\
\text { classification scheme }\end{array}$ & $\begin{array}{l}\text { Assesses physical } \\
\text { channel condition and } \\
\text { response potential; } \\
\text { both descriptive and } \\
\text { process based }\end{array}$ & $\begin{array}{l}\text { Developed for alluvial } \\
\text { mountain streams in } \\
\text { the Pacific Northwest }\end{array}$ \\
\hline $\begin{array}{l}\text { Natural channel } \\
\text { classification }\end{array}$ & $\begin{array}{l}\text { Beechie and } \\
\text { Imaki (2014) }\end{array}$ & $\begin{array}{l}\text { Predicts historical, or } \\
\text { predisturbance, } \\
\text { planform of alluvial } \\
\text { channels }\end{array}$ & $\begin{array}{l}\text { Based on process and } \\
\text { form, can be used to } \\
\text { estimate form under } \\
\text { baseline conditions }\end{array}$ & $\begin{array}{l}\text { Limited by what data is } \\
\text { available to input and } \\
\text { build the model; } \\
\text { determines } \\
\text { predisturbance channel } \\
\text { planform }\end{array}$ \\
\hline $\begin{array}{l}\text { Channel reach } \\
\text { classification }\end{array}$ & $\begin{array}{l}\text { Rosgen } \\
(1994,1996)\end{array}$ & $\begin{array}{l}\text { Uses geomorphic } \\
\text { surveys for a } \\
\text { standardized river } \\
\text { classification scheme }\end{array}$ & $\begin{array}{l}\text { Allows easy } \\
\text { identification of } \\
\text { specific patterns } \\
\text { during field visits }\end{array}$ & $\begin{array}{l}\text { Largely descriptive and } \\
\text { does not connect to } \\
\text { channel processes; } \\
\text { misses a variety of } \\
\text { channel types in } \\
\text { headwaters }\end{array}$ \\
\hline $\begin{array}{l}\text { Schumm's } \\
\text { conceptual } \\
\text { framework for river } \\
\text { classification }\end{array}$ & $\begin{array}{l}\text { Schumm } \\
(1963)\end{array}$ & $\begin{array}{l}\text { Emphasizes the } \\
\text { importance of } \\
\text { sediment load and silt- } \\
\text { clay content of the } \\
\text { floodplain }\end{array}$ & $\begin{array}{l}\text { Relates channel } \\
\text { patterns to driving } \\
\text { and resisting forces }\end{array}$ & $\begin{array}{l}\text { Largely qualitative and } \\
\text { developed for large } \\
\text { rivers with wide } \\
\text { floodplains }\end{array}$ \\
\hline $\begin{array}{l}\text { Channel evolution } \\
\text { models (CEMs) }\end{array}$ & $\begin{array}{l}\text { Simon and } \\
\text { Hupp (1986); } \\
\text { Watson et al. } \\
\text { (2002): } \\
\text { Simon and } \\
\text { Rinaldi } \\
\text { (2006); Hupp } \\
\text { and Rinaldi } \\
\text { (2007) } \\
\end{array}$ & $\begin{array}{l}\text { Describes the } \\
\text { sequence of channel } \\
\text { adjustments in } \\
\text { response to } \\
\text { disturbances, } \\
\text { particularly base-level } \\
\text { lowering }\end{array}$ & $\begin{array}{l}\text { Provides discussion } \\
\text { on factors controlling } \\
\text { the range of channel, } \\
\text { bank, and riparian } \\
\text { adjustments in } \\
\text { incised channels }\end{array}$ & $\begin{array}{l}\text { Typically focused on } \\
\text { predicting adjustments } \\
\text { in incised alluvial } \\
\text { streams }\end{array}$ \\
\hline $\begin{array}{l}\text { Stream evolution } \\
\text { model (SEM) }\end{array}$ & $\begin{array}{l}\text { Cluer and } \\
\text { Thorne } \\
(2014)\end{array}$ & $\begin{array}{l}\text { Update to CEMs; } \\
\text { predicts cyclical } \\
\text { changes in channel } \\
\text { hydrology, hydraulics, } \\
\text { substrate, habitat, } \\
\text { biota, and water quality } \\
\text { with a disturbance }\end{array}$ & $\begin{array}{l}\text { Relates channel form } \\
\text { to other physical and } \\
\text { biological attributes } \\
\text { and summarizes } \\
\text { stage of evolution and } \\
\text { expected changes }\end{array}$ & $\begin{array}{l}\text { Focused on single- } \\
\text { thread, active } \\
\text { meandering, } \\
\text { anastomosing, and } \\
\text { incised alluvial } \\
\text { channels }\end{array}$ \\
\hline
\end{tabular}


Table 2 (cont.). Descriptions of classification frameworks developed for a variety of purposes and applications, such as to describe flow regime, drainage networks, channel morphology, and floodplain morphology.

\begin{tabular}{|c|c|c|c|c|}
\hline Name & Reference & Purpose & Benefits & Limitations \\
\hline $\begin{array}{l}\text { Genetic classification } \\
\text { of floodplains }\end{array}$ & $\begin{array}{l}\text { Nanson and } \\
\text { Croke } \\
(1992)\end{array}$ & $\begin{array}{l}\text { Recognizes that } \\
\text { characteristic floodplain } \\
\text { morphologies are a } \\
\text { reflection of fluvial } \\
\text { processes }\end{array}$ & $\begin{array}{l}\text { Describes longer-term } \\
\text { processes }\end{array}$ & $\begin{array}{l}\text { Limited to unconfined } \\
\text { and partly confined } \\
\text { alluvial rivers }\end{array}$ \\
\hline \multicolumn{5}{|c|}{ Classification by riparian vegetation or other ecological factors } \\
\hline Ecoregion & $\begin{array}{l}\text { Omernik and } \\
\text { Griffith } \\
(2014)\end{array}$ & $\begin{array}{l}\text { Map areas based on } \\
\text { ecosystem similarities at } \\
\text { multiple spatial scales }\end{array}$ & $\begin{array}{l}\text { Provides a holistic } \\
\text { flexible framework for } \\
\text { comparison and } \\
\text { analysis of aquatic } \\
\text { resources }\end{array}$ & $\begin{array}{l}\text { Need to understand } \\
\text { what resolution is } \\
\text { effective when } \\
\text { analyzing and } \\
\text { comparing indicators }\end{array}$ \\
\hline $\begin{array}{l}\text { Riparian vegetation } \\
\text { flow response guilds }\end{array}$ & $\begin{array}{l}\text { Merritt et al. } \\
(2010)\end{array}$ & $\begin{array}{l}\text { Relates plants with } \\
\text { shared traits to a river } \\
\text { flow regime }\end{array}$ & $\begin{array}{l}\text { Relates changes in } \\
\text { the riparian response } \\
\text { guild to predicted } \\
\text { changes in flow }\end{array}$ & $\begin{array}{l}\text { Need to be able to } \\
\text { identify vegetation and } \\
\text { build regional response } \\
\text { guilds }\end{array}$ \\
\hline $\begin{array}{l}\text { Riparian vegetation } \\
\text { structure }\end{array}$ & $\begin{array}{l}\text { Osterkamp } \\
\text { and Hupp } \\
\text { (1984); } \\
\text { Hupp and } \\
\text { Osterkamp } \\
(1996)\end{array}$ & $\begin{array}{l}\text { Shows the expected } \\
\text { stratification of } \\
\text { vegetation in the } \\
\text { riparian zone in } \\
\text { temperate climates }\end{array}$ & $\begin{array}{l}\text { Assists in } \\
\text { understanding } \\
\text { changes in vegetation } \\
\text { community structure } \\
\text { and function in areas } \\
\text { adjacent to a stream }\end{array}$ & $\begin{array}{l}\text { Vegetation } \\
\text { communities will differ } \\
\text { based on climate, } \\
\text { geology, and land use }\end{array}$ \\
\hline Stream temperature & $\begin{array}{l}\text { Maheu et al. } \\
(2016)\end{array}$ & $\begin{array}{l}\text { Classifies streams } \\
\text { based on stream water } \\
\text { temperature regimes }\end{array}$ & $\begin{array}{l}\text { Framework assists } \\
\text { with cross-system } \\
\text { comparisons and } \\
\text { provides foundation } \\
\text { for defining reference } \\
\text { conditions }\end{array}$ & $\begin{array}{l}\text { Limited in resolution } \\
\text { and ability to provide } \\
\text { diel (daily) regimes }\end{array}$ \\
\hline \multicolumn{5}{|c|}{ Classification based on multiple factors } \\
\hline $\begin{array}{l}\text { Northeast Stream } \\
\text { Classification }\end{array}$ & $\begin{array}{l}\text { Olivero and } \\
\text { Anderson } \\
(2008)\end{array}$ & $\begin{array}{l}\text { Classifies stream } \\
\text { segments based on size, } \\
\text { gradient, geologic } \\
\text { buffering capacity, and } \\
\text { temperature }\end{array}$ & $\begin{array}{l}\text { Describes regionally } \\
\text { specific classification } \\
\text { system for } \\
\text { conservation planning } \\
\text { and management }\end{array}$ & $\begin{array}{l}\text { Some limitations in } \\
\text { resolution }\end{array}$ \\
\hline $\begin{array}{l}\text { Oregon Stream } \\
\text { Classification System }\end{array}$ & $\begin{array}{l}\text { Nadeau et } \\
\text { al. (2012); } \\
\text { Nadeau et } \\
\text { al. (2018, } \\
\text { Appendix B) }\end{array}$ & $\begin{array}{l}\text { Classifies stream } \\
\text { segments based on } \\
\text { hydrologic and geologic } \\
\text { drivers of stream } \\
\text { function by using local- } \\
\text { and watershed-scale } \\
\text { parameters (e.g., } \\
\text { landscape position, } \\
\text { water budget, seasonal } \\
\text { hydrology, and gradient) }\end{array}$ & $\begin{array}{l}\text { Provides state- } \\
\text { specific classification } \\
\text { developed, in part, to } \\
\text { support application of } \\
\text { the SFAM for Oregon }\end{array}$ & $\begin{array}{l}\text { Uses NHDPlus and } \\
\text { other spatial datasets, } \\
\text { which may result in } \\
\text { smaller streams being } \\
\text { classified per the local } \\
\text { unit of assessment }\end{array}$ \\
\hline $\begin{array}{l}\text { Stream Classification } \\
\text { System }\end{array}$ & $\begin{array}{l}\text { McManamay } \\
\text { and DeRolph } \\
(2019)\end{array}$ & $\begin{array}{l}\text { Classifies stream } \\
\text { segments based on size, } \\
\text { gradient, hydrology, } \\
\text { temperature, network } \\
\text { bifurcation, and valley } \\
\text { confinement }\end{array}$ & $\begin{array}{l}\text { Uses remote and } \\
\text { other spatial datasets } \\
\text { to model and classify } \\
\text { streams on a } \\
\text { continental scale }\end{array}$ & $\begin{array}{l}\text { Uses NHDPlus data to } \\
\text { develop the } \\
\text { classification system, } \\
\text { which may result in } \\
\text { smaller streams being } \\
\text { excluded }\end{array}$ \\
\hline
\end{tabular}


Figure 5. Example of spatial scales to consider when identifying stream functions and corresponding indicator metrics for those functions. Stream functions and categories from Fischenich (2006). (Map data @ 2020 Google). Spatนa Scale

Stream Functions
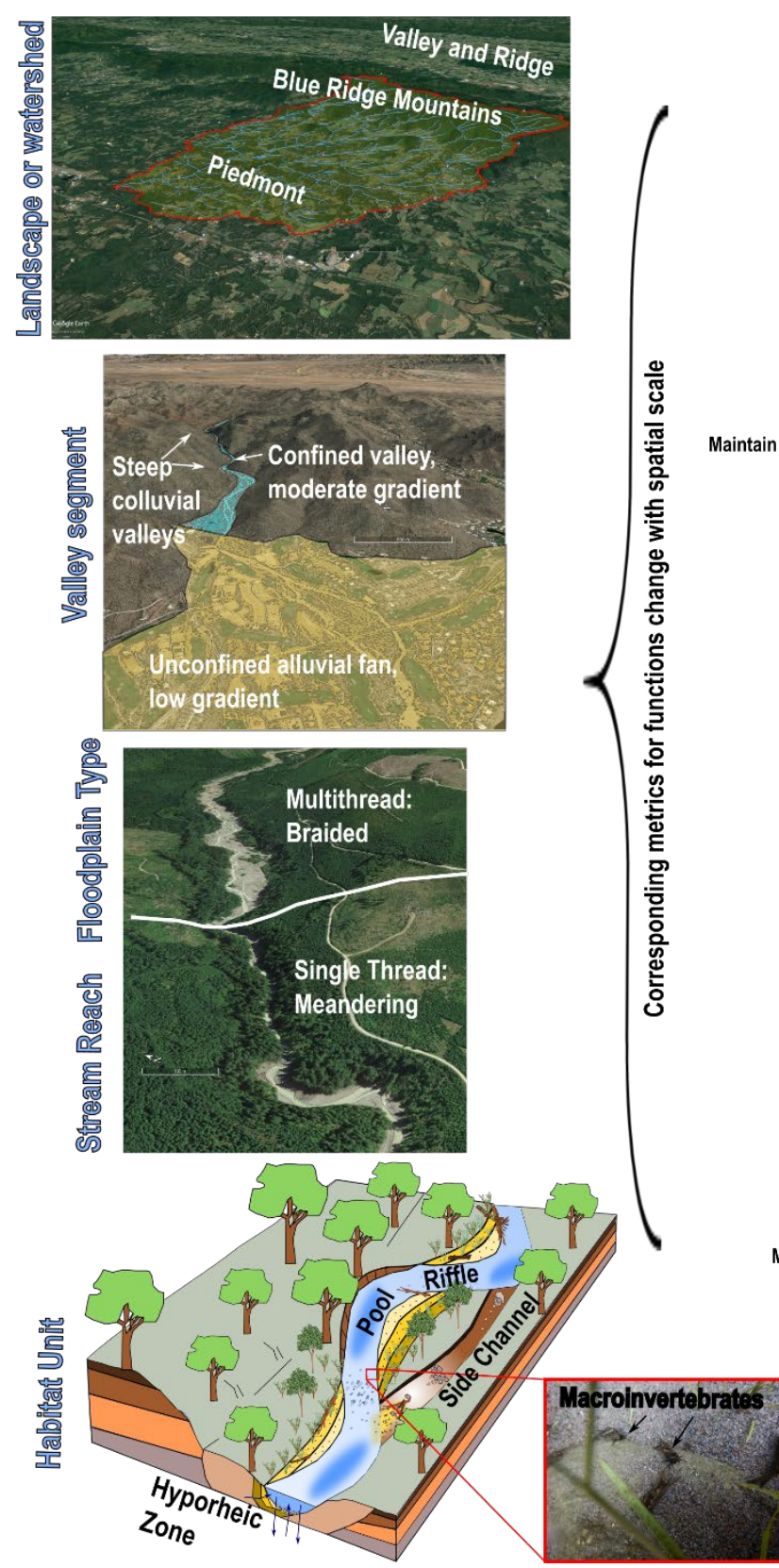

Maintain stream evolution processes Energy management processes Provide for riparian succession

Surface water storage processes Maintain surface/subsurface connections and processes General hydrodynamic balance

Sediment continuity Maintain substrates and structural processes Quality and quantity of sediments Support biological communiites and processes Provide necessary aquatic and riparian habitats Maintain trophic structure and processes

뭉

Maintain water and soil quality Maintain chemical processes and nutrient cycles Maintain landscape pathways

Note also that current stream conditions may not necessarily represent the former, long-term, or future conditions (Kondolf 1995). Streams that appear similar may not be equivalent and interchangeable if the processes that formed that feature differ in a region (Tadaki et al. 2014). In any given region, different processes and initial conditions can result in the same channel form (Fuller et al. 2013; Tadaki et al. 2014). For example, a 
braided river can occur because of rapid tectonic uplift in a region, from glacial outwash in another, or because of land use changes (e.g., rapid removal of vegetation). The end result of a braided system is the same, but the processes responsible for that braided system are different. Consequently, it is important to consider how unique site-specific or watershedscale processes may affect ecological processes, stream condition, or channel form (Kondolf 1995). Channel and stream evolution models, some of which are included in Table 3, attempt to account for and predict anticipated changes over time (Schumm 1985; Watson et al. 1986; Simon and Hupp 1986; Simon 1994; Fryirs and Brierley 2000; Booth and Fischenich 2015; Cluer and Thorne 2014).

When evaluating existing metrics (e.g., fish or macroinvertebrate indices of biotic integrity) developed by other parties, it is important to consider that such metrics may already be stratified by a specific classification scheme (e.g., multimetric indices for benthic macroinvertebrates are stratified by bioregion in Wyoming, ecoregion in Tennessee, and biotype in Colorado). Therefore, it is important to consider whether metrics from other regions can be applied outside of the region or classification scheme they were developed for or whether there are region-specific metrics and classifications that could be incorporated into the method. Furthermore, the assessment method should make clear if a metric is developed to assess functions in a specific stream type so that the metric is not misapplied. For instance, if a metric is developed for perennial channels, it should not be used in intermittent channels without additional testing. Section 2.4 will further discuss choosing regionally relevant metrics.

Before moving on to Phase 4, it is useful to document the efforts within this phase. This could be done by assembling a table or list that includes the dominant stream processes, variations in landscape and watershed variables, the range of stream types based on selected stratification or classification systems, and the related functions of interest. Recognize that stratification and classification frameworks identified in this phase may need to be revised during subsequent analysis of reference data. Well-documented deliberations and decisions by the multidisciplinary team throughout all phases of the assessment method development will ease subsequent revisions and provide a transparent record of the process for end users and stakeholders (e.g., Nadeau et al. 2018). 


\subsubsection{Steps in Phase 3}

The NCSA recommends the following considerations when stratifying or classifying stream types for development of a stream assessment method for the Regulatory Program:

1. Identify the landscape, watershed, and ecological factors that create a diversity of stream types in the target region and what factors create heterogeneity in streams within the region.

2. Consider the processes that influence stream functions and how they may vary within the stream network. Identify the key functions to be included in the stream assessment method.

3. Consider which approaches to use to stratify or classify streams in the target region.

4. Connect stratification and classification frameworks to stream functions of interest and associated metrics. Is the approach used to stratify or classify streams meaningful in the context of stream functions targeted for the assessment method?

5. Consider whether different frameworks are needed to stratify and/or classify streams based on geomorphic, biologic, hydrologic, or physiochemical characteristics or whether a single, integrated framework can be used or developed.

\subsection{Phase 4: Select regionally relevant metrics}

\subsubsection{Phase 4 description}

The ability for regulatory decision makers to assess the loss of function associated with impacts or the attainment of function associated with compensatory mitigation depends on successfully characterizing the condition and ultimately the functional capacity of the stream. Applicable indicator metrics used to quantify functional capacity must be firmly and explicitly grounded in applicable stream functions. When a metric is too many steps away from the actual function it is indicative of, there is a greater risk that it will inaccurately represent that function across the continuum of regional conditions. Additionally, a stream assessment method may suffer if indicator metrics are not sensitive or responsive to the situations encountered in regulatory decision-making.

Indicator metrics associated with stream functions may differ depending on the scale and landscape type. The stream and floodplain characteristics 
may require different metrics to account for the natural range of variability within the stream type. For instance, the metrics needed to assess streams in an alluvial valley in one ecoregion may differ from those required in an alluvial valley setting in a different ecoregion. Depending on the landscape scale and functions being assessed, the same metric may need to be scaled differently. For instance, flow velocity may be measured at a microhabitat scale if the indicator metric is aimed at assessing habitat preferences for a particular indicator species, or it may be averaged over a channel bedform or stream reach to determine substrate mobility. The same indicator metric may also have different applicable threshold values or ranges of values representative of high-quality conditions in differing geographic areas within the region or among different stream types in the region.

The process of selecting indicator metrics, evaluating the quality of the metrics, and determining which metrics to ultimately include in the stream assessment method is iterative and predicated on the main programmatic objectives for the assessment method (Phase 1). It is influenced by the selected stratification and classification approach (Phase 3); development of the reference framework (Phase 5); building, calibrating, and verifying assessment models (Phase 6); and field testing and validation (Phases 7 and 8). The multidisciplinary assessment team should regularly reevaluate, update, and improve indicator metrics as more information is learned about the local stream systems during application of the assessment method (Phase 9).

Metrics may be quantitative or qualitative, continuous or discrete, and measured in the field or office (Nadeau et al. 2018). In all cases, the selection of indicator metrics and rationale for their inclusion in the assessment method should be well documented and incorporated into the technical support documentation compiled and made available as part of the stream assessment method (Phases 8 and 9).

\subsubsection{Phase 4 guidelines}

\subsubsection{Special considerations for qualitative metrics}

As noted previously, the Regulatory Program is required to make decisions in a timely manner that likely precludes the direct assessment of stream functions or processes over time. Evaluation of stream condition can assist 
in understanding stream processes and the disturbances to these processes (Beechie et al. 2010) and is therefore typically used as a proxy for stream function.

The type of metric chosen as an indicator of stream function affects the repeatability (i.e., precision), accuracy, and utility of both the metric itself and the output of the assessment method in which it is included. Some metrics are quantitatively derived (i.e., measured using a standard procedure) while others may be more qualitative (i.e., based on a subjective assessment or ranking).

Qualitative metrics may be included in an assessment method, but they should attempt not to introduce too much subjectivity into the assessment. For example, qualitative data should be organized by discrete categories with well-defined thresholds between categories. Scientific literature helps to develop the categories and thresholds. The assessment development team should carefully evaluate the descriptions for selecting appropriate field values for qualitative metrics and the number of categories from which to choose. They should be clear in applicable instructions to users of the method.

Roper and Scarnecchia (1995) found that qualitative data can have high observer variability, influenced largely by the number of categories in the dataset and degree of observer training. If too few choices of categories are provided, the qualitative metric may lack resolution and thereby fail to effectively differentiate among streams in the region. If too many options of categories are given, users of the stream assessment method may have difficulty making fine distinctions based on rapid visual estimations. Adamus (2018) also observed that an odd number of available choices may lead users of the assessment method to be subconsciously biased towards the middle choice. Somerville and Pruitt (2004) summarized the precision and accuracy for many qualitative and quantitative measures of stream condition and/or function.

When selecting indicator metrics for a stream assessment method, the development team should consider the repeatability and defensibility of the metrics, as well as the efficiency (e.g., cost effectiveness) of including the metric in the assessment method. This is especially important when considering qualitative metrics, as their inclusion may affect the ability of the method to accurately and repeatedly characterize proposed impacts or 
mitigation projects. Testing qualitative metrics for repeatability, documentation and descriptions of categories, and focused training of end users of the assessment method are critically important.

\subsubsection{Considerations of scale}

When determining which metrics to include in the stream assessment method, the development team should also consider the scale at which data for specific metrics would be collected. Both time and spatial-scale controls on channel features vary based on the type of stream feature being assessed. Geomorphic channel features may adjust over long periods of time as a result of large-scale changes in climate (e.g., El Niño-Southern Oscillation) and tectonics, but they may also undergo rapid and sometimes dramatic changes in response to more localized extreme weather events (e.g., hurricanes and large flood events) or changes in watershed land use (e.g., dam construction or removal, urbanization, or localized changes in bank stability from activities like riparian vegetation removal). The spatial scale needed to measure geomorphic channel changes may consequently vary (Figure 6). It is important for stream assessment methods to identify the spatial scale over which all metrics must be measured.

Figure 6. Metrics describing stream morphology, which is measured at different scales (cross section, longitudinal profile, and planform).

\begin{tabular}{|c|c|c|}
\hline \multicolumn{3}{|c|}{ Examples of geomorphic metrics that can be quantified at differing spatial dimensions and views. } \\
\hline $\begin{array}{l}\text { Cross-sectional dimensions } \\
\text { Velocity } \\
\text { Discharge } \\
\text { Roughness } \\
\text { Bed grain size }\end{array}$ & $\begin{array}{l}\text { Gradient } \\
\text { Stream power } \\
\text { Relief } \\
\text { Stream bed elevation }\end{array}$ & $\begin{array}{l}\text { Sinuousity } \\
\text { Braiding index } \\
\text { Channel confinement } \\
\text { Valley width }\end{array}$ \\
\hline Cross section view & 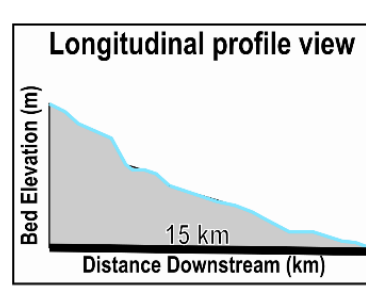 & Planform view \\
\hline Characterize channel bed grain size. & $\begin{array}{l}\text { Understand downstream trends in bed } \\
\text { grain size and expected changes with } \\
\text { gradient and stream power. }\end{array}$ & $\begin{array}{l}\text { Determine locations of sediment input and } \\
\text { storage and influence on bed grain size. }\end{array}$ \\
\hline \multicolumn{3}{|c|}{ Example of changes in evaluation of bed grain size at each scale and view. } \\
\hline
\end{tabular}

\subsubsection{Considerations for metric selection and evaluation}

As presented in this technical guide, the NCSA recommends defining stream functions and identifying metrics capable of assessing (estimating) 
a stream's ability to perform those functions precede metric selection (Figure 7). Adamus (2018) described this as a top-down approach. Metrics included in stream assessment methods for the Regulatory Program should be meaningful indicators of stream function and capable of quantifying changes in functional capacity within the time period typical of a proposed site impact or compensatory mitigation project.

Figure 7. Flow chart illustrating the iterative process of metric selection and evaluation (adapted from McKay et al. 2010).

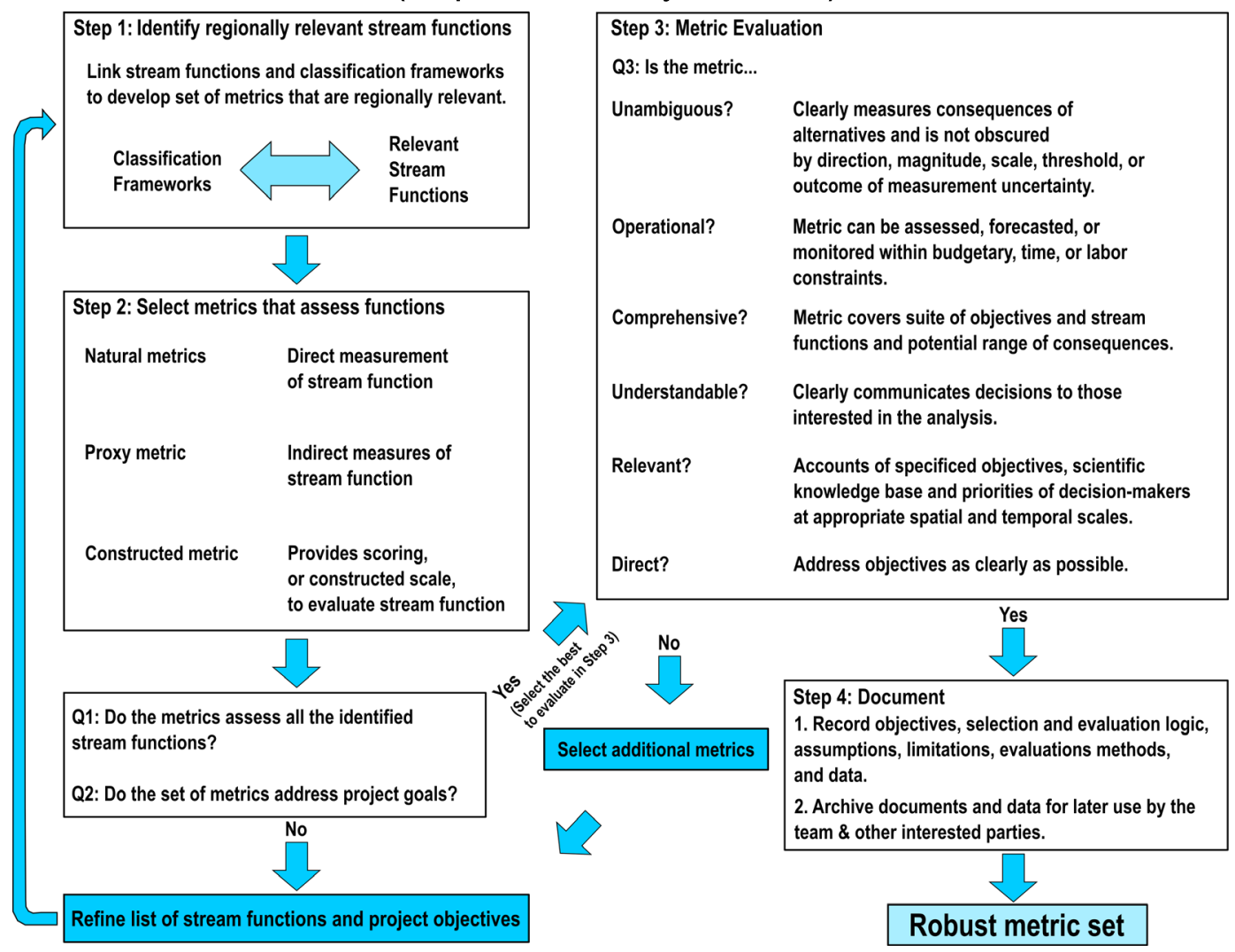

The development team should consider the following features to select responsive indicator metrics for the Regulatory Program:

1. Type of measurement: Consider whether the metric relies on qualitative or quantitative data and whether it measures function directly or represents a structural or compositional attribute that serves as an indicator of function. Consider the benefits and limitations associated with selecting each type of measurement.

2. Repeatable: Metrics need to be repeatable across independent assessment efforts conducted by different parties.

3. Able to be calibrated: Metrics that have only a binary response (yes/no) may not be adequate to reflect subtle but important differences in condition 
or assess changes in those conditions over time. Metrics should be flexible to allow them to be refined or updated as new data become available.

4. Sensitive: A metric should possess sufficient discriminatory power to distinguish differences within and among assessment sites.

5. Accurate: The metric should be reflective of the broader stream condition.

6. Precise: The measurement of metrics in the field should lead to minimal variation among observers. Precision can sometimes be improved with detailed descriptions of measurement methods and with training.

7. Reduce redundancy: The metric should provide different information on stream condition than other metrics. Correlation among metrics should be below target thresholds (e.g., $|r|<0.71$ [Stoddard et al. 2008]; $|r|<0.8$ [Sawyer et al. 2004]).

8. Consider cost and difficulty: The data collection methods for some metrics may be more costly or take more time to collect than others. Consider the skills and knowledge of the typical user of the stream assessment method (Dorney and Adamus 2018). For example, equipment needed to collect measurements should not be cost prohibitive for end users nor should the skills or training necessary to effectively use the equipment be beyond the capacity of typical end users. Additionally, the assessment method should not require burdensome, highly specialized training or analyses. Necessary skills should be quick to learn with appropriate training.

9. Translatable: It is important to ensure that metrics are understandable to the stakeholders and the general public and not just to the practitioners and regulators typically using the stream assessment method.

Using the conceptual models, functions, and stratification and/or classification frameworks identified in Phase 3, the development team should select metrics that accommodate regional differences in stream types and functions. Whenever possible, the team should identify and evaluate several candidate metrics to assess each function.

Not all metrics need to rely on field-based data collection; some metrics can be assessed by using remote sensing or other online data for geology, climate, land cover, soils, topography, and hydrography. For example, aerial imagery and desk review of online mapping programs available through many federal and state agencies can be used for initial assessment of field conditions and for understanding the landscape context of a site. When using remote sensing and other mapping data, it is important to recognize the limitations of the datasets, which regional expertise or documentation associated with the data may provide. 


\subsubsection{Steps in Phase 4}

The NCSA recommends the following steps when selecting regionally relevant metrics during development of a stream assessment method for the Regulatory Program:

1. Outline and define which metrics could be assessed based on regional considerations and goals.

2. Consider whether to select qualitative or quantitative metrics or a combination thereof.

3. Consider the scale of the assessment.

4. Consider how to minimize redundancy between metrics, which can lead to implicit weighting.

5. Reevaluate how stratification or classification of streams in the region may vary based on the functions and metrics selected; and allow flexibility in metric selection based on landscape, climatic, and anthropogenic factors and controls.

6. Describe the rationale or criteria used to select which metrics to include in the assessment method. Describe how these metrics support the specific programmatic goals of the method (compiling documentation discussed in Phases 8 and 9).

\subsection{Phase 5: Develop the reference framework}

\subsubsection{Phase 5 description}

Phase 5 focuses on identifying and defining reference information needed to build assessment models in Phase 6. Models (e.g., standard performance indices and reference curves) for each metric are developed to provide practitioners meaningful output, such as scores that facilitate interpretation of data. To understand the range of expected outputs obtained from metrics assessed in the field, sites need to be placed into context with other similar aquatic resources in the region. Placing the site in context requires an understanding of the expected range of variability for specific metrics within the region where the assessment method will be applied. Previous phases of this technical guide discuss stratification of regional stream resources, identification of regionally relevant functions, and indicator metrics of those functions. Thus, connections will have already been made during application of previous phases by the multidisciplinary assessment team, or those identified to develop the assessment method, be- 
tween regional streams, stream functions, and indicators of those functions. The next step requires an understanding of the direction and magnitude of change expected by those indicator metrics, the scale at which changes occur, and any critical indicator metric values that signify important thresholds or ranges of conditions for aquatic resources in the region. This requires development of a reference framework.

The discussion of reference presented in this phase conforms to the definition of reference aquatic resources in the 2008 Mitigation Rule: "a set of aquatic resources that represent the full range of variability exhibited by a regional class of aquatic resources as a result of natural processes and anthropogenic disturbances." It has historically been common in some regions of the country to identify site-specific high-quality reference sites with which to compare or evaluate individual project sites. However, sitespecific reference sites may be unnecessary if the stream assessment method itself directly incorporates regional reference information. Regional reference information may consist of field data collected from sites spanning a region's condition gradient; data extracted from applicable national or regional databases; virtual reference data compiled from regionally relevant literature; or transparent, well-justified expert opinion. In practice, stream assessment methods often use more than one or even all these sources of reference information to some degree. It is consequently important for developers of the stream assessment method to clearly identify and provide support for the applicable reference framework used by the method.

\subsubsection{Understanding the concept of reference}

The term reference condition traditionally refers to pristine or minimally disturbed conditions (Stoddard et al. 2006). This usage of the term persists despite the difficulty in some regions of the country to identify aquatic resources of this caliber due to the degree of landscape disturbance (Palmer, Bernhardt, et al. 2014). Least-disturbed conditions and best-attainable conditions are additional reference concepts often used in ecological restoration practice (Figure 8). The specific manner in which the concept of reference conditions is applied to ecosystem restoration in general, and stream restoration more specifically, has implications for the ability to 
use those reference conditions to inform project management, mitigation, and regulatory permit decisions (Figure 8).

Figure 8. Example of various concepts of biological reference conditions (adapted from

Stoddard et al. 2006). The dashed red line represents the differing levels of human disturbance on the landscape, whereas the solid black line is the natural range of variability. The range of conditions that currently exists can be evaluated based on different methods of grouping (i.e., stratifying) streams. Stream groups may be defined based on ecoregion, drainage area, or channel type. However, "minimally disturbed" reference streams may not exist among some groups ( $B$ and $C$ ) due to the degree of landscape disturbance.

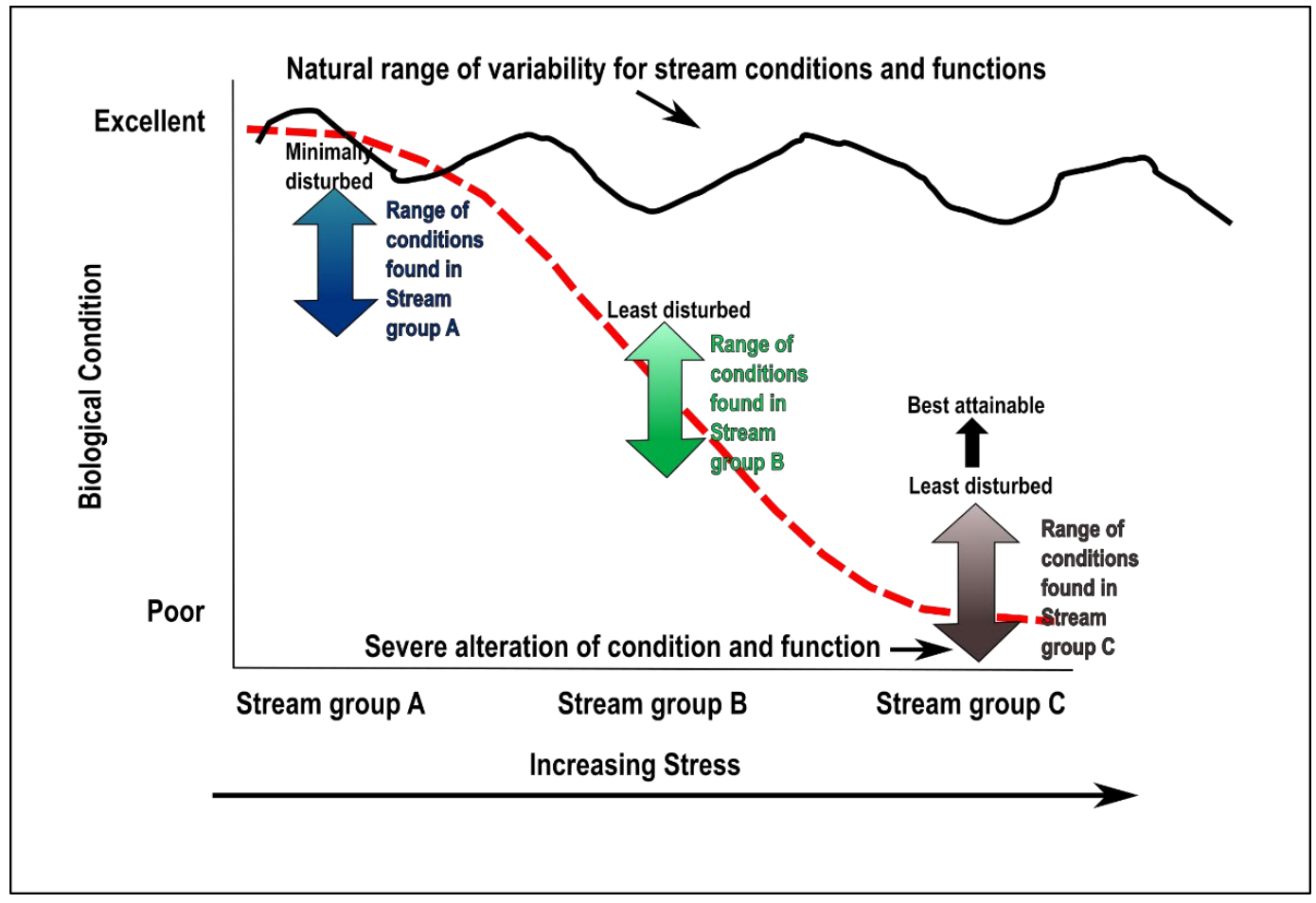

As previously noted, the 2008 Mitigation Rule uses the term reference to refer to the full range of variability caused by both anthropogenic and natural disturbances. This concept of reference conditions as a continuum from degraded to least disturbed is gaining greater attention in the field of stream restoration (e.g., McManamay et al. 2018). Once quantified, this continuum allows for the condition of any given stream to be placed into context with similar streams throughout a defined region. From a stream mitigation perspective, an assessment method that allows for streams to be placed into context along the continuum or gradient of conditions allows for objective demonstration of improving stream conditions, or improvements in functional capacity, along that gradient over time even if minimally disturbed conditions are not achieved or are unattainable. 
Understanding the continuum of conditions provides benefits for the regulatory evaluation of both proposed impacts and proposed compensatory mitigation. Comparison of existing stream conditions with those anticipated as a result of a proposed project allows regulatory decisions to be informed objectively by the anticipated adverse functional losses if the project is authorized. The 2008 Mitigation Rule states that both the amount and evaluation of compensatory mitigation required should be based on the aquatic resource functions lost as a result of the authorized activity. ${ }^{*}$ Such an evaluation requires that postproject conditions be evaluated in context with preproject conditions.

Similarly, by including a continuum of conditions in the reference framework of a stream assessment method, the generation of credits by a compensatory mitigation project can be based on the accrual or attainment of function associated with that that project rather than the actions undertaken. For example, instead of allocating mitigation credits based on categorical types or levels of stream mitigation activity (e.g., restoration vs. enhancement), credits may instead be based on measurable improvements to stream functions demonstrated during the postmitigation monitoring period (i.e., functional lift or improvements in functional capacity [ELI, Stream Mechanics, and The Nature Conservancy 2016]).

\subsubsection{Phase 5 guidelines}

\subsubsection{Define the range of reference aquatic resource data}

Because reference aquatic resources represent a continuum of condition, it is useful to define and classify ranges of condition within which to organize data and develop consistent ecological scoring (Phase 7). Thresholds, or benchmarks, represent how much and in what direction the measured condition departs from an expected condition (Hawkins, Olson, et al. 2010). Thresholds can be used to organize information into condition classes that relate to the capacity of a particular resource to provide a particular function (e.g., good, fair, poor; functioning, functioning-at-risk, not functioning; impaired, not impaired, etc.; reference an SQT; Nadeau et al. 2018). The development team should create a definition for condition classes and the thresholds that can be applied consistently across metrics and reference datasets for the assessment method. For example, consider

\footnotetext{
* 33 C.F.R. § 332.3(a); 33 C.F.R. § 332.3(f); Section 404(b)(1) Guidelines for Specification of Disposal Sites for Dredged or Fill Material, 40 C.F.R § 230.93(a) (2014); 40 C.F.R § 230.93(f).
} 
whether the class with the greatest functional capacity (e.g., good, functioning, or not impaired) will represent only the minimally or least disturbed condition or whether there may be circumstances that would include the best attainable condition also. When evaluating available reference information, consider whether the reference data accounts for the full range of conditions, as outlined above (Figure 8). If an existing data source includes sites that are only minimally disturbed, additional sources of reference information may be necessary to develop assessment models that reflect the full condition gradient.

Reference data often include information from multiple sources. Reference data that have been collected for other purposes, or using other methods, may be useful to inform only one or several metrics being considered by the development team for inclusion in the assessment method. Creating defined condition classes allows the development team to begin consistently compiling and organizing multiple sources of reference information and allows the team to identify whether additional reference sources or data collection may be needed to represent the full range of condition for reference aquatic resources in the region.

\subsubsection{Ecological thresholds in reference data}

For some metrics, there may already be virtual reference data compiled from regionally relevant literature; from data analyses for metrics used in other regional stream assessment methods; or from transparent, well-justified expert opinion. The regionally relevant literature may provide information on known thresholds of ecological condition derived from previous studies. For example, many states have developed water quality standards for both water quality and biological conditions (e.g., macroinvertebrate metrics) and have defined thresholds for attainment of these standards. These thresholds are often underlain by extensive data collection and analysis and could be incorporated into stream assessment methods for the Regulatory Program without much further evaluation. Similarly, fisheries departments often have existing thresholds for productivity classes, underlain by their own data efforts, that could be used to inform assessment models. Where existing thresholds or benchmarks are identified and are consistent with the definitions developed in section 2.5.2, the development team should include these sources of information as part of the reference information. 


\subsubsection{Compilation of reference data from available databases}

Reference data can be obtained from many different national, state, and regional datasets. Hydraulic regional curves can be used to assess regional relationships for hydraulic geometry, drainage area-discharge, and slopedrainage area. Federal ambient monitoring programs, natural resources agencies, and land management agencies collect data documenting instream biological assemblages (e.g., macroinvertebrates and fish), physical stream habitat, and in situ water quality conditions, often stratified by applicable external factors (e.g., hydrologic permanence, watershed size, physiography and bioregion, etc.). Applicable regional and national datasets may include those compiled by federal agencies, such as the EPA, the U.S. Geologic Survey (USGS), and the U.S. Forest Service (USFS) (Table 3). In some areas of the western U.S., there may also be U.S. Bureau of Land Management Multiple Indicator Monitoring or Assessing Inventory and Monitoring data. State resource agencies, heritage programs, or NatureServe programs (www.natureserve.org) may have geomorphic, water quality, biological, and riparian vegetation datasets available, including data collected from existing high-quality reference sites used for long-term biomonitoring.

A number of online resources for spatial datasets of remote data are available, including aerial imagery, national hydrography data, soils, climate, topography, geology, and land use (Appendix A). These data can be imported into various Geographic Information System (GIS) software programs. Oregon's SFAM provides an example of developing publicly available online mapping systems that are specifically used for collecting data needed for its functional assessment method (https://tools.oregonexplorer.info/ OE_HtmIViewer/Index.html?viewer=orwap_sfam).

Table 3. Examples of regional and national stream and riparian datasets.

\begin{tabular}{|l|l|}
\hline \multicolumn{1}{|c|}{ Reference Datasets } & \multicolumn{1}{c|}{ Websites } \\
\hline Multistate/regional monitoring program data \\
\hline $\begin{array}{l}\text { USFS PACFISH/INFISH (Pacific Anadromous } \\
\text { Fish / Inland Fish) }\end{array}$ & $\begin{array}{l}\text { https://www.fs.usda.gov/detail/r4/landmanagement } \\
\text { /resourcemanagement/?cid=stelprd3845865 }\end{array}$ \\
\hline $\begin{array}{l}\text { Regional Environmental Monitoring Networks } \\
\text { (RMNs) }\end{array}$ & https://cfpub.epa.gov/ncea/global/recordisplay.cfm?deid=307973 \\
\hline National Monitoring Data & https://waterwatch.usgs.gov/ \\
\hline USGS Stream Gage Data & https://streamstats.usgs.gov/ss/ \\
\hline USGS StreamStats & https://www.epa.gov/national-aquatic-resource-surveys/nrsa \\
\hline EPA National Rivers and Streams Assessment & https://water.usgs.gov/nawqa/ \\
\hline $\begin{array}{l}\text { USGS National Water Quality Assessment } \\
\text { (NAWQA) }\end{array}$ & \\
\hline
\end{tabular}




\subsubsection{Collecting local reference data}

Collecting and evaluating local reference data can be a time-consuming process. Proper planning is essential to maximize efficiency. The NCSA recommends the following steps if collecting data from local reference sites (based on Smith et al. 2013):

1. Outline a method for identifying local reference sites. Ensure that all applicable stratified stream types identified in Phase 3 are represented.

2. Adopt a field sampling protocol and field data form(s) (Phase 7).

3. Develop a Quality Assurance Protection Plan (QAPP) to guide collection of appropriate data; see EPA (2002) for an example.

4. The field sampling protocol, field data form(s), and QAPP should all be compatible with methods and forms used when applying the final assessment method.

Consider setting aside a subpopulation of reference sites for later testing of the assessment models. This subpopulation should not be sampled as part of efforts to collect reference data but should instead be sampled after the proposed stream assessment method has been developed to test its ability to discriminate among streams in varying levels of condition (Nadeau et al. 2015).

\subsubsection{Considerations for data quality}

Reference data collected from existing federal, state, or local agencies (or peer-reviewed literature) may obviate the need to collect new local field data to support development of a stream assessment method. However, data collected by different parties for different purposes are rarely collected using the same sampling or reporting protocols. Therefore, data quality may vary; and in some cases, data may not be comparable. The main considerations before using data collected by multiple groups or agencies, or before collecting new reference data in the field, include the following:

1. What $\mathrm{QA} / \mathrm{QC}$ (quality assurance / quality control) procedures were in place for data collection? Is there an established QAPP governing collection and analysis of the data?

2. How were outliers in the dataset identified and treated?

3. Are data collection methods comparable across all sources of reference information? Do the different methods allow transferrable results? 
4. Is the geographic area the data were collected in appropriate for the target region or area?

5. Is the data applicable to all geographic areas, ecoregions, process domains, or stratified stream types of interest?

6. Were there enough sites sampled to effectively capture the natural range of variability (both spatial and temporal) inherent to each metric?

7. Over what period of time were the data collected; and have there been changes in land use, climatic, or other external variables since the data were collected that now render contemporary validity of the data uncertain?

EPA (2003) outlines general guidelines for evaluating the quality of scientific information, which include "(1) soundness, (2) applicability and utility, (3) clarity and completeness, (4) uncertainty and variability, and (5) evaluation and review." Soundness refers to "the extent to which the scientific and technical procedures, measures, methods or models employed to generate the information are reasonable for, and consistent with, the intended application" (EPA 2003). Applicability and utility refer to whether the information is relevant to the intended use of the information. Clarity and completeness concern the documentation supporting the data and its collection (i.e., are the data, assumptions, methods, quality assurance, sponsoring organizations, and analyses all documented?). The uncertainty and variability need to be characterized in each step, including the initial information, procedures, measures, methods, and models. Evaluation and review require "independent verification, validation, and peer review of the information or of the procedures, measures, methods, or models" (EPA 2003).

\subsubsection{Steps in Phase 5}

The NCSA recommends that the following steps guide the identification and collection of reference data:

1. Understand and define the concept of reference.

2. Set standards for data documentation, quality, and use.

3. Define the range of reference aquatic resources, including relevant condition classes or thresholds, to characterize reference information and inform ecologically consistent scoring in the next phase.

4. Compile reference data available to characterize each proposed indicator metric. Develop a process to evaluate available reference data and/or to identify local reference sites and collect new field data. 


\subsection{Phase 6: Build assessment models and develop scoring procedures}

\subsubsection{Phase 6 description}

A stream assessment method is fundamentally "a model that defines the relationship between ecosystem- and landscape-scale variables and functional capacity" of a stream system (Smith et al. 1995). As discussed in Phase 4, the model for each indicator metric is developed and calibrated using reference information from a defined geographic area. An effective stream assessment method for the Regulatory Program must support quantitative decisions, including how much compensatory mitigation may be required for authorized impacts and how much mitigation credit to award at mitigation sites. Thus, a scoring system associated with a stream assessment method, as opposed to only categorical or narrative conclusions, may be an important consideration for stream assessment methods used in the Regulatory Program.

\subsubsection{Phase 6 guidelines}

\subsubsection{Conceptualization of assessment models}

The development team will need to consider how the results from the stream assessment method will be organized and communicated. Measured values for each metric will need to be combined and summarized in a way that meaningfully captures condition and relates to regionally relevant stream functions. If only a single indicator metric is used to represent a function, the assessment output for that metric will similarly represent the function. By contrast, if multiple metrics are used as indicators of a stream function, outputs of each metric will need to be combined into a single value to represent the function. Considerations taken by the development team to decide the approach for combining multiple indicator metrics are equally pertinent to decisions whether to combine the functional capacity of more than one function into function categories or into a single overall stream function score.

Note that while condensing the outputs of multiple metrics into a single value may facilitate communication with nontechnical stakeholders, it also results in a loss of information resolution and may impede the informative capacity of the assessment. Regardless of how metric scores are combined, the NCSA recommends that individual metric values (and scores) be com- 
municated as part of the output of a stream assessment to allow for identification of any specific metric or stream function that may be compromised or deviate from expectations.

\subsubsection{Reference data standardization and assessment scoring protocols}

The development team will need to determine how to relate indicator metrics of stream condition to regionally relevant stream functions. A stream assessment method will typically include data collection for multiple different metrics being scaled differently and having different units. Scaling refers to the length or area over which a metric is assessed and can differ depending on the metric. For instance, large wood, sometimes known as large woody debris, can be measured over a $100 \mathrm{~m}^{*}$ stream reach whereas riparian vegetation may be measured using $10 \times 10 \mathrm{~m}$ plots. The units in this example for large wood would then be reported as number of pieces per $100 \mathrm{~m}$ whereas the vegetation may be reported as a percent cover. Indicator metrics in different units, or those with differing degrees of variation across the complete range of stream conditions relative to other metrics, require standardization so that they can be uniformly compared and aggregated (Barbour et al. 1999; Stoddard et al. 2008). Standardization renders the metric data unitless, allowing them to be combined in a scoring procedure despite their original disparate units.

Standardization of reference data may be accomplished by converting the raw metric data to a unitless index (e.g., o to 1.o). If the reference data span the full range of conditions in the region, simple percentiles of the data for each metric may be assigned to representative index values consistent with stream condition thresholds defined in Phase 5. Alternatively, ecological thresholds for field metrics may also be used to assign index values to standardize metric data. For example, if an indicator metric below some threshold value is known to cause or contribute to degradation of the stream function for which that metric is an indicator, then that threshold may be assigned a specific index value indicative of degraded conditions. See also section 2.6.2.3 and Figures 10 and 11. Note that an indicator metric must be capable of differentiating streams across the range of regional conditions. A metric that does not vary in a predictable manner with increasing levels of disturbance or stream degradation is not a useful metric,

* For a full list of the spelled-out forms of the units of measure used in this document, please refer to U.S. Government Publishing Office Style Manual, 31st ed. (Washington, DC: U.S Government Publishing Office, 2016), 248-252, https://www.govinfo.gov/content/pkg/GPO-STYLEMANUAL-2016/pdf/GPO-

STYLEMANUAL-2016.pdf. 
nor is a metric that varies less in response to degradation than it does as a result of natural variation in space or time.

Once raw metric data are standardized into unitless index values, there are several approaches to combine metric values or function values into a single output for scoring if desired (e.g., Barbour et al. 1999; USACE 2011b; Wyoming Stream Technical Team 2018; Minnesota SQT Steering Committee 2019). The development team should carefully document scoring decisions, including why a particular approach to scoring was selected; and, if different weighting was used for different metrics or functions, the development team should ensure that there is an ecologically justified and welldocumented reason for doing so.

The simplest approach to scoring is to combine metric index values (or function values) via averaging. However, this approach assigns equal weight to all metrics (or functions) and may not be consistent with conceptual models of ecosystem function derived by the development team or accurately reflect how much a metric value contributes to the functions it informs. Other methods of combining values may provide greater accuracy in characterizing condition. For example, a weighted average may be more appropriate if a particular stream function is driven largely by one indicator metric but is also affected by other indicator metrics. The dominant metric can be weighted relatively higher to the nondominant metrics in the calculation of the representative function value to emphasize its influence on the overall function. Fischenich (2006) discusses the interconnectedness of various stream and riparian functions, which may help to inform these kinds of decisions by the development team. Additionally, metric weighting can be determined more empirically through statistical analysis of data resulting from the application of the stream assessment method at stratified study sites (Nadeau et al. 2018).

The developers of the assessment method will also need to decide the type of output most capable of meeting the intended programmatic uses of the assessment method. These decisions should consider how the output of the method will inform regulatory decision-making in the region. For example, the outputs of the stream assessment method may be used to directly represent credits and debits in related regulatory protocols (e.g., Tennessee Department of Environment and Conservation 2019), or the outputs may inform a separate calculation of credits and debits (e.g., Nadeau, Hicks et al. 2020). Similarly, depending on how the Regulatory 
Program will use the assessment outputs, the development team should consider whether the condition scores will be multiplied by a unit of measure (e.g., linear feet, area, volume; Harman et al. 2021).

The development team needs to also consider how the approach to scoring may affect the level of effort needed to update the stream assessment method in the future (e.g., following field testing, peer review, public comment, or beta-testing). For example, changing reference curves or index values in response to additional reference data would change the resolution for that metric but would not change the weighting of that indicator. In contrast, removing or adding a metric may require revision of weighting or calculation of the scores for which that metric is a component.

\subsubsection{Developing reference curves}

Reference curves are one method for developing unitless index values, incorporating a range of conditions directly into a regional reference framework, embedding threshold values, combining metric data having differing distributions, and scoring the output of stream assessments. Assessment approaches that use reference curves to evaluate proposed project impacts and compensatory mitigation projects in the Regulatory Program have recently been developed in Colorado, Georgia, Minnesota, Tennessee, and Wyoming. Additionally, SFAM, developed in the Pacific Northwest, includes standard performance indices (range of expected performance) that are very similar to reference curves for each measure of function included in the SFAM model (Nadeau et al. 2018).

Reference curves may be rooted in either mechanistic or empirical models. As used here, a mechanistic model is one that is based on a preexisting understanding of the ecosystem and how its various components affect its function level. By contrast, an empirical model is based on direct data collection and analysis seeking to elucidate the relationships of various metrics to the condition of the ecosystem. In practice, development of most reference curves for regulatory purposes has used a combination of these approaches. There is no single "correct" way to develop a reference curve. The process relies considerably on the availability of applicable data and the knowledge, skills, and familiarity with the ecosystem of the parties developing the reference curve. 
It is ideal for a reference curve to be based on metric data that sufficiently reflect the complete range of conditions for that metric in the target geographic area (Figure 9a). If sufficient data are available or can be collected, the distribution of the data itself may be used to assign sites into condition classes based on percentiles of the distribution (see Nadeau et al. 2018). In some cases, more statistically robust methods must first be used to identify a disturbance gradient from which streams, stream reaches, or biological communities may then be assigned to various condition classes (e.g., Davies and Jackson 2006; Blocksom and Johnson 2009). Then, metric data can be explored for potential discriminatory efficiency between condition classes (Barbour et al. 1996). It is preferable that metrics discriminate throughout the range of conditions (Figure $9 b$ ), but they must at a minimum effectively discriminate most-degraded from least-disturbed conditions. Where reference data do not span the full range of conditions, additional sources of reference information, such as literature or transparent, well-justified expert opinion may be needed to supplement reference datasets.

There are a number of methods available for developing reference curves (Smith et al. 2013; Fong et al. 2017; Dorney et al. 2018; Nadeau et al. 2018). Figure 10 illustrates an example of using percentiles to define index values and build reference curves. Index values are assigned to the data based on percentiles of the complete data distribution, and then a regression line is fitted to these points. This provides an equation that converts any additional metric data value to a corresponding index value for each metric.

It is important to consider the statistical assumptions used to develop reference curves, including data distribution, sample size, etc. The curves illustrated in Figure 10 assume a linear relationship for the indicator metrics and a normal distribution of residuals. If a linear relationship does not appear to be the best fit, other methods for representing the relationship between variables will be necessary.

Nadeau et al. (2018) provide an example of using ecological threshold values to develop reference curves and index values (Figure 11). Once the development team identified metrics and reference data sources, the next step was to define connections between those metrics and stream functions. Index values of 0.3 and 0.7 were deemed threshold index values separating low to moderate levels of functioning and moderate to high levels, 
respectively. Reference data and regional literature were used to assign corresponding field values for each indicator metric to the above-referenced function threshold index values, and linear relationships between index values then defined the reference curve.

Figure 9. Example of how to identify discriminatory assessment metrics: (a) A scatter plot of an indicator metric (function-based metric) versus an independent variable across the range of conditions in the region. (b) A box plot illustrating the discriminatory power of the metric $(y)$ relative to stream condition classes.

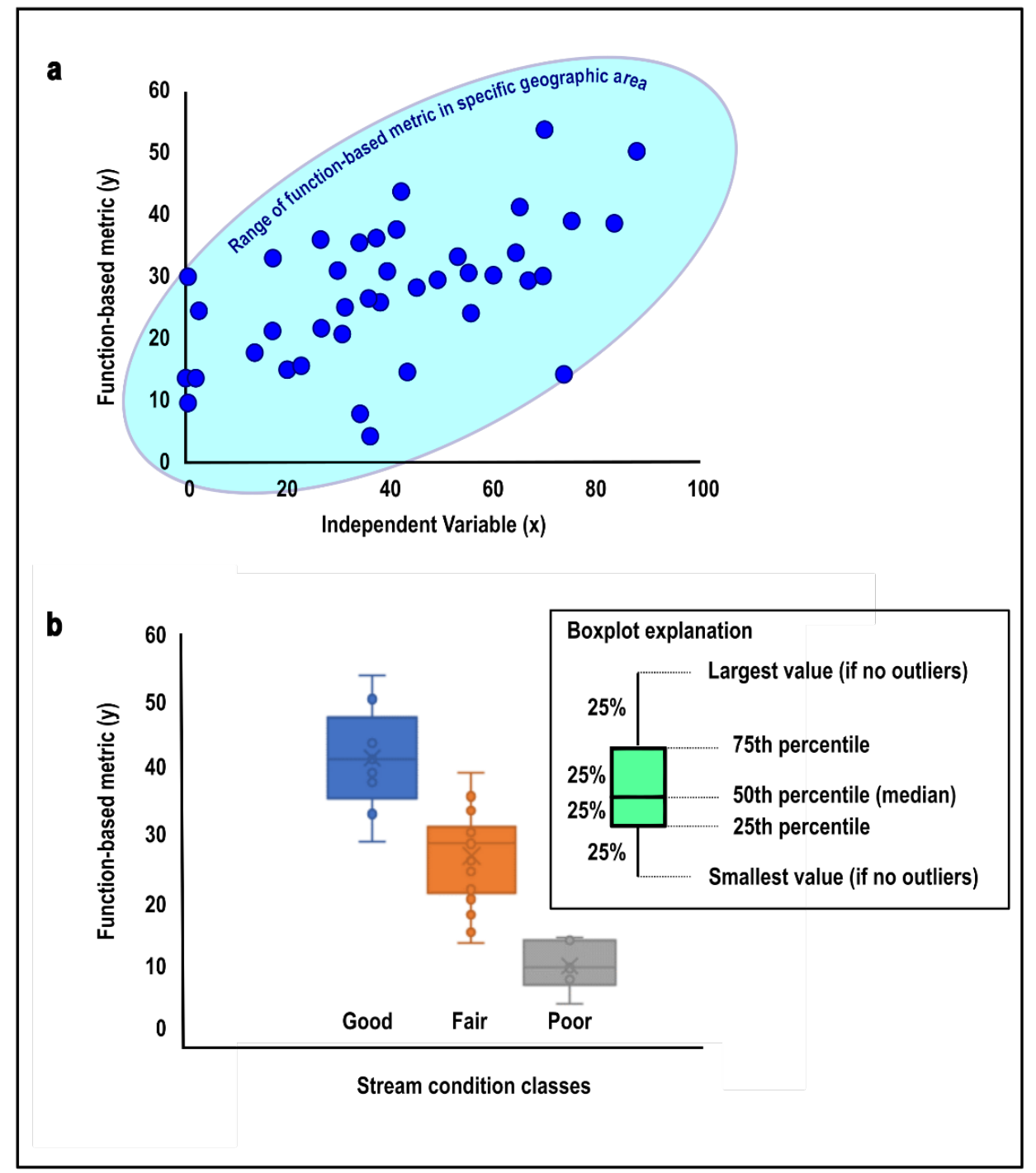


Figure 10. Examples illustrating standardized function-based metrics converted to index values (top) for development of a reference curves (bottom).

Index values ( 0 to 1.0 ) assigned to each of two function-based metrics for which raw data has been standardized.

\begin{tabular}{|c|c|c|c|}
\hline \multicolumn{4}{|c|}{ Standardized Mitigation Index Values } \\
\hline Value & Percentile & $\begin{array}{c}\text { Function- } \\
\text { Based Metric } \\
\text { (a) }\end{array}$ & $\begin{array}{c}\text { Function- } \\
\text { Based Metric } \\
\text { (b) }\end{array}$ \\
\hline 0 & $5^{\text {th }}$ & 10.5 & 0 \\
\hline 0.3 & $25^{\text {th }}$ & 33.3 & 34.7 \\
\hline 0.5 & Median $^{\text {th }}$ & 53.9 & 50.6 \\
\hline 0.7 & $75^{\text {th }}$ & 60.9 & 75.3 \\
\hline 1 & $95^{\text {th }}$ & 76.3 & 88.7 \\
\hline
\end{tabular}

Performance curve for function-based metric a

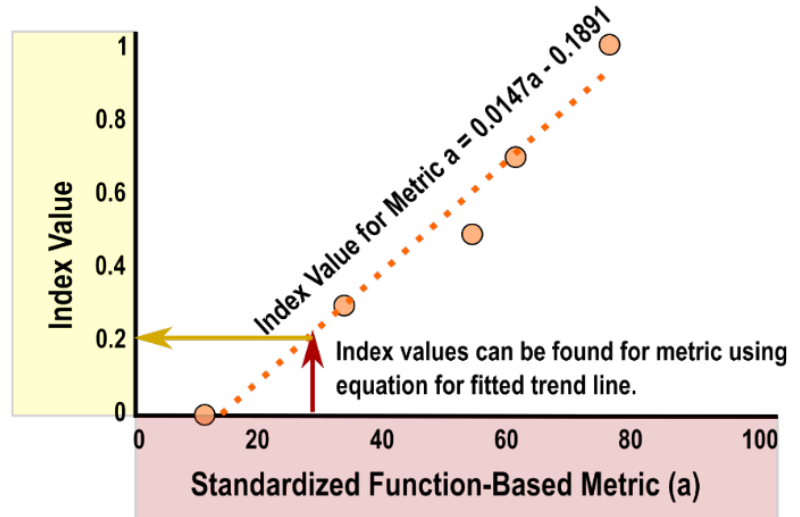

Performance curve for function-based metric b

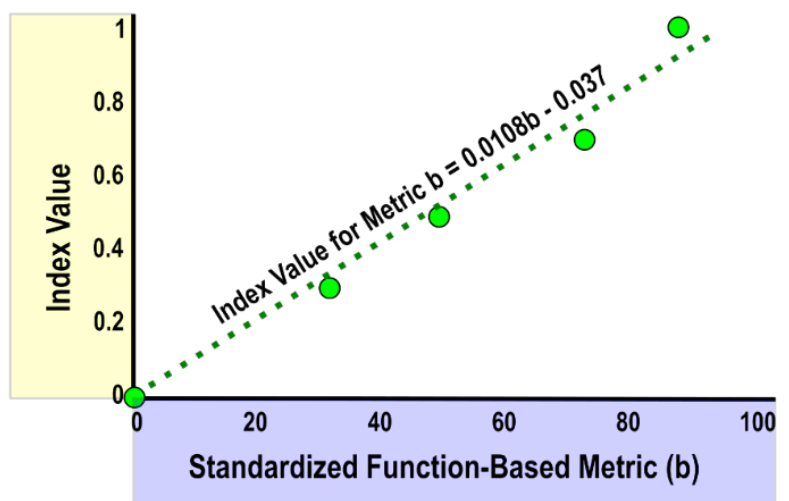


Figure 11. Example from Nadeau et al. (2018) of how to convert indicator metric data into index values. (Image reproduced from Nadeau et al. 2018. Public domain.)

\section{Establish index scales (axes).}

For each index, the $x$-axis represents the field metric, and the range varies depending on the metric type (e.g., 0-100 for percentages). The y-axis represents possible index values, ranging from 0.0 to 1.0. Linear models are needed to translate field metrics to numeric index values.

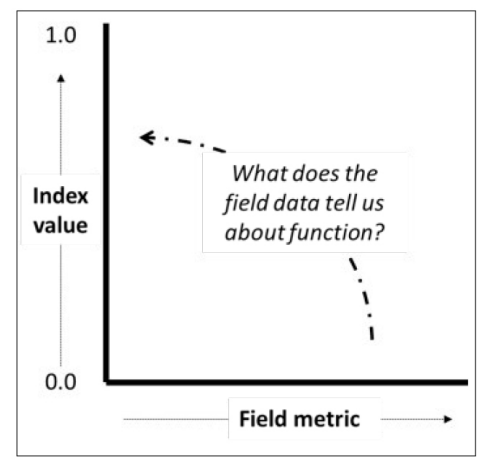

\section{Identify index value thresholds (calibrate y-axis).}

Standard function thresholds were applied to the index value scale in order to ensure that all measures are assigned scores that have consistent ecological meaning. The threshold indicating a shift from lower to moderate functioning is set at 0.3 . The threshold indicating the difference between moderate and higher functioning is set at 0.7 .

\section{Identify field metric thresholds (calibrate $\mathrm{x}$-axis).}

Regional ecological literature and data sets were evaluated to identify field metric values that correspond with a change in functioning. These ecological thresholds indicate the point at which the functional rate of return may shift.

See the following section for further description of the methods used to determine field metric thresholds.
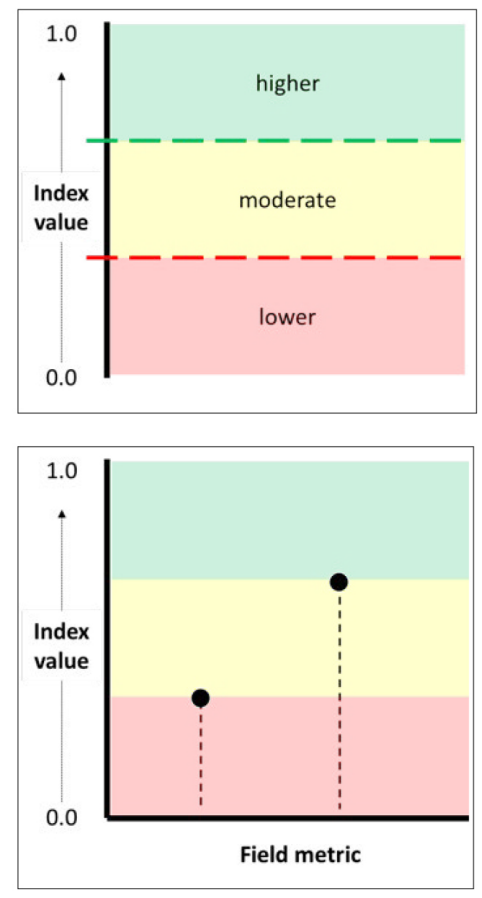

\section{Create linear models between thresholds.}

The models describe the rate of functional return expected for increases (or, for inverse scales, decreases) in the field metric value. The use of linear (continuous) models allows the measure score to reflect incremental changes.

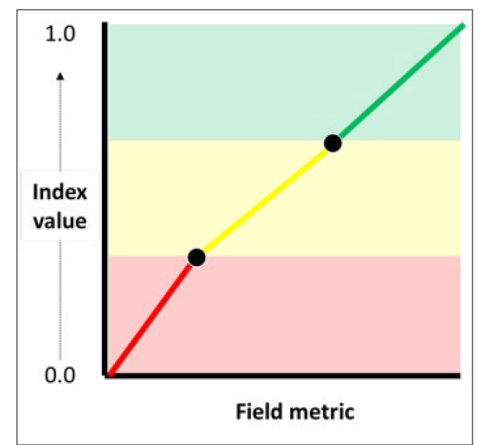

\subsubsection{Verification of assessment models and scoring procedures}

Once assessment models and a scoring procedure have been developed, verify the approach to ensure that the metrics included in the model are 
responsive to changes in stream condition and function and that there is not excessive redundancy in the metrics. Verification is a check on the logic of assessment models and how sensitive they are to the types and magnitudes of impacts in stream systems. Wakeley and Smith (2001) describe two basic approaches for testing the logic of an assessment model: (1) performing a sensitivity analysis and (2) applying the model to sample datasets. Depending on the availability of datasets and statistical expertise available, the indicator metrics could be evaluated to determine response variability within regional classification frameworks, metrics that best explain the response variability, and relationships (correlation) between metrics and redundancies in the model. If datasets are not available to support this level of analysis, existing literature or other professional sources may inform applicability of metrics in the assessment method.

The literature provides many examples for testing and supporting metric suitability (Karr and Chu 1997; Hughes et al. 1998; Klemm et al. 2003; Whittier et al. 2007; Hawkins, Cao, et al. 2010; Smith et al. 2013). Revisions to assessment models should consider the following (adapted from Smith et al. 2013):

1. Do the metric index values and scoring (models) perform as envisioned by the development team?

2. Are the metrics included sensitive to the types of project impacts and restoration approaches expected to occur within streams in the region?

3. Do the metrics and their weighting reflect the important attributes and processes that influence the function?

4. Are all metrics needed, or could the model be simplified without much loss of sensitivity?

5. Is the mathematical equation used to combine metric scores appropriate?

6. Are different metrics given appropriate weight in the outcome?

Sensitivity was introduced in Phase 5 concerning metric selection but should be reconsidered during model development to verify the logic and sensitivity of assessment models (Wakeley and Smith 2001; Smith et al. 2013). Sensitivity analyses evaluate how a model reacts when both moderate and extreme values of a metric are input into a model and will help identify which combination of metrics has the most influence on the scoring output. Usually this is evaluated by verifying that the model behaves 
as intended with incremental changes in a metric. Figure 12 shows an example of a sensitivity analysis presented by Smith et al. (2013) that shows a hypothetical three-variable model of carbon-export function of a riverine wetland.

Figure 12. Example of a sensitivity analysis adapted from Smith et al. (2013). The different color lines indicate that a variable is being held constant at $0,0.1,0.5$, and 1.0. On the left, flood frequency is changing on the $x$-axis while holding constant for leaf litter and coarse woody debris. On the right, leaf litter (or coarse woody debris) is being changed on the x-axis while holding constant for flood frequency. Leaf litter and coarse woody debris produced the same results; therefore, the same plot is shown. Flood frequency is found to be more influential on Functional Capacity Index (FCl) scores in this example.

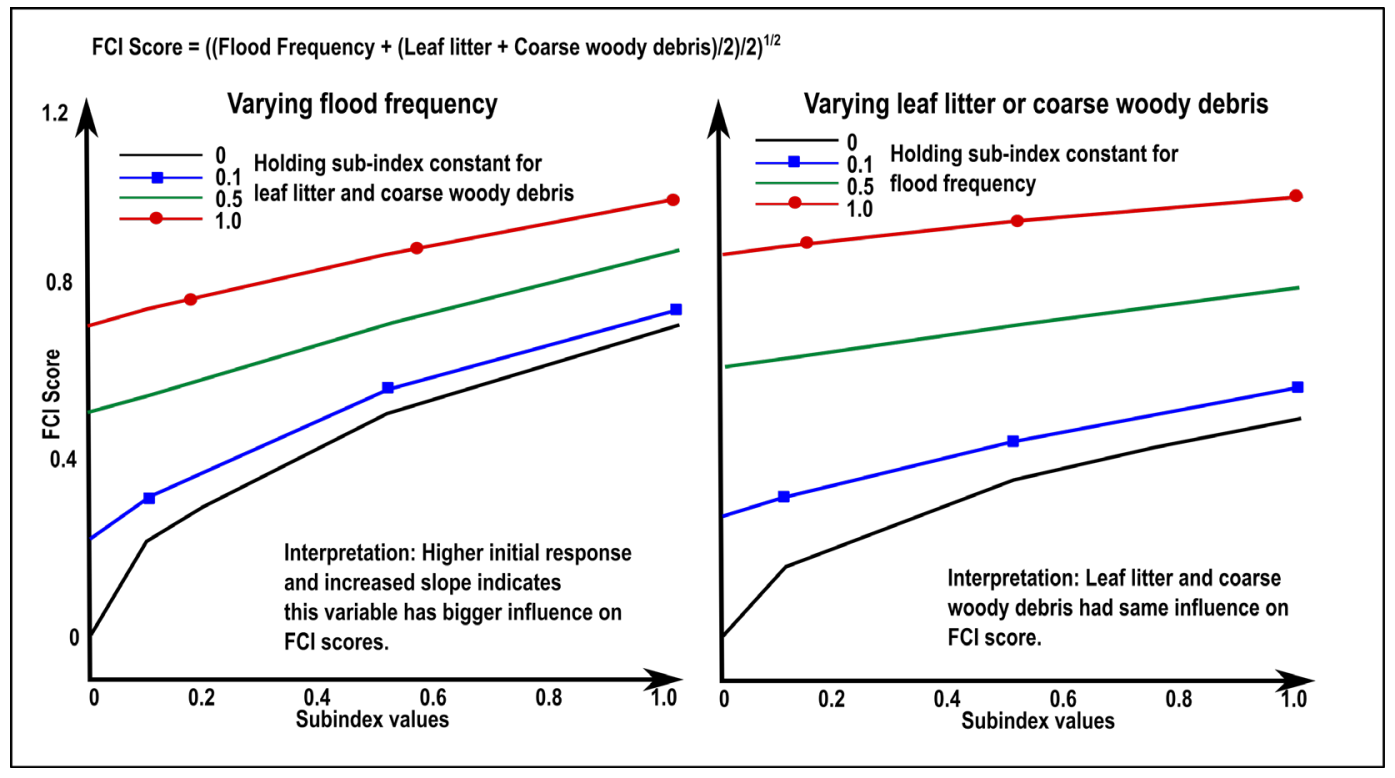

\subsubsection{Iteration of steps to build rapid and intensive assessment models}

When developing assessment models and scoring procedures, consider whether a more intensive assessment method could be "scaled down" for use on small projects (or how a rapid assessment method could be "scaled up" for projects demanding more rigorous assessment). Each respective method should be subject to independent analysis by the development team to assess the method's sensitivity and degree of concurrence with the other more intensive or more rapid method.

In general, rapid stream assessment methods that include either a smaller subset of metrics or fewer quantitative metrics, will not provide the same level of resolution or quantification as more intensive assessment methods, and therefore the methods and their associated metrics may not be interchangeable. 
In light of the lower level of resolution, such a method should not be used to determine whether a compensatory mitigation project has successfully restored stream biological communities. Additionally, the specific metrics and scoring protocol to inform outputs of rapid versus detailed assessment approaches may also differ.

\subsubsection{Documentation of assessment models and scoring procedures}

During this phase, it is useful to begin compiling information on how the assessment method was developed, including references to any technical background information that went into the assessment. Documentation related to this phase should include the metrics selected for use and the developed scoring procedure. It should clearly explain why a metric is used; what channel, floodplain, or watershed condition it measures; what goals and objectives it addresses; and how successful it is at evaluating functions (McKay et al. 2010). Documentation should include (1) the name of the metric; (2) the metric description; (3) the metric index values, thresholds, and reference curves; (4) the scientific support for the assessed stream function; (5) metric development, including how thresholds and index values were derived (e.g., values selected to represent categorical divisions between condition classes) and what reference information was used; and (5) rationale for inclusion of the specific metric (Barbour et al. 1999; Nadeau et al. 2018). The development team should also document the process and supporting logic for the scoring procedure. It is likely that following this phase, not all metrics identified in Phase 4 will be carried forward in the method. If particular metrics were evaluated but then excluded from the method by the team developing the assessment method, describe that also.

Compile this documentation in a technical support document, which is separate from user manuals that provide detail on specific data collection methods. The technical support document must be legally defensible and should include a purpose, background, definitions, an outline of the process for how metrics were selected and how scoring was developed, and a discussion of limitations (e.g., Nadeau et al. 2018; Wyoming Stream Technical Team 2018; CSQT Steering Committee 2019b).

\subsubsection{Steps in Phase 6}

The NCSA recommends the following steps for building assessment models and developing a scoring procedure: 
1. Conceptualize assessment models.

2. Determine the type of assessment outputs (e.g., scoring procedures) that best support intended programmatic uses of the stream assessment method.

3. Develop scoring and scaling procedures for each metric.

4. Develop protocols for incorporating threshold or benchmark values, if applicable.

5. Develop reference curves, if applicable.

6. Determine protocols for combining metrics and/or functions, including provisions for assigning various weights to different metrics and functions.

7. Verify and refine the scoring procedure (e.g., sensitivity analysis).

8. Iterate through these steps to help build both rapid and intensive procedures when applying the stream assessment method for differing project scopes or applications.

9. Develop documentation for assessment models and scoring procedures.

\subsection{Phase 7: Develop assessment method protocols, validation, and intercalibration}

\subsubsection{Phase 7 description}

Phase 7 includes compilation of protocols for implementing the assessment method and then testing it both for accuracy (validation) to determine if the outputs from the scoring procedure correspond to actual stream functions (Wakeley and Smith 2001; Nadeau et al. 2018) and for repeatability (intercalibration). Validation may include testing the method at new sites that were not part of the method's development or comparing outputs with detailed long-term measurements of conditions, and ultimately functions, from available datasets, peer-reviewed journals, and expert knowledge (Smith et al. 2013; Morandi et al. 2014; Dorney et al. 2018; Munoz et al. 2018).

The results of validation exercises may illustrate the need to refine the stream assessment method, such as improving the stratification of stream types in the region, revising the scaling of indicator metrics, or selecting alternative metrics. Validation prior to widespread use of the assessment method is encouraged. However, time and resource constraints may require that validation consist of long-term continual testing and revision following implementation of the stream assessment method. 
While repeatability of individual metrics was discussed in Phase 4, efforts to ensure repeatability of the assessment method in its entirety (i.e., intercalibration) should take place during this phase. Repeatability of the method among different users assures that users generate the same outputs and reach similar conclusions. For example, it is not uncommon for different practitioners to collect field data over the course of a multiyear monitoring period. Problems with repeatability of the stream assessment method may consequently lead to significant variability and perhaps differing conclusions. The development team should address poor repeatability of the stream assessment method by adding additional description and clarity in applicable user manuals that provide step by step instructions on how to collect data for each included measure (see Phase 7) and ensure that adequate training for end users of the assessment method can be provided as part of the method's implementation (see Phase 9).

\subsubsection{Phase 7 guidelines}

\subsubsection{Develop data forms and protocols for data collection}

Prior to field testing the assessment method, the development team will need to develop a standardized approach for data collection. This approach should include (1) a user manual or standard operating procedure that outlines field protocols, data collection and analysis methods, and metric calculations and (2) a standardized format for recording and compiling data, such as field forms or other standardized data templates.

When adapting an existing assessment method, users should consider what aspects of the existing user manual and data templates (if any) can be retained, and what aspects may need to be revised or adapted to use them in a new region or for a new purpose (e.g., adapting a nonregulatory assessment method for use in the Regulatory Program). The development team should also consider whether improvements to the existing method can improve accuracy and usability.

A user manual or standard operating procedure should include the following:

- All data collection methods, including clear diagrams and figures that assist with understanding how and where to apply the data collection methods in the field.

- Information on how field data should be processed and used to calculate metrics, including any applicable mathematical operations (e.g., 
equations, standardization of raw field data, calculation of multimetric indices, etc.).

- A list of equipment required to collect data.

- An explanation of data templates and data management expectations.

The NCSA recommends that data forms be sequenced to align with workflow. Separate data forms should be developed for remote or desktop analyses relative to those for collecting data in the field. If the assessment method includes optional metrics or metrics that are only applicable under certain conditions (e.g., for certain stream types), these should be clearly indicated on data forms to reduce data collection errors or collection of inapplicable data. Smith et al. (2013) provide specific considerations for constructing field forms for data collection.

Data collection protocols should be clearly described in a user manual and standardized to the extent practicable. Electronic data templates, if applicable, should include metadata templates (e.g., who collected the data, where was it collected, why was it collected, etc.) and incorporate automated data checkers and/or drop-down menus from which applicable entries may be selected to reduce input errors.

At this point, the development team should consult the data management plan (section 2.1.1.3) and consider how to approach the following:

- How will field data be transcribed into an electronic format (i.e., spreadsheets and databases)? Consider whether to develop electronic data forms (for use on handheld devices) or paper forms as it relates to $\mathrm{QA} / \mathrm{QC}$ needs and costs. If paper forms are used, a standard method for scanning and digitally saving copies should be part of the recommended data management plan.

- How will data be used, compiled, and shared? Will data be compared across assessment sites? Will it be compared over time for the same site? Could the data be incorporated into existing databases for longterm and publicly accessible storage of assessment results?

- Is it feasible to use open data formats to make it easy for practitioners to create their own digital data collection tools? For example, data can be structured in XML format to accommodate open data practices and web services. 


\subsubsection{Field-testing procedure}

Validity and repeatability of the stream assessment method should be evaluated using field testing. Field testing should allow the development team to determine how long it takes to execute a stream assessment in the field under different environments and conditions, identify incomplete or ambiguous instructions, ensure that the level of training and expertise required to apply the assessment method is appropriate, and ensure applicability of the assessment method (Wakeley and Smith 2001).

To test repeatability, multiple independent field crews unaffiliated with development of the stream assessment method itself should apply the assessment method in the field. These crews should be provided equivalent training and guidance (e.g., user manuals) and assess the same sites spanning a range of conditions and representing different stream types throughout the region (Dorney et al. 2018; Nadeau et al. 2018). If possible, field testing should also include assessing the same stream in different seasons of the year to test for temporal effects.

The number of sites targeted for field testing will be influenced by the approach used to stratify and/or classify streams in the assessment method. Selecting the number of sites necessary and how many data collection events should occur at each site can be based on a project-cost analysis or determined statistically. When adapting existing assessment methods to a new region, field validation should include sites in stream types or field conditions not applicable or anticipated by the original method. For example, if the original method was developed for use in perennial streams but the aim of the development team is to also apply the method in intermittent streams, field testing should be conducted in both these systems.

Applicability of the assessment method refers to how well the results of the assessment accurately represent stream conditions across a range of different stream types. Two approaches for evaluating applicability include (1) experimental manipulation of the assessed streams and (2) comparing scores derived from the assessment to an independent, quantitative method (Smith et al. 2013). 


\subsubsection{Revisiting and revising products and decisions from earlier Phases}

The development team may need to revisit products or decisions from earlier phases to address concerns that arise during or as a result of field testing. Changes may be necessary to improve stratification and classification, modify metrics and scoring procedures, or add clarity or other updates to user manuals and data templates. For example, field testing may reveal redundancy among metrics; and consequently, metrics may need to be revised or removed. Field testing also often highlights pertinent sections of user manuals that require additional clarity. The development team should document the results of validation exercises, including detailed descriptions of how any shortcomings of the method are or will be addressed.

\subsubsection{Steps in Phase 7}

The NCSA recommends the following steps for field testing stream assessment methods developed for the Regulatory Program:

1. Construct (or revise) data forms and develop data collection protocols.

2. Compile a user manual, Standard Operating Procedure, or both for application of the assessment method.

3. Compile a plan for field testing, including who will conduct it, where will it be conducted, at how many sites, and over what time frame will it be conducted.

4. Evaluate limitations of the assessment method based on field testing, and determine changes needed as necessary.

5. Clearly document the results of the field-testing exercise.

\subsection{Phase 8: Carry out peer review, public comment, and beta- testing}

\subsubsection{Phase 8 description}

Phase 8 emphasizes the need for the stream assessment method to undergo review by those who were not involved in its development. There are several approaches to obtain this feedback, including through peer review and public comment. The goals of the peer review include determining the usability, applicability, credibility, and relevance of measures (Nadeau et al. 2018). 


\subsubsection{Phase 8 guidelines}

\subsubsection{Peer review}

In this phase, it is important that individuals outside of the development team review the stream assessment method. Peer review could include staff from within the development team's agencies, experts from outside the development team's agencies, practitioners, and other stakeholders. Including both internal and external peer review allows more opportunity for individuals and groups outside the development team to participate in the development of the method, bringing in additional expertise and possibly facilitating the transition from old practices to new.

Ideally, there should be both an internal and external review process of the assessment method, including the technical documents, user manuals, field forms, and other tools. Barbour et al. (1999) provide details on how to set up a peer review process. Peer review is an essential component of the stream assessment method development process and should be planned and budgeted for in the scope of work (Phase 1). The development team should consider specific feedback sought from peer reviewers and provide a short list of questions to guide responses. This will assist in focusing and targeting the feedback from peer review.

\subsubsection{Public comment and beta-testing}

A public comment period allows the broadest cross section of practitioners and stakeholders to provide feedback on the stream assessment method to the development team prior to implementation. The public comment period should be long enough to allow the public time to test the assessment method, analyze data, and provide feedback. Early during the public comment period, the development team should schedule training workshops in sufficiently distributed locations throughout the region. These technical workshops can be a good way to introduce the assessment method to practitioners and answer any immediate questions to maximize the completeness and efficiency of public comments.

The development team should consider whether there is specific information or types of feedback they want to receive during public comment (e.g., related to the usability of the methods or the availability of any additional datasets) and include this in the public notice. Consider how to craft the questions so that commenters provide feedback in a way that can be 
most readily addressed in the method revisions or in development of the training materials.

Concurrent with the public comment period, a beta-testing period (e.g., 90 days, 6 months, 1 year, etc.) is also useful to allow practitioners time to actually use the assessment method themselves to help formulate their feedback (Fritz et al 2020). The beta-testing period should coincide with the typical field season and be within any recommended biological index periods for sampling. During the beta-testing period, the NCSA also recommends that permit applicants and mitigation project sponsors complete the beta version of the assessment tool in addition to whatever assessment method is currently being used (Smith et al. 2013). This will provide the development team with real-world data from throughout the region to evaluate how well the new stream assessment method is working. In addition, the beta testing period will allow both agency personnel and practitioners to become more familiar with collection and review of field data, analysis of those data, and identifying unforeseen implementation issues.

\subsubsection{Revisions following peer review and public comment}

The peer review process and public comment period may occur sequentially or concurrently. When peer review precedes public comment, it will be useful to address peer review comments prior to releasing a version to the public. Once the peer review and public comment processes are complete, revise the stream assessment method, field forms, and training methods as needed. Changes may be necessary to improve stratification and/or classification of stream resources in the region, modify metrics and scoring procedures, or add clarity or other updates to user manuals and data templates.

The development team should review all comments received as a result of peer review, the public comment, and beta-testing period and evaluate potential edits and revisions to the stream assessment method necessary to be responsive to those comments. Cataloguing comments received by the development team and the responses to those comments is an important component of Phase 8. 


\subsubsection{Steps in Phase 8}

Phase 8 is iterative with previous phases. It is likely that previous phases of the process will need to be revisited following peer review, public comment, and beta-testing. The NCSA recommends the following steps to guide this phase of assessment method development:

1. Carry out peer review of assessment method.

2. Administer public comment and beta testing.

3. Revise assessment method, documentation, and training methods based on user feedback.

\subsection{Phase 9: Implement the stream assessment method}

\subsubsection{Phase 9 description}

Implementing the stream assessment method will include formalizing and distributing the final products and all documentation to end users, including the regulated community. Training, field audits and testing, certification (in some cases), data management, periodic method updates, and end-user assistance should all be considered as part of the broader implementation phase.

User manuals and supporting documents should be finalized, and training modules implemented and periodically updated. A long-term plan should be in place to guide continual evaluation of the stream assessment method to ensure that it keeps pace with current science. A scientific support document should clearly describe the rationale for selecting the metrics, the origin of the data used to generate assessment models, and any assumptions and limitations of those data. Supporting documents may also include scientific support for the metrics and the assessment method as whole. Fritz et al. (2020) describe a process for assessment method implementation, including documentation and training considerations.

\subsubsection{Phase 9 guidelines}

\subsubsection{Documentation and updates}

Documentation is a continuous process throughout the development of the stream assessment method, and much of the necessary documentation should have been initiated during all previous phases of this process. Documentation includes user manuals, standard operating procedures, data 
forms, tools (spreadsheets, etc.), decision matrices, training materials, and any other technical support documents or documents that memorialize considerations and decisions of the development team.

All documentation should include a version table at the beginning of the document or within the metadata section of data templates. If new versions of the stream assessment method are released, this table should be updated in all documentation to provide the new version number; date of update; and a description of the updates, errata, or edits that were made. Consider how to document updates prior to releasing the initial method. For example, beta versions are often numbered as 0.9, with an initial release of a final stream assessment method identified as version 1.o. Future updates that are relatively minor or that address errors in formulas or simple clarifications may be indicated by smaller version updates, such as 1.1, 1.2, etc., whereas more substantial revisions to the tool may involve release of version 2.0, 3.0, etc.

The science of evaluating the ecosystem functions of streams is continually evolving. Therefore, it is important to reevaluate stream assessment methods periodically to help ensure they adhere to current and sound scientific principles. Assessment methods may need to be updated or adjusted as additional data or new methodologies for assessing streams or assessing different metrics become available. The NCSA recommends that the development team consider how to approach updates to the stream assessment method prior to its original release for implementation. For example, the process for accommodating minor updates or changes (e.g., formula errors or clarification of methods) may be different from a more formal process to address major updates (e.g., changes to metrics or underlying datasets). The development team leader should outline a plan for addressing updates, including who may be involved and how it will be resourced, what may trigger updates, and whether updates would necessitate additional public comment or peer review.

\subsubsection{Training}

The NCSA recommends development of a plan to provide training for applicable federal, state, and local regulators, as well as end users, stakeholders, and interested members of the regulated public. This training plan should also identify who will prepare the training content and conduct the training, the format for the training, and the frequency of any live training events. Consider both cost and logistics when developing training modules. 
Target audiences for training may include the following:

- USACE district regulatory personnel

- Cooperating state and federal regulatory agencies

- Environmental consultants

- Planners and engineers

- Personnel from departments of transportations and other nonresource agencies

- Representatives of the academic community

- Nonprofit conservation groups

Logistics and cost constraints may affect the schedule or opportunities to provide training. Training for USACE regulators and other federal and state regulatory agencies should be prioritized, but efforts should be made to offer training to all end users as soon as feasible to help ensure that application of the stream assessment method is as consistent as possible. It can be beneficial to train any federal, state, and local regulatory staff that will be using the method in their program decision-making in advance of the stream assessment method's release. When training is planned in this way, it prepares agencies to answer questions and review incoming results from the application of the method. On-demand or prerecorded training modules or train-the-trainer exercises (Fritz et al. 2020) can be useful to reach the broadest possible audience. Training for practitioners should also include a field component.

A training plan should also consider ways to assess comprehension of the stream assessment method by those receiving training and could include checkpoints for comprehension in each portion of the assessment method or other certification approaches. Pre- and posttests may be used to evaluate the effectiveness of the training modules. These would allow the instructors to determine whether trainees are retaining and appropriately applying the information provided during training and could guide adjustments to future training if warranted.

When developing the content of training modules, offer training at all levels. Training should be commensurate with the technical level of detail of the stream assessment method and end-user expertise. Expertise, however, is not a substitute for additional training when implementing a new assessment method (Herlihy et al. 2009). 
In addition to outlining a training approach prior to and following the initial release of the stream assessment method, a training plan should also consider how to provide continuous training once the method has been implemented and new training following release of significant updates or new versions of the assessment method. For example, training modules may include abbreviated "refresher" training, especially if updates to the assessment method are made following the initial training sessions. These abbreviated modules should reintroduce the basic concepts of the assessment method and focus on updates or areas where additional training is necessary.

\subsubsection{Distribution to end users}

Distribution of the stream assessment method, manuals, documentation, and training opportunities should be as wide as possible. All applicable documentation should also be easily accessible online. Upfront, the multidisciplinary assessment team should identify the agency retaining responsibility of this information. This ensures the agency has the capacity to provide updated materials for the foreseeable future. It may be important to designate a single point of contact responsible for ensuring information is disseminated to the appropriate end users. Communication and distribution channels may include the following:

- Public notice

- Email distribution list of end users

- USACE district website

- Other agency websites

- Regulatory In-Lieu Fee and Bank Information Tracking System (RIBITS)

Distribution to end users should not be considered a discrete event. Once the assessment method is distributed and in use, the agency should plan to provide continuing support and technical assistance. It is difficult to foresee all possible problems that may affect implementation of a stream assessment method, even with a robust peer review, public comment, and beta-testing periods. Continuing support and technical assistance can be in the form of continuous training, webinars, or technical review of more difficult stream reaches. One or more designated points of contact should be available to answer questions and direct end users to the appropriate contact for additional technical assistance. 


\subsubsection{Steps in Phase 9}

The NCSA recommends the following steps to guide finalization and implementation of the stream assessment method:

1. Finalize documentation of the assessment method.

2. Develop a plan for reviewing and updating the assessment method and data management approaches as the need arises.

3. Develop a training plan.

4. Distribute documentation for the stream assessment method to end users, stakeholders, and the public.

5. Provide continuing support, training, and technical assistance.

6. Update the assessment method, training, and data management as the need arises. 


\section{Summary}

The framework presented in this technical guide provides national-level guidelines to assist multidisciplinary teams develop new stream assessment methodologies for the Regulatory Program or to evaluate methods currently in use in other regions or for nonregulatory purposes. Table 4 provides a short description and summary of the factors that need to be considered under each phase. To facilitate work efforts, the table combines the rationale and recommendations of the NCSA under each phase. Although the phases are presented individually and sequentially, completing the work outlined in each phase is often iterative, with decisions of one phase having significant feedback loops with other phases.

Stream assessment methods are a critical part of the USACE Regulatory Program. In making CWA Section 404 permitting and compensatory mitigation decisions, the USACE Regulatory Program, along with its federal, state, and local partners, must consider the loss (impacts) or accrual of aquatic resource functions (compensatory mitigation).

The ability for regulatory decision makers to assess the impact of a proposed action on an aquatic resource or the amount of mitigation needed to compensate for unavoidable losses of aquatic resources is dependent on successfully characterizing the condition and ultimately the function of that resource. The NCSA hopes that this technical guide facilitates the development or adaptation of stream assessment methods to fulfill that objective for the USACE Regulatory Program. 
Table 4. Summary of the phases and the factors to consider in each phase of developing stream assessment approaches (adapted from Dorney and Adamus 2018).

\begin{tabular}{|c|c|c|}
\hline $\begin{array}{l}\text { Phases for Developing } \\
\text { Stream Protocols }\end{array}$ & Description & Factors to Consider \\
\hline $\begin{array}{l}\text { Phase 1: Develop a } \\
\text { scope of work (iterative } \\
\text { with Phase 2) }\end{array}$ & $\begin{array}{l}\text { Emphasizes the need to } \\
\text { consider the plan of action by } \\
\text { writing a scope of work that } \\
\text { identifies assessment } \\
\text { objectives and includes a } \\
\text { budget and timeline }\end{array}$ & $\begin{array}{l}\text { - What are the main programmatic objectives for developing a stream assessment } \\
\text { method? What type of method is needed? Will a new method be developed, or will an } \\
\text { existing method be adapted for a new use or for a new region? What kind of } \\
\text { stratification may be needed to address all stream types in a region? } \\
\text { - Who will use this, and what skill level do they have? } \\
\text { - What tasks and products will be needed? Who will be the project leader to keep the } \\
\text { project moving forward? } \\
\text { - What are the funding sources and the budgets? Expenses for travel? Materials? } \\
\text { Consultants and peer reviewers? } \\
\text { - Is there a target date for implementation, and how much time (e.g., per week, per } \\
\text { month, etc.) can the project team members devote to the project? What is the } \\
\text { - } \quad \text { Whedule? } \\
\text { - What plan will be made to solicit stakeholder input? } \\
\text { open data platforms be used? How will data be stored? What is the long-term data } \\
\text { access plan? What metadata will be collected, and how will the metadata be stored and } \\
\text { accessed? }\end{array}$ \\
\hline $\begin{array}{l}\text { Phase 2: Gather a } \\
\text { multidisciplinary project } \\
\text { team (iterative with } \\
\text { Phase 1) }\end{array}$ & $\begin{array}{l}\text { Describes the need for and } \\
\text { compilation of a } \\
\text { multidisciplinary team to } \\
\text { develop the stream } \\
\text { assessment method }\end{array}$ & $\begin{array}{l}\text { - Will the team be agency staff or multiagency? Does the team have representatives from } \\
\text { all relevant disciplines? Are there possible conflicts of interest for potential team } \\
\text { members? If so, are those resolvable, or does the team need to be changed? } \\
\text { - Are there initial trainings, presentations, or workshops necessary to familiarize all team } \\
\text { members with the conceptual approach identified in Phase } 1 \text { that will guide } \\
\text { development or adaptation of a stream assessment method (may require that parts of } \\
\text { phase } 1 \text { be revisited)? }\end{array}$ \\
\hline $\begin{array}{l}\text { Phase 3: Determine the } \\
\text { types of streams, } \\
\text { associated stream } \\
\text { functions, and } \\
\text { necessary stratification } \\
\text { for streams in the region }\end{array}$ & $\begin{array}{l}\text { Discusses how to } \\
\text { conceptualize the types of } \\
\text { streams found in a region and } \\
\text { their functions and how to } \\
\text { approach stratification and } \\
\text { classification to reduce the } \\
\text { heterogeneity of stream } \\
\text { characteristics in the } \\
\text { assessment region }\end{array}$ & $\begin{array}{l}\text { - What is the range (heterogeneity) of stream types in the region? } \\
\text { - Is there a need to stratify stream types as part of the stream assessment? } \\
\text { - What existing classification systems are available, and do they inform stratification? } \\
\text { - Hill multiple different methods of stratification or classification be necessary? }\end{array}$ \\
\hline
\end{tabular}


Table 4 (cont.). Summary of the phases and the factors to consider in each phase of developing stream assessment approaches (adapted from Dorney and Adamus 2018).

\begin{tabular}{|c|c|c|}
\hline $\begin{array}{l}\text { Phases for Developing } \\
\text { Stream Protocols }\end{array}$ & Description & Factors to Consider \\
\hline $\begin{array}{l}\text { Phase 4: Select } \\
\text { regionally relevant } \\
\text { metrics }\end{array}$ & $\begin{array}{l}\text { Describes how to define and } \\
\text { select regionally relevant } \\
\text { metrics as indicators of } \\
\text { stream functions }\end{array}$ & $\begin{array}{l}\text { - Does variation of stream types in the region lead to different stream functions or } \\
\text { necessary metrics to represent those functions? } \\
\text { - What regionally relevant metrics can be used? How will relevant metrics be selected? } \\
\text { - } \quad \text { If new data must be collected, how will measurements be made (i.e., field sampling } \\
\text { protocols)? } \\
\text { - What would be the plan for collecting these new data? Who? When? Where? }\end{array}$ \\
\hline $\begin{array}{l}\text { Phase 5: Develop the } \\
\text { reference framework }\end{array}$ & $\begin{array}{l}\text { Describes how to incorporate } \\
\text { reference information }\end{array}$ & $\begin{array}{l}\text { - What is reference? How will reference information inform development of the } \\
\text { assessment method? } \\
\text { - What reference information is available, and will new reference data need to be } \\
\text { collected? } \\
\text { - } \quad \text { Review or develop a QAPP for any reference or baseline data that are gathered or used. } \\
\text { - How will the quality of new and existing data be determined? Is data collected by } \\
\text { - How wiferent parties using different protocols comparable? } \\
\text { statistical algorithm? Will site selection be based on stratification or classification from } \\
\text { Phase } 4 \text { (i.e., geography, ecoregion, channel geomorphic type, channel gradient, degree } \\
\text { of prior disturbance, other, all, etc.)? }\end{array}$ \\
\hline $\begin{array}{l}\text { Phase 6: Build } \\
\text { assessment models and } \\
\text { develop scoring } \\
\text { procedures }\end{array}$ & $\begin{array}{l}\text { Discusses how to build and } \\
\text { verify assessment models } \\
\text { and how to use those models } \\
\text { to develop scoring procedures } \\
\text { and outputs for the stream } \\
\text { assessment method }\end{array}$ & $\begin{array}{l}\text { - How do metrics interact to represent functions and determine assessment outputs? } \\
\text { - Will metric data need to be standardized before combining to represent functions? } \\
\text { - Will functions be combined to result in a total assessment score? }\end{array}$ \\
\hline $\begin{array}{l}\text { Phase 7: Develop } \\
\text { assessment method } \\
\text { protocols, validation, } \\
\text { and intercalibration }\end{array}$ & $\begin{array}{l}\text { Describes method validation } \\
\text { and field testing }\end{array}$ & $\begin{array}{l}\text { - How will a stream assessment be executed in the field? } \\
\text { - Will validation occur at additional sites that were not used for calibration? How many } \\
\text { - How Over what geographic area? } \\
\text { assessment method? }\end{array}$ \\
\hline
\end{tabular}


Table 4 (cont.). Summary of the phases and the factors to consider in each phase of developing stream assessment approaches (adapted from Dorney and Adamus 2018).

\begin{tabular}{|c|c|c|}
\hline $\begin{array}{l}\text { Phases for Developing } \\
\text { Stream Protocols }\end{array}$ & Description & Factors to Consider \\
\hline $\begin{array}{l}\text { Phase 8: Carry out peer } \\
\text { review, public comment, } \\
\text { and beta-testing }\end{array}$ & $\begin{array}{l}\text { Describes the need for } \\
\text { independent peer review of } \\
\text { the assessment method and } \\
\text { opportunity for public } \\
\text { comment }\end{array}$ & $\begin{array}{l}\text { - Will there be both internal and external peer review? } \\
\text { - How will the initial roll-out for public comment, including all supporting documentation } \\
\text { (e.g., user manuals, support documents, etc.), be implemented? } \\
\text { - Will there be a period allotted for beta testing by all stakeholders prior to full } \\
\text { implementation? }\end{array}$ \\
\hline $\begin{array}{l}\text { Phase 9: Implement the } \\
\text { stream assessment } \\
\text { method }\end{array}$ & $\begin{array}{l}\text { Describes implementation of } \\
\text { the stream assessment } \\
\text { method, which includes } \\
\text { distribution to end users, } \\
\text { training, and continued } \\
\text { support and technical } \\
\text { assistance }\end{array}$ & $\begin{array}{l}\text { - How much training will be required? Conducted by public sector? By private sector? } \\
\text { Both? How will quality be maintained? } \\
\text { - What will be included in the final compilation of necessary user manuals, scientific } \\
\text { support documents, etc.? } \\
\text { - Is the data management plan in place and accessible to the public? }\end{array}$ \\
\hline
\end{tabular}




\section{Glossary}

Assessment method or model: "A simple model that defines the relationship between ecosystem and landscape scale variables and functional capacity of a [stream system]. The model is developed and calibrated using reference [streams] from a reference domain" (Smith et al. 1995).

Buffer: "An upland, wetland, and/or riparian area that protects and/or enhances aquatic resource functions associated with wetlands, rivers, streams, lakes, marine, and estuarine systems from disturbances associated with adjacent land uses."*

Categorical rating: This score is developed from the result of an assigned rating evaluation of categorical groups (i.e., "Poor," "Good," "Excellent," "Low," "High").

Compensatory mitigation: "The restoration (reestablishment or rehabilitation), establishment, enhancement, and/or in certain circumstances preservation of aquatic resources for the purposes of offsetting unavoidable adverse impacts that remain after all appropriate and practicable avoidance and minimization has been achieved.”

Credit: "A unit of measure (e.g., a functional or areal measure or other suitable metric) representing the accrual or attainment of aquatic functions at a compensatory mitigation site. The measure of aquatic functions is based on the resources restored, established, enhanced, or preserved.”

Cumulative effects: "Determination of cumulative effects on the aquatic ecosystem. [1] Cumulative impacts are the changes in an aquatic ecosystem that are attributable to the collective effect of a number of individual discharges of dredged or fill material. Although the impact of a particular discharge may constitute a minor change in itself, the cumulative effect of numerous piecemeal changes can result in a major impairment of the water resources and interfere with the productivity and water quality of exist-

* 40 C.F.R § 230.92.

† 33 C.F.R. § 332.2.

₹ 33 C.F.R. § 332.2. 
ing aquatic ecosystems. [2] Cumulative effects attributable to the discharge of dredged or fill material in WOTUS should be predicted to the extent reasonable and practical. The permitting authority shall collect information and solicit information from other sources about the cumulative impacts on the aquatic ecosystem. This information shall be documented and considered during the decision-making process concerning the evaluation of individual permit applications, the issuance of a general permit, and monitoring and enforcement of existing permits."*

Debit: "A unit of measure (e.g., a functional or areal measure or other suitable metric) representing the loss of aquatic functions at an impact or project site. The measure of aquatic functions is based on the resources impacted by the authorized activity." ${ }^{\dagger}$

Ecological performance standards: “(a) The approved mitigation plan must contain performance standards that will be used to assess whether the project is achieving its objectives. Performance standards should relate to the objectives of the compensatory mitigation project, so that the project can be objectively evaluated to determine if it is developing into the desired resource type, providing the expected functions, and attaining any other applicable metrics (e.g., acres). (b) Performance standards must be based on attributes that are objective and verifiable. Ecological performance standards must be based on the best available science that can be measured or assessed in a practicable manner. Performance standards may be based on variables or measures of functional capacity described in functional assessment methodologies, measurements of hydrology or other aquatic resource characteristics, and/or comparisons to reference aquatic resources of similar type and landscape position. The use of reference aquatic resources to establish performance standards will help ensure that those performance standards are reasonably achievable, by reflecting the range of variability exhibited by the regional class of aquatic resources as a result of natural processes and anthropogenic disturbances. Performance standards based on measurements of hydrology should take into consideration the hydrologic variability exhibited by reference aquatic resources, especially wetlands. Where practicable, performance standards

\footnotetext{
* 40 C.F.R. $\S 230.11(\mathrm{~g})$.

† 33 C.F.R. $\S 332.2$.
} 
should take into account the expected stages of the aquatic resource development process, in order to allow early identification of potential problems and appropriate adaptive management."*

Enhancement: "The manipulation of the physical, chemical, or biological characteristics of an aquatic resource to heighten, intensify, or improve a specific aquatic resource function. Enhancement results in the gain of selected aquatic resource functions but may also lead to a decline in other aquatic resource functions. Enhancement does not result in a gain in aquatic resource area.”

Functional capacity: "The degree to which an area of aquatic resource performs a specific function." *

Functions: "Physical, chemical, and biological processes that occur in ecosystems." $\$$ Functions are the combination of processes that create and support a stream system (changes over time and space) (Nadeau et al. 2018).

Index score: This is a score derived from an index (e.g., a multicategory rating system, such as an EPA RBP habitat evaluation) and adding up the subcategories to produce a final score.

Impact: "Adverse effect."**

Metric: A specific tool, equation, measured values, or assessment method used to assess the condition of a structural measure or function-based parameter (McKay et al. 2010; Wyoming Stream Technical Team 2018).

Performance standards: "Observable or measurable physical (including hydrological), chemical and/or biological attributes that are used to determine if a compensatory mitigation project meets its objectives." ${ }^{+\dagger}$

\footnotetext{
* 33 C.F.R. § 332.5.

$\dagger 33$ C.F.R. § 332.2 .

‡ 33 C.F.R. $\S 332.2$.

$\S 33$ C.F.R. $\S 332.2$.

** 33 C.F.R. § 332.2.

†† 33 C.F.R. § 332.2.
} 
Reestablishment: "The manipulation of the physical, chemical, or biological characteristics of a site with the goal of returning natural/historic functions to a former aquatic resource. Reestablishment results in rebuilding a former aquatic resource and results in a gain in aquatic resource area and functions."*

Reference or reference condition: The full range of variability exhibited by a regional class of aquatic resources as a result of natural processes and anthropogenic disturbances.

Reference aquatic resources: "A set of aquatic resources that represent the full range of variability exhibited by a regional class of aquatic resources as a result of natural processes and anthropogenic disturbances.” ${ }^{\prime}$

Rehabilitation: "The manipulation of the physical, chemical, or biological characteristics of a site with the goal of repairing natural/historic functions to a degraded aquatic resource. Rehabilitation results in a gain in aquatic resource function but does not result in a gain in aquatic resource area."*

Restoration: "The manipulation of the physical, chemical, or biological characteristics of a site with the goal of returning natural/historic functions to a former or degraded aquatic resource. For the purpose of tracking net gains in aquatic resource area, restoration is divided into two categories: reestablishment and rehabilitation.”

Riparian areas: Lands adjacent to streams, rivers, lakes, and estuarinemarine shorelines. Riparian areas provide a variety of ecological functions and services and help improve or maintain local water quality.

Secondary effects: "Effects on an aquatic ecosystem that are associated with a discharge of dredged or fill materials but do not result from the actual placement of the dredged or fill material. Information about secondary (indirect) effects on aquatic ecosystems shall be considered prior to the time final Section 404 action is taken by permitting authorities. Some examples of secondary effects on an aquatic ecosystem are fluctuating water

* 33 C.F.R. § 332.2.

$\dagger 33$ C.F.R. $\S 332.2$.

‡ 33 C.F.R. $\S 332.2$.

$\S 33$ C.F.R. $\S 332.2$. 
levels in an impoundment and downstream associated with the operation of a dam, septic tank leaching and surface runoff from residential or commercial developments on fill, and leachate and runoff from a sanitary landfill located in WOTUS."*

Service: How a society perceives the ecological and societal benefits (value) of one or more ecosystem functions (Nadeau et al. 2018).

Stream functional capacity score: A rating system that includes a combination of both categorical ratings and numerical values, which are combined to determine the overall stream function.

Stream condition: "The relative ability of an aquatic resource to support and maintain a community of organisms having a species composition, diversity and functional organization comparable to reference aquatic resources in the region." ' A single or multivariate snapshot of a stream system (at a moment in time but can vary in space) (see Nadeau et al. 2018).

Stream Function Assessment Method (SFAM): A tool that assesses stream ecological processes at the site scale in the context of the larger watershed, using a range of expected performance for 11 defined functions, the opportunity to provide each function and the local significance of each function. SFAMs are a quantitative method that result in unitless outputs that, in combination with a stream mitigation accounting protocol, calculate credits generated from stream mitigation activities or debits associated with adverse stream impacts. SFAMs are based on the stream functions described by Fischenich (2006).

Stream Quantification Tool (SQT): A stream functional assessment tool used to assign scalings to metric values within functional categories to determine ecological lift. SQTs are a semi- to fully quantitative method to calculate credits generated from stream mitigation activities or debits associated with adverse stream impacts. SQTs are based on the stream functions pyramid concept presented by Harman et al. (2012).

Watershed: The land area that drains to a common waterway, such as a stream, lake, estuary, wetland, or ultimately the ocean.

* 40 C.F.R. $\S 230.3(\mathrm{~h})$.

$\dagger 33$ C.F.R. § 332.2. 


\section{References}

Adamus, P. 2018. "Selecting Indicators, Creating and Testing the Data Forms." In Wetland and Stream Rapid Assessments: Development, Validation, and Application, edited by J. Dorney, R. Savage, and R. W. Adamus, 219-227. London: Academic Press, Elsevier Inc. https://doi.org/10.1016/B978-0-12-8050910.00030-X.

Alexander, R. B., E. W. Boyer, R. A. Smith, G. E. Schwarz, and R. B. Moore. 2007. "The Role of Headwater Streams in Downstream Water Quality." Journal of the American Water Resources Association 43 (1): 41-59. https://doi.org/10.1111/i.1752-1688.2007.00005.x.

Bain, M. B., T. C. Hughes, and K. K. Arend. 1999. "Trends in Methods for Assessing Freshwater Habitats." Fisheries 24 (4): 16-21. https://doi.org/10.1577/15488446(1999)024\%3C0016:TIMFAF\%3E2.0.C0;2.

Barbour, M. T., J. Gerritsen, B. D. Snyder, and J. B. Stribling. 1999. Rapid Bioassessment Protocols for Use in Streams and Wadeable Rivers: Periphyton, Benthic Macroinvertebrates and Fish. 2nd ed. EPA 841-B-99-002. Washington, D.C: U.S. Environmental Protection Agency, Office of Water.

Barbour, M. T., J. B. Stribling, J. Gerritsen, and J. R. Karr. 1996. Biological Criteria: Technical Guidance for Streams and Small Rivers. Rev. ed. EPA 822-B-96001. Washington, DC: U.S. Environmental Protection Agency, Office of Science and Technology.

Beechie, T., and H. Imaki. 2014. "Predicting Natural Channel Patterns Based on Landscape and Geomorphic Controls in the Columbia River Basin, USA." Water Resources Research 50:39-57. https://doi.org/10.1002/2013WR013629.

Beechie, T. J., D. A. Sear, J. D, G. R. Pess, J. M. Buffington, H. Moir, P. Roni, P, and M. M. Pollock. 2010. "Process-Based Principles for Restoring River Ecosystems." Bioscience 6o (3): 209-222. https://doi.org/10.1525/bio.2010.60.3.7.

Belletti, B., M. Rinaldi, M. Bussettini, F. Comiti, A. Gurnell, L. Mao, L. Nardi, and P. Vezza. 2017. "Characterising Physical Habitats and Fluvial Hydromorphology: A New System for the Survey and Classification of River Geomorphic Units." Geomorphology 283:143-157. https://doi.org/10.1016/i.geomorph.2017.01.032.

Blocksom, K. A., and B. R. Johnson. 2009. "Development of a Regional Macroinvertebrate Index for Large River Bioassessment." Ecological Indicators 9:313-328. https://doi.org/10.1016/j.ecolind.2008.05.005.

Booth, D. B., and C. J. Fischenich. 2015. "A Channel Evolution Model to Guide Sustainable Urban Stream Restoration.” Area 47 (4): 408-421. https://doi.org/10.1111/area.12180.

Brierley, G. J., and K. A. Fryirs. 2005. Geomorphology and River Management: Applications of the River Styles Framework. Oxford, UK: Blackwell Publishing. 
Cluer, B., and C. Thorne. 2014. "A Stream Evolution Model Integrating Habitat and Ecosystem Benefits." River Research and Applications 30 (2): 135-154. https://doi.org/10.1002/rra.2631.

Collins, B. D., D. R. Montgomery, K. L. Fetherston, and T. B. Abbe. 2012. "The Floodplain Large-Wood Cycle Hypothesis: A Mechanism for the Physical and Biotic Structuring of Temperate Forested Alluvial Valleys in the North Pacific Coastal Ecoregion." Geomorphology 139-140:460-470. https://doi.org/10.1016/j.geomorph.2011.11.011.

Compensatory Mitigation for Losses of Aquatic Resources. 2008. 73 Fed. Reg. 70 (10 Apr. 2008). https://www.govinfo.gov/content/pkg/FR-2008-04-10/pdf/E8-6918.pdf\#page=78.

Compensatory Mitigation for Losses of Aquatic Resources. 2011. 33 C.F.R. § 332.3(a). https://www.govinfo.gov/content/pkg/CFR-2011-title33-vol3/pdf/CFR-2011-title33-vol3part332.pdf.

CSQT (Colorado Stream Quantification Tool) Steering Committee. 2019a. Colorado Stream Quantification Tool and Debit Calculator (CSQT) User Manual, Beta Version. Contract \# EPC-17-001. Washington, DC: U.S. Environmental Protection Agency, Office of Wetlands, Oceans and Watersheds.

CSQT (Colorado Stream Quantification Tool) Steering Committee. 2019b. Scientific Support for the Colorado Stream Quantification Tool, Beta Version. Contract \# EP-C-17-001. Washington, DC: U.S. Environmental Protection Agency, Office of Wetlands, Oceans and Watersheds.

Davies, S. P. 2000. "Development of a National River Bioassessment System (AUSRIVAS) in Australia." In Assessing the Biological Quality of Freshwaters: RIVPACS and Similar Techniques, edited by J. F. Wright, D. W. Sutcliffe, and M. T. Furse, 113128. Cumbria, UK: Freshwater Biological Association.

Davies, S. P., and S. K. Jackson. 2006. "The Biological Condition Gradient: A Descriptive Model for Interpreting Change in Aquatic Ecosystems." Ecological Applications 16 (4): 1251-1266. https://doi.org/10.1890/1051-0761(2006)016[1251:TBCGAD]2.0.C0;2.

Dollar, E. D. J., C. S. James, K. H. Rogers, and M. C. Thoms. 2007. “A Framework for Interdisciplinary Understanding of Rivers as Ecosystems." Geomorphology 89 (1-2): 147-162. https://doi.org/10.1016/j.geomorph.2006.07.022.

Dorney, J., and P. Adamus. 2018. "Process for Adapting or Developing a RAM.” In Wetland and Stream Rapid Assessments: Development, Validation, and Application, edited by J. Dorney, R. Savage, and R. W. Adamus, 209-218. London: Academic Press, Elsevier Inc.

Dorney, J., R. Savage, and R. W. Adamus, ed. 2018. Wetland and Stream Rapid Assessments: Development, Validation, and Application. 1st ed. London: Academic Press, Elsevier Inc.

ELI (Environmental Law Institute). 2020. Citizen Science Programs at Environmental Agencies: Best Practices. Washington, DC: Environmental Law Institute. https://www.eli.org/sites/default/files/eli-pubs/eli-citizen-science-best-practices-report.pdf. 
ELI (Environmental Law Institute) and The Nature Conservancy. 2014. Watershed Approach Handbook: Improving Outcomes and Increasing Benefits Associated with Wetland and Stream Restoration and Protection Projects. U.S.

Environmental Protection Agency (EPA), EPA Wetlands Program Development Grant No. WD-83501201, 188 pp.https://www.eli.org/sites/default/files/elipubs/watershed-approach-handbook-improving-outcomes-and-increasing-benefits-associatedwetland-and-stream_0.pdf.

ELI (Environmental Law Institute), Stream Mechanics, and The Nature Conservancy. 2016. Stream Mitigation: Science, Policy, and Practice. Washington, DC: Environmental Law Institute. https://www.eli.org/sites/default/files/eli-pubs/streammitigation-science-policy-and-practice-final-report.pdf.

EPA (U.S. Environmental Protection Agency). 2002. Guidance for Quality Assurance Protection Plans. EPA/240/R-02/009. Washington, DC: U.S. Environmental Protection Agency, Office of Environmental Information. https://www.epa.gov/sites/default/files/2015-06/documents/g5-final.pdf.

EPA (U.S. Environmental Protection Agency). 2003. A Summary of General Assessment Factors for Evaluating the Quality of Scientific and Technical Information. EPA 100/B-03/001.Washington, DC: U.S. Environmental Protection Agency, Science Policy Council. https://www.epa.gov/sites/production/files/2015-

01/documents/assess2.pdf.

EPA (U.S. Environmental Protection Agency). 2006. Wadeable Stream Assessment. EPA 841-B-06-002. Washington, DC: U.S. Environmental Protection Agency, Office of Research and Development, Office of Water. https://www.epa.gov/sites/default/files/201410/documents/2007_5_16_streamsurvey_wsa_assessment_may2007.pdf.

EPA (U.S. Environmental Protection Agency. 2016. National Rivers and Stream Assessment 2008-2009: A Collaborative Survey. EPA/841/R-16/007. Washington, DC: U.S. Environmental Protection Agency, Office of Research and Development. http://www.epa.gov/national-aquatic-resource-surveys/nrsa.

EPA (U.S. Environmental Protection Agency). 2020. National Rivers and Stream Assessment 2013-2014: A Collaborative Survey. (Data and metadata files). EPA 841-R-19-001. Washington, DC: U.S. Environmental Protection Agency. https://www.epa.gov/sites/default/files/2020-12/documents/nrsa_201314 final_report_2020-12-17.pdf.

Fischenich, J. C. 2006. Functional Objectives for Stream Restoration. ERDC TNEMRRP-SR-52. Vicksburg, MS: U.S. Army Engineer Research and Development Center. https://hdl.handle.net/11681/3962.

Fong, L. S., E. D. Stein, and R. F. Ambrose. 2017. "Development of Restoration Performance Curves for Streams in Southern California Using an Integrative Condition Index." Wetlands 37:289-299. https://doi.org/10.1007/s13157-016-0869-x.

Fritz, K. M., B. R. Johnson, and D. M. Walters. 2006. Field Operations Manual for Assessing the Hydrologic Permanence and Ecological Condition of Headwater Streams. EPA 600/R-06/126. Washington, DC: U.S. Environmental Protection Agency, Office of Research and Development. 
Fritz, K. M., T.-L. Nadeau, J. E. Kelso, W. S. Beck, R. D. Mazor, R. A. Harrington, and B. J. Topping. 2020. "Classifying Streamflow Duration: the Scientific Basis and an Operational Framework for Method Development." Water 12 (9): 2545. https://doi.org/10.3390/w12092545.

Fryirs, K., and G. Brierley. 200o. "A Geomorphic Approach to the Identification of River Recovery Potential." Physical Geography 21 (3): 244-77. https://doi.org/10.1080/02723646.2000.10642708.

Fuller, I. C., H. E. Reid, and G. J. Brierley. 2013. "Methods in Geomorphology: Investigating River Channel Form.” In Treatise on Geomorphology, edited by J. Shroder, A. D. Switzer, and D. M. Kennedy, 14:73-91. San Diego, CA: Academic Press.

Goodwin, C. N. 1999. "Fluvial Classification: Neanderthal Necessity or Needless Normalcy." In Wildland Hydrology, edited by D. S. Olson and J. P. Potyondy, 229-236. Herndon, VA: American Water Resources Association.

Grabowski, R. C., N. Surian, and A. Gurnell. 2014. "Characterizing Geomorphological Change to Support Sustainable River Restoration and Management." Wiley Interdisciplinary Reviews: Water 1 (5): 483-512. https://doi.org/10.1002/wat2.1037.

Harman, W, A. James, T.-L. Nadeau, B. Topping, M. Kondratieff, K. Boyd, G. Athanasakes, J. Wheaton. 2021. Stream Mitigation Accounting Metrics: Exploring the Use of Linear-based, Area-based, and Volume Units of Measure to Calculate Impacts and Offsets to Different Stream Archetypes. EPA 840-R21003. Washington, DC: U.S. Environmental Protection Agency.

Harman, W., R. Starr, M. Carter, K. Tweedy, M. Clemmons, K. Suggs, and C. Miller. 2012. A Function-Based Framework for Stream Assessment and Restoration Projects. EPA 843-K-12-006. Washington, DC: U.S. Environmental Protection Agency, Office of Wetlands, Oceans, and Watersheds.

Hatch, C. E., A. T. Fisher, C. R. Ruehl, and G. Stemler. 2010. "Spatial and Temporal Variations in Streambed Hydraulic Conductivity Quantified with Time-Series Thermal Methods." Journal of Hydrology 389 (3-4):276-288. https://doi.org/10.1016/i.jhydrol.2010.05.046.

Hawkins, C. P., Y. Cao, Y., and B. Roper. 2010. "Method of Predicting Reference Condition Biota Affects the Performance and Interpretation of Ecological Indices." Freshwater Biology 55 (5): 1066-1085. https://doi.org/10.1111/i.13652427.2009.02357.x.

Hawkins, C. P., J. R. Olson, and R. A. Hill. 2010. “The Reference Condition: Predicting Benchmarks for Ecological and Water-Quality Assessments." Journal of the North American Benthological Society 29 (1): 312-343. https://doi.org/10.1899/09-092.1.

Herlihy, A. T., J. Sifneos, C. Bacon, A. D. Jacobs, M. E. Kentula, and M. Fennessy. 2009. "An Approach for Evaluating the Repeatability of Rapid Wetland Assessment Methods: The Effects of Training and Experience." Environmental Management 44 (2): 369-377. https://doi.org/10.1007/s00267-009-9316-6. 
Horton, R. E. 1945. "Erosional Development of Streams and Their Drainage Basins: Hydrophysical Approach to Quantitative Morphology.” Bulletin of the Geological Society of America 56 (3): 275-370. https://doi.org/10.1130/00167606(1945)56[275:EDOSAT]2.0.C0;2.

Hughes, R. M., P. R. Kaufmann, A. T. Herlihy, T. M. Kincaid, L. Reynolds, and D. P. Larsen. 1998. "A Process for Developing and Evaluating Indices of Fish Assemblage Integrity." Canadian Journal of Fisheries and Aquatic Sciences 55 (7): 1618-1631. https://doi.org/10.1139/f98-060.

Hupp, C. R., and W. R. Osterkamp. 1996. "Riparian Vegetation and Fluvial Geomorphic Processes.” Geomorphology 14 (4): 277-295. https://doi.org/10.1016/0169$\underline{555 \times(95) 00042-4 .}$.

Hupp, C. R., and M. Rinaldi. 2007. "Riparian Vegetation Patterns in Relation to Fluvial Landforms and Channel Evolution along Selected Rivers of Tuscany (Central Italy)." Annals of the Association of Geographers 97 (1): 12-30. https://doi.org/10.1111/j.1467-8306.2007.00521.x.

Karr, J. R., E. W. Chu. 1997. Biological Monitoring and Assessment: Using Multimetric Indexes Effectively. EPA 235-R97-001. Seattle: University of Washington.

Kasprak, A., N. Hough-Snee, T. Beechie, N. Bouwes, G. Brierley, R. Camp, K. Fryirs, H. Imaki, M. Jensen, G. O’Brien, D. Rosgen, and J. Wheaton. 2016. “The Blurred Line between Form and Process: A Comparison of Stream Channel Classification Frameworks." PLoS ONE 11 (3): 1-31. https://doi.org/10.1371/journal.pone.0150293.

Klemm, D. J., K. A. Blocksom, F. A. Fulk, A. T. Herlihy, R. M. Hughes, P. R. Kaufmann, D. V. Peck, J. L. Stoddard, W. T. Thoeny, M. B. Griffith, and W. S. Davis. 2003. "Development and Evaluation of a Macroinvertebrate Biotic Integrity Index (MBII) for Regionally Assessing Mid-Atlantic Highlands Streams." Environmental Management 31 (5): 656-669. https://doi.org/10.1007/s00267-0022945-7.

Kondolf, G. M., 1995. "Geomorphological Stream Channel Classification in Aquatic Habitat Restoration: Uses and Limitations." Aquatic Conservation: Marine and Freshwater Ecosystems 5:127-141. https://doi.org/10.1002/aqc.3270050205.

Leopold, L. B., and M. G. Wolman. 1957. River Channel Patterns: Braided, Meandering, and Straight. Professional Paper 282-B. Reston, VA: U.S. Geological Survey.

Maheu, A., N. L. Poff, and A. St-Hilaire. 2016. "A Classification of Stream Water Temperature Regimes in the Conterminous USA." River Research and Applications 32 (5): 896-906. https://doi.org/10.1002/rra.2906.

Marine Protection, Research, and Sanctuaries Act of 1972. 2010. 33 U.S.C. § 1401. https://www.govinfo.gov/content/pkg/COMPS-1680/pdf/COMPS-1680.pdf.

McKay, S. K., B. A. Pruitt, M. Harberg, A. P. Covich, M. A. Kenney, and J. C. Fischenich. 2010. Metric Development for Environmental Benefits Analysis. ERDC TNEMRRP-EBA-4. Vicksburg, MS: U.S. Army Engineer Research and Development Center. https://hdl.handle.net/11681/4047. 
McManamay, R. A., and C. R. DeRolph. 2019. "A Stream Classification System for the Conterminous United States.” Scientific Data. 6:190017. https://doi.org/10.1038/sdata.2019.17.

McManamay, R. A., J. G. Smith, R. T. Jett, T. J. Mathews, and M. J. Peterson. 2018. "Identifying Non-Reference Sites to Guide Stream Restoration and Long-Term Monitoring." Science of the Total Environment 621:1208-1223. https://doi.org/10.1016/i.scitotenv.2017.10.107.

Melles, S. J., N. E. Jones, and B. Schmidt. 2014. "Evaluation of Current Approaches to Stream Classification and a Heuristic Guide to Developing Classifications of Integrated Aquatic Networks." Environmental Management 53: 549-566. https://doi.org/10.1007/s00267-014-0231-0.

Merritt, D. M., M. L. Scott, N. L. Poff, G. T. Auble and D. A. Lytle. 2010. “Theory, Methods and Tools for Determining Environmental Flows for Riparian Vegetation: Riparian Vegetation-Flow Response Guilds.” Freshwater Biology 55 (1) : 206-225. https://doi.org/10.1111/j.1365-2427.2009.02206.x.

Miller, S. W., P. Budy, and J. C. Schmidt. 2010. "Quantifying Macroinvertebrate Responses to In-Stream Habitat Restoration: Applications of Meta-Analysis to River Restoration.” Restoration Ecology 18 (1): 8-19. https://doi.org/10.1111/j.1526-100X.2009.00605.x.

Minnesota SQT (Stream Quantification Tool) Steering Committee. 2019. Minnesota Stream Quantification Tool and Debit Calculator (MNSQT) User Manual, Version 1.o. Contract \# EPC-17-001. Washington, DC: U.S. Environmental Protection Agency, Office of Wetlands, Oceans and Watersheds. https://bwsr.state.mn.us/sites/default/files/201909/MNSQT\%20User\%20Manual\%20v1.0\%2008292019_combined.pdf.

Montgomery, D. R. 1999. "Process Domains and the River Continuum.” Journal of the American Water Resources Association 35 (2): 397-410. https://doi.org/10.1111/i.1752-1688.1999.tb03598.x.

Montgomery, D. R., and J. M. Buffington. 1997. "Channel-Reach Morphology in Mountain Drainage Basins.” Geological Society of America Bulletin 109 (5): 596-611. https://doi.org/10.1130/0016-7606(1997)109\%3C0596:CRMIMD\%3E2.3.C0;2.

Montgomery, D. R., and L. H. MacDonald, 2002. "Diagnostic Approach to Stream Channel Assessment and Monitoring." Journal of the American Water Resources Association 38 (1): 1-16. https://doi.org/10.1111/j.1752-1688.2002.tb01530.x.

Morandi, B., H. Piégay, N. Lamouroux, and L. Vaudor. 2014. "How is Success or Failure in River Restoration Projects Evaluated? Feedback from French Restoration Projects.” Journal of Environmental Management 137:178-188. https://doi.org/10.1016/i.jenvman.2014.02.010.

Munoz, B., R. Savage, and V. Baker. 2018. "General Issues in Statistical Analysis of RAMs.” In Wetland and Stream Rapid Assessments: Development, Validation, and Application, edited by J. Dorney, R. Savage, and R. W. Adamus, 251-258. London: Academic Press, Elsevier Inc. https://doi.org/10.1016/B978-0-12-805091$\underline{0.00037-2}$. 
Nadeau, T.-L., D. Hicks, C. Trowbridge, N. Maness, R. Coulombe, and N. Czarnomski. 2020. Stream Function Assessment Method for Oregon (SFAM, Version 1.1). EPA 910-R-20-002. Seattle, WA: U.S. Environmental Protection Agency, Region 10. https://oe.oregonexplorer.info/externalcontent/sfam/SFAM_User_Manual_V1.1.pdf.

Nadeau, T.-L., S. G. Leibowitz, P. J. Wigington Jr., J. L. Ebersole, K. M. Fritz, R. Coulombe, R. L. Comeleo, and K.A. Blocksom. 2015. "Validation of Rapid Assessment Methods to Determine Streamflow Duration Classes in the Pacific Northwest, USA." Environmental Management 56: 34-53. https://doi.org/10.1007/s00267-015-0466-4.

Nadeau, T.-L., C. Trowbridge, D. Hicks, and R. Coulombe. 2018. A Scientific Rationale in Support of the Stream Function Assessment Method for Oregon (SFAM, Version 1.o). EPA 910-S-18-001. Seattle, WA: U.S. Environmental Protection Agency, Region 10. https://oe.oregonexplorer.info/externalcontent/sfam/SFAM_Scientific_Rationale_V1.1.pdf.

Nadeau, T.-L., P. J. Wigington Jr., R. L. Comeleo, S. G. Leibowitz, J. R. Brooks, S. Patil, and D. J. Sobota. 2012. "A Dualistic Stream Classification System for Oregon: In Support of a Stream Compensatory Mitigation Framework." Presented at the American Geophysical Union, Fall Meeting, San Francisco, CA.

Nanson, G. C., and J. C. Croke. 1992. "A Genetic Classification of Floodplains." Geomorphology 4 (6):459-486. https://doi.org/10.1016/0169-555X(92)90039-Q.

Natural Resources Conservation Service. 2009. National Biology Handbook Subpart BConservation Planning, Part 614, Stream Visual Assessment Protocols Version 2 (SVAP2). 190-VI-NBH. Washington, DC: United States Department of Agriculture, Natural Resources Conservation Service. https://www.nrcs.usda.gov/Internet/FSE_DOCUMENTS/nrcs144p2_042678.pdf.

North Carolina Stream Functional Assessment Team. 2015. N.C. Stream Assessment Method (NC SAM) User Manual. Version 2.1. http://www.ncaep.org/resources/ Documents/NCSAM/NC\%20SAM\%20User\%20Manual\%20v2.1.pdf.

Olivero, A. P., and M. G. Anderson. 2008. Northeast Aquatic Habitat Classification System. Boston, MA: The Nature Conservancy. http://easterndivision.s3.amazonaws.com/Freshwater/nahcs_report_20080930rev1NE_Aquati cHabitatClassificationSystem2008.pdf.

Omernik, J. M., and G. E. Griffith. 2014. "Ecoregions of the Conterminous United States: Evolution of a Hierarchical Spatial Framework." Environmental Management 54: 1249-1266. https://doi.org/10.1007/s00267-014-0364-1.

Osterkamp, W. R., and C. R. Hupp. 1984. "Geomorphic and Vegetative Characteristics along Three Northern Virginia Streams.” Bulletin of the Geological Society of America 95 (9): 1093-1101. https://doi.org/10.1130/00167606(1984)95\%3C1093:GAVCAT\%3E2.0.C0;2.

Palmer, M., E. Bernhardt, E. Chornesky, S. Collins, A. Dobson, C. Duke, B. Gold, R. Jacobson, S. Kingsland, R. Kranz, M. Mappin, M. L. Martinez, F. Micheli, J. Morse, M. Pace, M. Pascual, S. Palumbi, O. J. Reichman, A. Simons, A. Townsend, and M. Turner. 2014. "Ecology for a Crowded Planet.” Science 304 (5675): 1251-1252. https://doi.org/10.1126/science.1095780. 
Palmer, M. A., K. L. Hondula, and B. J. Koch. 2014. "Ecological Restoration of Streams and Rivers: Shifting Strategies and Shifting Goals." Annual Review of Ecology, Evolution and Systematics 45:247-269. https://doi.org/10.1146/annurev-ecolsys120213-091935.

Pasternack, G. B., D. Baig, M. D. Weber, and R. A. Brown. 2018a. "Hierarchically Nested River Landform Sequences. Part 1: Theory." Earth Surface Processes and Landforms 43 (12): 2510-2518. https://doi.org/10.1002/esp.4411.

Pasternack, G. B., D. Baig, M. D. Weber, and R. A. Brown. 2018b. "Hierarchically Nested River Landform Sequences. Part 2: Bankfull Channel Morphodynamics Governed by Valley Nesting Structure." Earth Surface Processes and Landforms 43 (12): 2519-2532. https://doi.org/10.1002/esp.4410.

Poff, N. L., J. D. Allan, M. B. Bain, J. R. Karr, K. L. Prestegaard, B. D. Richter, R. E. Sparks, and J. C. Stromberg. 1997. "The Natural Flow Regime: A Paradigm for River Conservation and Restoration. Bioscience.” BioScience 47 (11): 769-784. https://doi.org/10.2307/1313099.

Rinaldi, M., A. M. Gurnell, M. Gonzalez del Tanago, M. Bussettini, and D. Hendriks. 2016. "Classification of River Morphology and Hydrology to Support Management and Restoration." Aquatic Sciences 78:17-33. https://doi.org/10.1007/s00027-015-0438-z.

Rinaldi, M., N. Surian, F. Comiti, and M. Bussettini. 2015. “A Methodological Framework for Hydromorphological Assessment, Analysis and Monitoring (IDRAIM) Aimed at Promoting Integrated River Management." Geomorphology 251:122-136. https://doi.org/10.1016/i.geomorph.2015.05.010.

Rivers and Harbors Appropriation Act of 1899. 2019. 33 U.S.C. §403 et seq. https://www.govinfo.gov/content/pkg/USCODE-2019-title33/pdf/USCODE-2019-title33chap9-subchapl-sec403a.pdf.

Roni, P., and T. Beechie. 2013. Stream and Watershed Restoration: A Guide to Restoring Riverine Processes and Habitats. West Sussex, UK: Wiley-Blackwell.

Roni, P., K. Hanson, and T. Beechie. 2008. "Global Review of the Physical and Biological Effectiveness of Stream Habitat Rehabilitation Techniques." North American Journal of Fisheries Management 28 (3): 856-890. https://doi.org/10.1577/M06$\underline{169.1}$.

Roper, B. B., J. L. Kershner, E. Archer, R. Henderson, and N. Bouwes. 2002. "An Evaluation of Physical Stream Habitat Attributes Used to Monitor Streams." Journal of the American Water Resources Association 38 (6): 1637-1646.

Roper, B. B., and D. L. Scarnecchia. 1995. "Observer Variability in Classifying Habitat Types in Stream Surveys." North American Journal of Fisheries Management 15 (1): 49-53. https://doi.org/10.1577/1548-8675(1995)015\%3C0049:0VICHT\%3E2.3.C0;2.

Rosgen, D. 1994. "A Classification of Natural Rivers." Catena 22 (3): 169-199. https://doi.org/10.1016/0341-8162(94)90001-9.

Rosgen, D. L., 1996. Applied River Morphology. Pagosa Springs, CO: Wildland Hydrology Inc. 
Sawyer, J. A., P. M. Stewart, M. M. Mullen, T. P. Simon, and H. H. Bennett. 2004. "Influence of Habitat, Water Quality, and Land Use on Macro-Invertebrate and Fish Assemblages of a Southeastern Coastal Plain Watershed, USA." Aquatic Ecosystem Health \& Management 7 (1): 85-99. https://doi.org/10.1080/14634980490281353.

Scarsbrook, M. R., and C. R. Townsend. 1993. "Stream Community Structure in Relation To Spatial and Temporal Variation: A Habitat Templet Study of Two Contrasting New Zealand Streams." Freshwater Biology 29 (3): 395-410. https://doi.org/10.1111/i.1365-2427.1993.tb00774.x.

Schumm, S. A. 1963. A Tentative Classification of Alluvial River Channels: An Examination of Similarities and Differences among Some Great Plains Rivers. Geological Survey Circular 477. Washington DC: U.S. Geological Survey.

Schumm, S. A. 1977. The Fluvial System. New York: John Wiley and Sons.

Schumm, S. A. 1985. "Patterns of Alluvial Rivers." Annual Review of Earth and Planetary Sciences 13:5-27. https://doi.org/10.1146/annurev.ea.13.050185.000253.

Section 404(b)(1) Guidelines for Specification of Disposal Sites for Dredged or Fill Material. 2014. 40 C.F.R § 230. https://www.govinfo.gov/content/pkg/CFR-2014-title40vol25/pdf/CFR-2014-title40-vol25-part230.pdf.

Section 404 of the Federal Water Pollution Control Act. 2011. 33 U.S.C. $§ 1344$ et seq. https://www.govinfo.gov/content/pkg/USCODE-2018-title33/pdf/USCODE-2018-title33chap26.pdf.

Simon, A. 1994. Gradation Processes and Channel Evolution in Modified West Tennessee Streams: Process, Response, and Form. U.S. Geological Survey Professional Paper 1470. Washington, DC: United States Government Printing Office.

Simon, A., and C. Hupp. 1986. "Channel Evolution in Modified Tennessee Channels." In Proceedings of the 4th Federal Interagency Sedimentation Conference, Las Vegas, 571-582.

Simon, A., and M. Rinaldi. 2006. "Disturbance, Stream Incision, and Channel Evolution: The Roles of Excess Transport Capacity and Boundary Materials in Controlling Channel Response." Geomorphology 79 (3-4): 361-383. https://doi.org/10.1016/i.geomorph.2006.06.037.

Smith, R. D., A. Ammann, C. Bartoldus, and M. M. Brinson. 1995. An Approach for Assessing Wetland Functions Using Hydrogeomorphic Classification, Reference Wetlands, and Functional Indices. Wetlands Research Program Technical Report WRP-DE-9. Washington, DC: U.S. Army Corps of Engineers.

Smith, R. D., C. V. Noble, and J. F. Berkowitz. 2013. Hydrogeomorphic (HGM) Approach to Assessing Wetland Functions: Guidelines for Developing Guidebooks (Version 2). ERDC/EL TR-13-11. Vicksburg, MS: U.S. Army Engineer Research and Development Center. https://hdl.handle.net/11681/6955. 
Somerville, D. E. 2010. Stream Assessment and Mitigation Protocols: A Review of Commonalities and Differences. EPA 843-S-12-003. Washington, DC: U.S. Environmental Protection Agency, Office of Wetlands, Oceans, and Watersheds Division .https://www.epa.gov/sites/default/files/201507/documents/stream_protocols_2010.pdf.

Somerville, D. E., and B. A. Pruitt. 2004. Physical Stream Assessment: A Review of Selected Protocols for Use in the Clean Water Act Section 404 Program. EPA 843-S-12-002. Washington, DC: U.S. Environmental Protection Agency, Office of Wetlands, Oceans, and Watersheds Division. https://www.epa.gov/sites/default/files/201508/documents/physical_stream_assessment_0.pdf.

Stoddard, J. L., A. T. Herlihy, D. V. Peck, R. M. Hughes, T. R. Whittier, and E. Tarquinio. 2008. "A Process for Creating Multimetric Indices for Large-Scale Aquatic Surveys.” Journal of the North American Benthological Society 27 (4): 878-891. https://doi.org/10.1899/08-053.1.

Stoddard, J. L., D. P. Larsen, C. P. Hawkins, R. K. Johnson, and R. H. Richard. 2006. "Setting Expectations for the Ecological Condition of Streams: The Concept of Reference Condition." Ecological Applications 16 (4): 1267-1276. https://doi.org/10.1890/1051-0761(2006)016[1267:SEFTEC]2.0.C0;2.

Strahler, A. N. 1952. "Dynamic Basis of Geomorphology." Geological Society of America Bulletin 63 (9): 923-938. https://doi.org/10.1130/00167606(1952)63[923:DBOG]2.0.C0;2.

Summers, E. A., C. V. Noble, J. F. Berkowitz, and F. Spilker. 2017. Operational Draft Regional Guidebook for the Functional Assessment of High-Gradient Headwater Streams and Low-Gradient Perennial Streams in Appalachia. ERDC/EL TR-17-1. Vicksburg, MS: U.S. Army Engineer Research and Development Center. https://hdl.handle.net/11681/21462.

Tadaki, M., G. Brierley, and C. Cullum. 2014. "River Classification: Theory, Practice, Politics." WIRE Water 1 (4): 349-367. https://doi.org/10.1002/wat2.1026.

Tennessee Department of Environment and Conservation. 2019. Stream Mitigation Guidelines. DWR-NR-G-01. Nashville, TN: Tennessee Department of Environment and Conservation, Division of Natural Resources, Natural Resources Unit. https://www.tn.gov/environment/permit-permits/water-permits1/aquaticresource-alteration-permit--arap-/permit-water-arap-compensatory-mitigation.html.

Thoms, M. C., and M. Parsons, 2002. "Eco-Geomorphology: An Interdisciplinary Approach to River Science." In The Structure, Function and Management Implications of Fluvial Sedimentary Systems (Proceedings of an International Symposium, Alice Springs, Australia, September 2002). IAHS Publ. no. 276.

Thorne, C. R., R. D. Heyand, and M. D. Newson, ed. 1997. Applied Fluvial Geomorphology for River Engineering and Management. Chichester, UK: John Wiley. 
U.S. Bureau of Reclamation and U.S. Army Engineer Research and Development Center. 2016. National Large Wood Manual: Assessment, Planning, Design, and Maintenance of Large Wood in Fluvial Ecosystems: Restoring Process, Function, and Structure. https://www.usbr.gov/research/projects/download_product.cfm?id=1481.

USACE (U.S. Army Corps of Engineers). 2011a. Charleston District Regulatory Program Standard Operating Procedure. Charleston, SC: U.S. Army Corps of Engineers, Charleston District.

USACE (U.S. Army Corps of Engineers). 2011b. West Virginia Stream and Wetland Valuation Metric, Version 2.o. Huntington, WV: U.S. Army Corps of Engineers, Huntington District.

USACE (U.S. Army Corps of Engineers). 2013. Level 1 Stream Condition Assessment for All Ephemeral and Intermittent Streams and for Impacts Less than 500 Linear Feet to Intermittent Streams with Perennial Pools, Perennial Streams and Wadeable Rivers. Galveston, TX: U.S. Army Corps of Engineers, Galveston District.

USACE (U.S. Army Corps of Engineers). 2015. The Texas Rapid Assessment Method (TXRAM). Wetland and Streams Modules, Version 2.o. Final. Fort Worth, TX: U.S. Army Corps of Engineers, Fort Worth District.

USACE (U.S. Army Corps of Engineers). 2018a. Georgia Interim Stream Quantification Tool User Manual. Version 1.o. Savannah, GA: U.S. Army Corps of Engineers, Savannah District.

USACE (U.S. Army Corps of Engineers). 2018b. Standard Operating Procedure for Compensatory Mitigation. Savannah, GA: U.S. Army Corps of Engineers, Savannah District.

USACE (U.S. Army Corps of Engineers). 2018c. Wyoming Stream Quantification Tool User Manual (Version 1.o). Cheyenne, WY: U.S. Army Corps of Engineers, Omaha District, Wyoming Regulatory Office. https://stream-mechanics.com/wpcontent/uploads/2018/07/WY-SQT-User-Manual-V1.0_COMBINED.pdf.

USACE (U.S. Army Corps of Engineers) and Virginia Department of Environmental Quality. 2007. Unified Stream Methodology for use in Virginia. Final Draft for Implementation. Norfolk, VA: U.S. Army Corps of Engineers, Norfolk District, and Virginia Department of Environmental Quality.

Vannote, R. L., G. W. Minshall, K. W. Cummins, J. R. Sedell, and C. E. Cushing. 1980. "The River Continuum Concept." Canadian Journal of Fisheries and Aquatic Sciences 37 (1): 130-137. https://doi.org/10.1139/f80-017.

Wakeley, J. S., and R. D. Smith. 2001. Hydrogeomorphic Approach to Assessing Wetland Functions: Guidelines for Developing Regional Guidebooks, Chapter 7: Verifying, Field Testing, and Validating Assessment Models. ERDC/EL TR-0131. Vicksburg, MS: U.S. Army Engineer Research and Development Center. http://hdl.handle.net/11681/6981. 
Watson, C. C., D. S. Biedenharn, and B. P. Bledsoe, 2002. "Use of Incised Channel Evolution. Models in Understanding Rehabilitation Alternatives." Journal of the American Water Resources Association 38 (1): 151-160. https://doi.org/10.1111/j.1752-1688.2002.tb01542.x.

Watson, C., M. Harvey, and J. Garbrecht. 1986. "Geomorphic-Hydraulic Simulation of Channel Evolution." In Proceedings of the 4th Federal Interagency Sedimentation Conference, Las Vegas, 521-530. Washington, DC: U.S. Government Printing Office.

Whittier, T. R., R. M. Hughes, J. L. Stoddard, G. A. Lomnicky, D. V. Peck, and A. T. Herlihy, 2007. "A Structured Approach for Developing Indices of Biotic Integrity: Three Examples from Streams and Rivers in the Western USA." Transactions of the American Fisheries Society 136 (3): 718-735. https://doi.org/10.1577/T06-128.1.

Wipfli, M. S., J. S. Richardson, and R. J. Naiman. 2007. “Ecological Linkages between Headwaters and Downstream Ecosystems: Transport of Organic Matter, Invertebrates and Wood Down Headwater Channels." Journal of the American Water Resources Association 43 (1): 72-85. https://doi.org/10.1111/i.17521688.2007.00007.x.

Wohl, E. 2016. "Spatial Heterogeneity as a Component of River Geomorphic Complexity." Progress in Physical Geography 40 (4): 598-615. https://doi.org/10.1177\%2F0309133316658615.

Wohl, E. 2018. Sustaining River Ecosystems and Water Resources. Cham, Switzerland: Springer.

Wohl, E., N. Kramer, V. Ruiz-Villanueva, D. N. Scott, F. Comiti, A. M. Gurnell, H. Piegay, K. B. Lininger, K. L. Jaeger, D. M. Walters, and K. D. Fausch. 2019. "The Natural Wood Regime in Rivers." Bioscience 69 (4): 259-273.

https://doi.org/10.1093/biosci/biz013.

Wyoming Stream Technical Team. 2018. Scientific Support for the Wyoming Stream Quantification Tool, Version 1.o. Cheyenne, WY: U.S. Army Corps of Engineers, Omaha District, Wyoming Regulatory Office. 


\section{Appendix A: State GIS Data}

Table A-1. Source of GIS data for U.S. states. This is list is not exhaustive but is meant to provide users with primary locations for GIS data for U.S. states.

\begin{tabular}{|c|c|}
\hline State & GIS Data Source Host \\
\hline \multirow[t]{2}{*}{ Alabama } & Geological Survey of Alabama \\
\hline & U.S. Forest Service \\
\hline Alaska & Alaska Department of Natural Resources \\
\hline Arizona & $\begin{array}{l}\text { AZGEO Clearinghouse, an Arizona Geographic Information Council initiative, } \\
\text { hosted by Arizona State Land Department }\end{array}$ \\
\hline Arkansas & Arkansas Department of Transportation \\
\hline California & California Spatial Information Library \\
\hline Colorado & Colorado Department of Local Affairs \\
\hline Connecticut & University of Connecticut Library-Map and Geographic Information Center \\
\hline Delaware & Delaware Office of State Planning Coordination \\
\hline Florida & State of Florida Geodata \\
\hline Georgia & Georgia GIS Clearinghouse \\
\hline Hawaii & Hawaii State Office of Planning \\
\hline Idaho & Idaho Geospatial Office \\
\hline \multirow[t]{3}{*}{ Illinois } & $\begin{array}{l}\text { University of Illinois Springfield-Geographic Information Systems } \\
\text { Laboratory }\end{array}$ \\
\hline & USGS Upper Midwest Environmental Services Center-IIlinois GIS data \\
\hline & $\begin{array}{l}\text { University of Illinois at Urbana-Champaign-Illinois Geospatial Information } \\
\text { Clearinghouse }\end{array}$ \\
\hline \multirow[t]{2}{*}{ Indiana } & State of Indiana-IndianaMap \\
\hline & University of Indiana-Indiana Spatial Data Portal \\
\hline lowa & State of lowa-lowa Geodata \\
\hline Kansas & State of Kansas-Kansas Data Access and Support Center \\
\hline \multirow[t]{2}{*}{ Kentucky } & Commonwealth of Kentucky-Kentucky Geonet \\
\hline & Kentucky Geological Survey-Geospatial Data Library \\
\hline \multirow[t]{2}{*}{ Louisiana } & Louisiana Department of Transportation and Development-GIS Data \\
\hline & LSU Atlas GIS \\
\hline Maine & Maine Office of GIS-Data Catalog \\
\hline \multirow[t]{2}{*}{ Maryland } & State of Maryland-GIS Data Catalog \\
\hline & Maryland Department of Transportation-GIS Open Data Portal \\
\hline Massachusetts & Massachusetts Bureau of Geographic Information-MassGIS \\
\hline Michigan & State of Michigan-GIS Open Data \\
\hline \multirow[t]{2}{*}{ Minnesota } & Minnesota IT Services-Geospatial Information Office \\
\hline & Minnesota Geospatial Commons \\
\hline Mississippi & State of Mississippi-Mississippi Geospatial Clearinghouse \\
\hline Missouri & University of Missouri-Spatial Data Information Service Open Data Site \\
\hline
\end{tabular}


Table A-1 (cont.). Source of GIS data for U.S. states. This is list is not exhaustive but is meant to provide users with primary locations for GIS data for U.S. states.

\begin{tabular}{|c|c|}
\hline State & GIS Data Source Host \\
\hline Montana & State of Montana-Geographic Information Clearinghouse \\
\hline Nebraska & State of Nebraska Geographic Information Office-NebraskaMap \\
\hline \multirow[t]{2}{*}{ Nevada } & $\begin{array}{l}\text { University of Nevada at Reno Virtual Clearinghouse for Nevada Geographic } \\
\text { Information }\end{array}$ \\
\hline & Nevada Division of State Lands-GIS Mapping Data \\
\hline New Hampshire & New Hampshire GRANIT GIS Clearinghouse \\
\hline \multirow[t]{2}{*}{ New Jersey } & New Jersey Department of GIS \\
\hline & New Jersey Geographic Information Network \\
\hline \multirow[t]{2}{*}{ New Mexico } & New Mexico State Land Office-GIS Data Download \\
\hline & University of New Mexico Resource Geographic Information System \\
\hline New York & State of New York GIS Data \\
\hline North Carolina & NC OneMap \\
\hline \multirow[t]{2}{*}{ North Dakota } & North Dakota GIS HUB Data Portal \\
\hline & North Dakota Department of Geographic Information Systems \\
\hline Ohio & Ohio Geographically Referenced Information Program \\
\hline \multirow[t]{2}{*}{ Oklahoma } & Oklahoma Geographic Information Systems Council \\
\hline & University of Oklahoma Center for Spatial Analysis \\
\hline \multirow[t]{2}{*}{ Oregon } & State of Oregon Geospatial Data Clearinghouse \\
\hline & Oregon Spatial Data Library \\
\hline Pennsylvania & Pennsylvania State University-Pennsylvania Geospatial Data Clearinghouse \\
\hline Rhode Island & Rhode Island Geographic Information System \\
\hline South Carolina & $\begin{array}{l}\text { South Carolina Department of Health and Environment Control-GIS Data } \\
\text { Clearinghouse }\end{array}$ \\
\hline South Dakota & South Dakota Department of Natural Resources-Digital Base Data \\
\hline Tennessee & Tennessee GIS Clearinghouse \\
\hline Texas & Texas General Land Office-GIS Maps and Data \\
\hline Utah & Utah Automated Geographic Reference Center \\
\hline Vermont & Vermont Center for Geographic Information \\
\hline Virginia & Virginia Information Technologies Agency-GIS Clearinghouse \\
\hline Washington & $\begin{array}{l}\text { Washington Office of the Chief Information Officer-Washington Geospatial } \\
\text { Open Data Portal }\end{array}$ \\
\hline West Virginia & West Virginia GIS Technical Center-GIS Data/Services \\
\hline Wisconsin & Geodata@Wisconsin \\
\hline Wyoming & Wyoming State Geological Survey-GIS Data \\
\hline
\end{tabular}




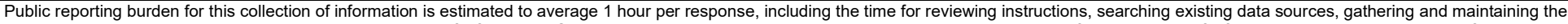

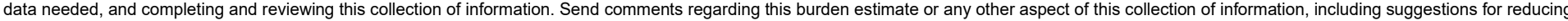

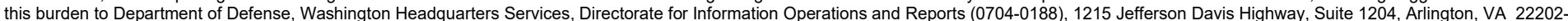

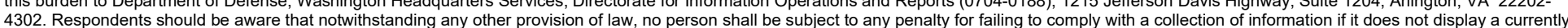

4302. Respondents should be aware that notwithstanding any other provision of law, no person shal
valid OMB control number. PLEASE DO NOT RETURN YOUR FORM TO THE ABOVE ADDRESS
1. REPORT DATE (DD-MM-YYYY)
September 2021
2. REPORT TYPE
3. DATES COVERED (From - To)
4. TITLE AND SUBTITLE
Final Report
FY17-FY21
5a. CONTRACT NUMBER

Technical Guide for the Development, Evaluation, and Modification of Stream Assessment Methods for

the Corps Regulatory Program

5b. GRANT NUMBER

5c. PROGRAM ELEMENT

6. AUTHOR(S)

Gabrielle C. L. David, D. Eric Somerville, Julia M. McCarthy, Spencer D. MacNeil, Faith Fitzpatrick, Ryan

Evans, and David Wilson

\section{5d. PROJECT NUMBER}

5e. TASK NUMBER

5f. WORK UNIT NUMBER

7. PERFORMING ORGANIZATION NAME(S) AND ADDRESS(ES)

U.S. Army Engineer Research and Development Center

Cold Regions Research and Engineering Laboratory

72 Lyme Road

Hanover, NH 03755

8. PERFORMING ORGANIZATION REPORT NUMBER

ERDC/CRREL SR-21-2

\section{SPONSORING / MONITORING AGENCY NAME(S) AND ADDRESS(ES)}

Headquarters, U.S. Army Corps of Engineers

Washington, DC 20314-1000

\section{SPONSOR/MONITOR'S ACRONYM(S)} USACE

\section{SPONSOR/MONITOR'S REPORT NUMBER(S)}

\section{DISTRIBUTION / AVAILABILITY STATEMENT}

Approved for public release; distribution is unlimited.

\section{SUPPLEMENTARY NOTES}

AMSCO for this work is 088893; the funding account is U4371457

\section{ABSTRACT}

The U.S. Army Corps Regulatory Program considers the loss (impacts) and gain (compensatory mitigation) of aquatic resource functions as part of Clean Water Act Section 404 permitting and compensatory mitigation decisions. To better inform this regulatory decision-making, the Regulatory Program needs transparent and objective approaches to assess the function and condition of aquatic resources, including streams.

Therefore, the Regulatory Program needs function-based stream assessments (1) to characterize a stream's condition or function, (2) to improve understanding of the impact of a proposed action on an aquatic resource, and/or (3) to inform the development of stream compensatory mitigation tools rooted in stream condition and/or function. A function-based stream assessment can provide regulatory decision makers with the resources to objectively consider alternatives, minimize impacts, assess unavoidable impacts, determine mitigation requirements, and monitor the success of mitigation projects.

A multiagency National Committee on Stream Assessment (NCSA) convened to create these guideline to inform the development of new methods and evaluation of both national-level and regional methods currently in use. The resulting guidelines present nine phases, including rationale and recommendations to facilitate work efforts. The NCSA hopes that this technical guide promotes transparency, technical defensibility, and consistent application of stream assessments in the Regulatory Program.

\section{SUBJECT TERMS}

Assessment method, Environmental management, Method development, Qualitative assessment method, Quantitative assessment method, Regulatory, Rivers--Evaluation, Stream assessment, Stream condition, Stream function, Stream mitigation

\section{SECURITY CLASSIFICATION OF:}

\section{a. REPORT}

Unclassified

\section{b. ABSTRACT}

Unclassified c. THIS PAGE

Unclassified

\section{LIMITATION OF ABSTRACT}

SAR
18. NUMBER OF PAGES

102 19a. NAME OF RESPONSIBLE PERSON

19b. TELEPHONE NUMBER (include area code) 


\section{PERFORMING ORGANIZATION NAME(S) AND ADDRESS(ES) (CONT.)}

U.S. Environmental Protection Agency

Region 4, Water Division

980 College Station Road

Athens, GA 30605-2720

U.S. Environmental Protection Agency

Region 8, Water Division

1595 Wynkoop Street

Denver, CO 80202

U.S. Geological Survey

Upper Midwest Water Science Center

8505 Research Way

Middleton, WI 53562

U.S. Army Corps of Engineers

Los Angeles District

6o S. California Street, Suite 201

Ventura, CA 93001

U.S. Army Corps of Engineers

Nashville District

3701 Bell Road

Nashville, TN 37214

U.S. Army Corps of Engineers

Charleston District

69-A Hagood Avenue

Charleston, SC 29403-5104 